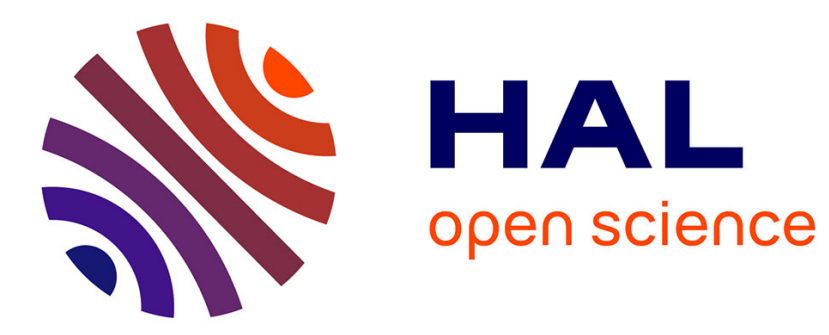

\title{
SiGe nanostructures: new insights into growth processes
}

I. Berbezier, A. Ronda, A. Portavoce

\section{To cite this version:}

I. Berbezier, A. Ronda, A. Portavoce. SiGe nanostructures: new insights into growth processes. J. Phys.: Condens. Matter, 2002, 14, pp.8283 - 8331. hal-02393626

\section{HAL Id: hal-02393626 \\ https://hal-amu.archives-ouvertes.fr/hal-02393626}

Submitted on 4 Dec 2019

HAL is a multi-disciplinary open access archive for the deposit and dissemination of scientific research documents, whether they are published or not. The documents may come from teaching and research institutions in France or abroad, or from public or private research centers.
L'archive ouverte pluridisciplinaire $\mathbf{H A L}$, est destinée au dépôt et à la diffusion de documents scientifiques de niveau recherche, publiés ou non, émanant des établissements d'enseignement et de recherche français ou étrangers, des laboratoires publics ou privés. 


\title{
SiGe nanostructures: new insights into growth processes
}

\author{
I Berbezier ${ }^{1}$, A Ronda ${ }^{1}$ and A Portavoce ${ }^{1,2}$ \\ ${ }^{1}$ CRMC2-CNRS Campus de Luminy, Case 913, F13288 Marseille Cedex 9, France \\ ${ }^{2}$ L2MP-CNRS, Av. Escandrille Normandie-Niemen, Case 151, F13397 Marseille Cedex 13, \\ France \\ E-mail: berbezier@crmc2.univ-mrs.fr
}

Received 10 April 2002, in final form 3 July 2002

Published 22 August 2002

Online at stacks.iop.org/JPhysCM/14/8283

\begin{abstract}
During the last decade, $\mathrm{Si} / \mathrm{Si}_{1-x} \mathrm{Ge}_{x}$ heterostructures have emerged as a viable system for use in CMOS technology with the recent industrial production of heterojunction bipolar transistor-based integrated circuits. However, many key problems have to be solved to further expand the capabilities of this system to other more attractive devices. This paper gives a comprehensive review of the progress achieved during the last few years in the understanding of some fundamental growth mechanisms. The discrepancies between classical theories (in the framework of continuum elasticity) and experimental results are also specially addressed. In particular, the major role played by kinetics in the morphological evolution of layers is particularly emphasized. Starting from the unexpected differences in $\mathrm{Si}_{1-x} \mathrm{Ge}_{x}$ morphological evolution when deposited on (001) and on (111), our review then focuses on: (1) the strain control and adjustment (from fully strained to fully relaxed 2D and 3D nanostructures) in particular, some original examples of local CBED stress measurements are presented; (2) the nucleation, growth, and self-assembly processes, using self-patterned template layers and surfactant-mediated growth; (3) the doping processes (using $\mathrm{B}$ for type $\mathrm{p}$ and $\mathrm{Sb}$ for type $\mathrm{n}$ ) and the limitations induced by dopant redistribution during and after growth due to diffusion, segregation, and desorption. The final section will briefly address some relevant optical properties of $\mathrm{Si}_{1-x} \mathrm{Ge}_{x}$ strained layers using special growth processes.
\end{abstract}

(Some figures in this article are in colour only in the electronic version)

\section{Introduction}

Let us first consider the impact of $\mathrm{Si}_{1-x} \mathrm{Ge}_{x}$ heterojunctions on the CMOS production line and the future prospects of this technology. The first $\mathrm{Si}_{1-x} \mathrm{Ge}_{x}$-based device to have been integrated with a conventional CMOS production line is the heterojunction bipolar transistor 
(HBT). The main reason is that it presents a minimum additional cost to CMOS and a very simple design with a narrow $\mathrm{Si}_{1-x} \mathrm{Ge}_{x}$ base layer inserted into a bipolar BiCMOS fabrication process. However, even if this technology is quite mature, the device characteristics obtained in production lines are much less good than those demonstrated for research devices. This result has not been explained so far, but the high thermal budget, used in present CMOS production, is assumed to have the major detrimental effect. Indeed, it causes strain relaxation (by dislocation nucleation and also by interdiffusion of $\mathrm{Si} / \mathrm{Si}_{1-x} \mathrm{Ge}_{x}$ ), dopant diffusion, interface roughening, and Ge clustering. All these phenomena are well known to degrade the electrical properties of HBTs.

Recent research developments also focus on other attractive devices such as the p-type $\mathrm{Si}_{1-x} \mathrm{Ge}_{x}$ MOSFET, since $\mathrm{p}$ channels represent so far the major limiting factor in CMOS performance. Indeed, the mobility of $\mathrm{Si}_{1-x} \mathrm{Ge}_{x}$ p MOSFET is only $20 \%$ larger than those of conventional transistors. This is attributed to parallel conduction due to the small band offset of $\mathrm{Si}_{1-x} \mathrm{Ge}_{x}$ channels that contain low Ge content. Further improvements would then rely on an increase of the Ge content to increase the band offset. This is expected to give stronger transfer and confinement of the carriers, preventing parallel conduction from taking place. However, this faces serious problems, since at large Ge contents, both the critical thickness of dislocation nucleation $\left(h_{c r}\right)$ and the critical thickness of 2D-3D growth transition $\left(H_{S K}\right)$ are very low. A good control and understanding of stress relaxation in $2 \mathrm{D}$ wells is consequently a major issue to address for these devices.

Recently, the most striking performances have been reported for $\mathrm{Si}_{1-x} \mathrm{Ge}_{x}$ modulationdoped field effect transistors (MODFETs) grown on virtual substrates (fully relaxed by a network of misfit dislocations (MDs)) yielding faster transistors than any other p-channel transistor in the literature [1]. In spite of the high mobility achieved, the overall success of $\mathrm{Si}_{1-x} \mathrm{Ge}_{x}$ MODFETs has so far been limited because of the high dislocation density and the poor surface morphology (cross-hatch pattern) which impair further the processing of the structures. Since the cross-hatch pattern originates from the MDs lying mainly in the graded buffer layer, the search for new processes of fabrication of the relaxed buffer layer is a hot topic.

Finally for the future, alternative routes to CMOS technology should also be developed for feature sizes approaching 50-30 nm. A new generation of nanometric devices should then be found as a matter of urgency, in order to permit the current scaling trend to continue, following the conventional CMOS approach. For this reason, many new quantum device concepts have recently been reported in the literature. However, there are major bottlenecks in the development of these emerging devices relating to:

(1) the morphology, composition, and self-assembly of 1D and OD nanostructures (e.g. for nanocrystal memory);

(2) the control and reduction of spatial distribution of dopants in highly doped quantum wells (e.g. for resonant tunnelling diodes);

(3) the realization of virtual substrates (e.g. for laser cascade).

As a consequence, for the majority of present or future devices, the improvement of the device features mainly depends on a better understanding (and control) of the fundamental processes of growth (strain control and adjustment, composition and morphology, and dopant incorporation).

The paper is organized as follows. Section 2 will briefly recall the techniques and the experimental conditions used for the growth and characterization (composition, microstructure, morphology, and physical properties) of $\mathrm{Si}_{1-x} \mathrm{Ge}_{x}$ nanostructures. 
Section 3 is devoted to the strain adjustment and control. First, the elastic energy and the critical thickness of dislocation nucleation calculated for two nominal orientations $\mathrm{Si}(001)$ and (111) will be compared to the experimental results obtained. Then the local measurement of stress in highly strained structures (2D and 3D) will be reported. Deviations from the standard elastic theories due to kinetics and to $\mathrm{Si} / \mathrm{Ge}$ interdiffusion processes will be evidenced. At the end, the microstructure and morphology of relaxed $\mathrm{Si}_{1-x} \mathrm{Ge}_{x}$ channels on top of virtual substrates (relaxed $\mathrm{Si}_{1-x} \mathrm{Ge}_{x}$ buffers) will be discussed. Some key processes used to pin the propagation of dislocations towards the top layer will be presented.

In section 4 , kinetic and stress-driven instabilities, growth, and self-assembly processes will be reviewed. Kinetic phase diagrams of $\mathrm{Si}_{1-x} \mathrm{Ge}_{x}$ morphologies with the deposited thickness and the stress (Ge concentration) have been drawn. The morphological evolution of $\mathrm{Si}_{1-x} \mathrm{Ge}_{x}$ layers deposited on $\mathrm{Si}(001)$ and (111) are compared. The influence of step density, substrate orientation, miscut angle, and kinetics on the instability will be analysed. A comparison between kinetic and stress-driven instability will also be presented. At the end, the improvement provided by either a two-step process or by surfactant-mediated growth will be evidenced.

Section 5 will show new insights into dopant redistribution processes (during and after growth). In particular, the separate effects of stress and composition on bulk diffusion, kinetic segregation, and desorption will be introduced. Different processes of dopant incorporation are compared. We finally discuss further the segregation effect of p-type (B) and n-type (Sb) dopants.

In the remainder of the paper we will briefly review some relevant PL characterizations of nanostructures grown by solid-source or gas-source molecular beam epitaxy (MBE).

\section{Experimental details}

Most of the $\mathrm{Si}_{1-x} \mathrm{Ge}_{x}$ nanostructures were grown using RIBER solid-source molecular beam epitaxy (SSMBE) equipment with a background pressure in the $10^{-11}$ Torr range [2]. Si and Ge were evaporated from an electron gun evaporator and an effusion cell, respectively, with beam fluxes calibrated in situ by reflection high-energy electron diffraction (RHEED) oscillations and $e x$ situ by $\mathrm{x}$-ray diffraction (XRD) to provide accurate control of the alloy ratio. For both Si and $\mathrm{Ge}$, the fluxes used resulted in a growth rate of about $1 \mathrm{~nm} \mathrm{~min}{ }^{-1}$. Sb and B were evaporated from effusion cells with fluxes calibrated ex situ by secondary-ion mass spectrometry (SIMS). At low temperatures, the substrate temperature was calibrated using the melting point of In and $\mathrm{Ga}$ and extrapolated with a power law, and in the high-temperature $(\mathrm{HT})$ range $\left(T>500^{\circ} \mathrm{C}\right)$ it was measured with an optical pyrometer. Growth temperatures ranged between 350 and $750^{\circ} \mathrm{C}$.

For comparison, some $\mathrm{Si}_{1-x} \mathrm{Ge}_{x}$ layers were also grown using a modified VG Semicon gassource molecular beam epitaxy (GSMBE) cold-wall system with a $2 \times 10^{-11}$ Torr background pressure [3]. Disilane $\left(\mathrm{Si}_{2} \mathrm{H}_{6}\right)$ and germane $\left(\mathrm{GeH}_{4}\right)$ were used as $\mathrm{Si}$ and $\mathrm{Ge}$ sources respectively and diborane $\left(\mathrm{B}_{2} \mathrm{H}_{6}\right.$ diluted to $1 \%$ by argon) as the source of boron doping. During continuous doping experiments, $\mathrm{B} / \mathrm{Si}$ flux ratios $\left(\mathrm{B}_{2} \mathrm{H}_{6} / \mathrm{Si}_{2} \mathrm{H}_{6}\right)$ were varied between $4 \times 10^{-4}$ and $6 \times 10^{-3}$. For experiments involving the pre-adsorption of $\mathrm{B}$, the flux of $\mathrm{Si}_{2} \mathrm{H}_{6}$ was turned off and $\mathrm{B}_{2} \mathrm{H}_{6}$ was adsorbed on the $\mathrm{Si}(001)$ buffer layer at temperatures between 450 and $650^{\circ} \mathrm{C}$.

Prior to loading in the growth chamber, samples were chemically cleaned using the Shiraki process, which leaves the surface covered by a protective oxide layer. In situ cleaning consisted of a two temperature process $\left(850^{\circ} \mathrm{C} / 30 \mathrm{~min}+1230^{\circ} \mathrm{C} / 2 \mathrm{~min}\right)$, which removes the oxide layer by sublimation, and results in a sharp 2D RHEED pattern indicative of a defect-free surface. $7 \times 7$ and $2 \times 1$ surface reconstructions were observed on $\mathrm{Si}(111)$ and (001), respectively. 
Prior to the growth of $\mathrm{Si}_{1-x} \mathrm{Ge}_{x}$ layers, a $20 \mathrm{~nm}$ thick Si buffer layer was systematically grown at $750^{\circ} \mathrm{C}$ in order to obtain a reproducible surface. Si wafers of microelectronic grade were used with misorientations varying between $0^{\circ}$ and $10^{\circ}$ (with an angle precision of $0.5^{\circ}$ ). The misorientations were systematically checked by means of Laue diffraction.

Transmission electron microscopy (TEM) investigations were performed using a Jeol 2000FX equipped with an energy dispersive spectrometer (EDS) for X-ray analysis. Highspatial-resolution quantitative analyses were performed by means of convergent beam electron diffraction (CBED) and EDS in a field effect analytical microscope (Jeol 2010 FEG) with highconvergence coils. Diffraction patterns were recorded at $200 \mathrm{kV}$ with a typical convergence half-angle of $20 \mathrm{mrad}$ and a minimum $2.4 \mathrm{~nm}$ probe size. Lattice imaging was achieved using a Jeol 4000EX microscope operating at $400 \mathrm{kV}$ with a point-to-point resolution of $0.14 \mathrm{~nm}$. Both plan- and cross-section-view geometries have been investigated in order to cross-check relaxation measurements. Cross-section TEM samples were prepared by mechanical polishing down to $20 \mu \mathrm{m}$ and subsequent Ar-ion milling to perforation. Plan-view samples were prepared by chemical etching. Moreover, CBED experiments have been repeated on several samples, in various geometries, but also along various axes, to avoid artefacts and accidental relaxation during the preparation of TEM thin samples.

Grazing incidence X-ray diffraction (GIXRD) experiments were performed using a highresolution triple-axis diffractometer coupled with a rotating anode $\mathrm{X}$-ray generator. X-ray scattering measurements were recorded with a beam wavelength of $0.154 \mathrm{~nm}$. Investigations focused on the (220), (004), and (111) bulk diffraction peaks. The statistical description of the surface was obtained thanks to reflectivity measurements that probe the surface as regards the long-range order (for details see [4]).

Morphological characterization was performed by atomic force microscopy (AFM) in air in non-contact mode. To analyse the formation of 3D patterns we mainly investigated two parameters: the root mean square (rms) roughness on $5 \times 5 \mu \mathrm{m}^{2}$ areas and the self-correlation function (to measure the periodicity of the pattern).

The dopant concentration profiles (B and $\mathrm{Sb}$ ) were measured from SIMS using a Cameca IMS4F operated at $12.5 \mathrm{keV}$ with $\mathrm{O}^{2+}$ primary ions.

For the segregation/diffusion studies the samples were grown using a specific cycle of growth that enables us to determine both segregation and diffusion coefficients for every sample.

Moreover, double sequences of $\left(\mathrm{Ge} / \mathrm{Si}_{1-x} \mathrm{Ge}_{x}\right)$ structures separated by a $\mathrm{Si}$ cap layer sufficiently thick (about $20 \mathrm{~nm}$ ) to avoid coupling effects between the active wells were also elaborated in order to allow both AFM and photoluminescence (PL) characterization on the same sample.

PL was excited by the $514 \mathrm{~nm}$ line of an $\mathrm{Ar}^{+}$laser with power densities between 6 and $200 \mathrm{~mW} \mathrm{~mm}^{-2}$ and was detected by a nitrogen-cooled Ge detector in a lock-in configuration [5].

All the results presented hereafter are extracted from a compilation of several experiments performed on a large number of samples with a large range of Ge concentrations. They are reproducible under our growth conditions.

\section{Strain adjustment and control}

\subsection{Highly strained structures}

Before presenting the experimental results on the stress-relief mechanisms in $\operatorname{Si}_{1-x} \mathrm{Ge}_{x}(111)$ and $(001)[6,7]$ let us consider the predictions that can be deduced from the calculation of elastic energy at different misfits. 


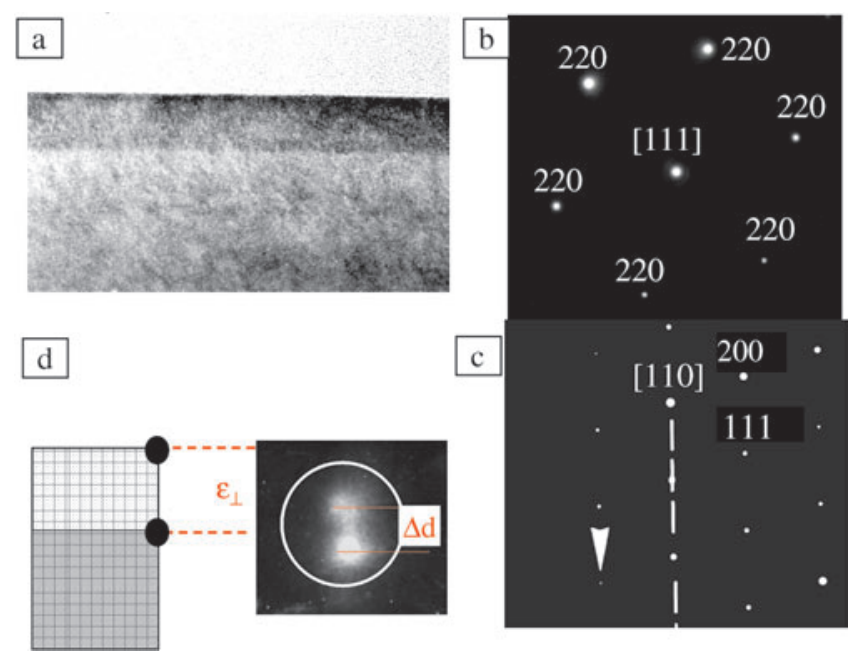

Figure 1. (a) A TEM cross-section view of the $\sim 20 \mathrm{~nm}$ thick $\mathrm{Si}_{0.85} \mathrm{Ge}_{0.15}$ deposited on $\mathrm{Si}(111)$. TED patterns with (b) [111] and (c) [110] zone axes. (d) A schematic view of the tetragonal distortion.

At low misfits, the thin planar epitaxial layer is expected to be coherent with the thick Si substrate. The strain of the epilayer lattice is described by the standard linear elasticity theory (Hooke's law):

$$
\sigma_{i j}=[\mathbf{C}] \varepsilon_{k l}
$$

where $\sigma_{i j}$ and $\varepsilon_{k l}$ are the stress and strain tensors, respectively, and [C] is the elastic constants matrix.

For the growth of $\mathrm{Si}_{1-x} \mathrm{Ge}_{x}$ on $\mathrm{Si}(100)$, the film is biaxially compressed in the growth plane and expands in the direction perpendicular to it. Therefore, $\varepsilon_{1}=\varepsilon_{2}=-m$ where $m$ is the misfit defined by $\left(a_{\mathrm{SiGe}}-a_{\mathrm{Si}}\right) / a_{\mathrm{Si}}$ with $a_{\mathrm{SiGe}}$ and $a_{\mathrm{Si}}$ the $\mathrm{Si}_{1-x} \mathrm{Ge}_{x}$ and Si lattice parameters respectively. $\varepsilon_{3}$ is the tetragonal distortion of the layer $\left(\varepsilon_{\perp}\right)$. For the growth on $\operatorname{Si}(001), \varepsilon_{\perp}$ is described by

$$
\varepsilon_{\perp}=(-2 v) m /(1-v)=-2 m C_{12} / C_{11}
$$

where $v$ is Poisson's ratio and $C_{i j}$ are the appropriate elastic constants of the $\mathrm{Si}_{1-x} \mathrm{Ge}_{x}$ alloy.

For the growth on (111), the film is anisotropically compressed along the $\langle 110\rangle$ and $\langle 112\rangle$; the elastic and shear moduli and the Poisson's ratio must be decomposed along these two directions. The tetragonal distortion is then described by

$$
\varepsilon_{\perp}=2 m\left[C_{11}+2 C_{12}-2 C_{44}\right] /\left[C_{11}+2 C_{12}+4 C_{44}\right] .
$$

The elastic energy stored inside the layer $\left(E_{e l}\right)$ is given by

$$
E_{e l}=2 \mu m^{2}(1+v) /(1-v)(\mathrm{GPa}) .
$$

It is important to remark here, regarding the expressions given above, that a larger tetragonal distortion and a lower elastic energy are expected on $\mathrm{Si}(001)$ than on $\mathrm{Si}(111)$. Table 1 gives the calculated values of $\varepsilon_{\perp}$ for two concentrations of Ge.

In a preliminary experiment, $\varepsilon_{\perp}$ can be simply detected from transmission electron diffraction (TED) patterns as shown in figure 1 for a $\sim 20 \mathrm{~nm}$ thick $\mathrm{Si}_{1-x} \mathrm{Ge}_{x}$ layer deposited on $\operatorname{Si}(111)$ with $x=0.15(m=0.63 \%)$. In this case, the cell is fully coherent with the substrate; consequently only one series of diffraction spots are observed on the plan-view pattern ([111] 

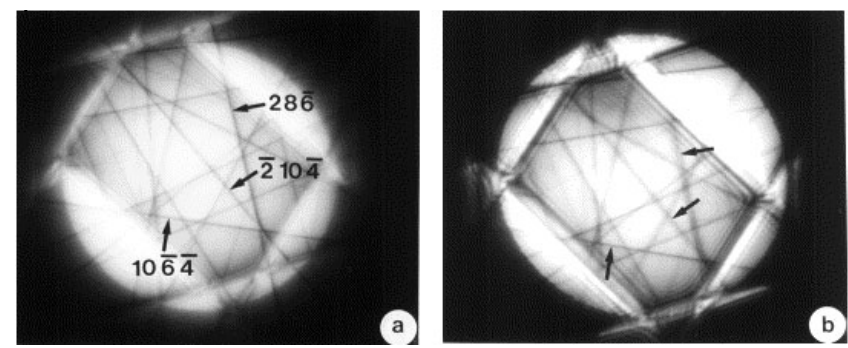

Figure 2. CBED patterns recorded in the plan-view geometry along the [4 35] axis for (a) the single (111) Si substrate and (b) the superimposition of the substrate and the $20 \mathrm{~nm}$ thick, flat, tetragonally distorted $\mathrm{Si}_{0.85} \mathrm{Ge}_{0.15}$ layer. The $(10 \overline{6} \overline{4}) \mathrm{HOLZ}$ line, corresponding to a plane perpendicular to the surface, is not split, testifying a fully strained in-plane lattice parameter. The $\left(\begin{array}{ll}2 & 8 \\ \overline{6}\end{array}\right)$ and $(\overline{2} 10 \overline{4})$ lines, corresponding to planes parallel to the surface, are split, giving rise to a normal lattice parameter misfit.

Table 1. Tetragonal distortion calculated from the elasticity theory.

\begin{tabular}{lll}
\hline Ge content $(\%)$ & $x=0.15$ & $x=0.30$ \\
\hline Misfit & 0.63 & 1.2 \\
$\varepsilon_{\perp}^{(111)}$ & 0.27 & 0.5 \\
$\varepsilon_{\perp}^{(001)}$ & 0.46 & 0.9 \\
\hline
\end{tabular}

zone axis; figure 1(b)), while two series of spots aligned along the growth direction are observed in the cross-section pattern ([110] zone axis; figure 1(c)). However, because of the limited resolution of this technique, it is not possible to accurately measure the tetragonal distortion (in this case, the $\Delta d$ expected is $\sim 8 \times 10^{-4} \mathrm{~nm}$ ).

Complementary and more accurate information can be deduced from CBED as shown in figure $2[6,7]$. Experiments were performed on a thick area (thicker than $100 \mathrm{~nm}$ ) of a planview sample in order to minimize the relaxation in the substrate. The sample was tilted from the [111] axis along a $\langle 220\rangle$ Kikuchi band. Figure 2 displays [3-5] CBED patterns recorded on (a) the bare substrate and (b) the superimposed substrate/epilayer system.

The tetragonal distortion can be observed as a splitting of Bragg contours relative to crystallographic planes inclined at an angle with respect to the substrate plane. The tetragonal distortion $\left(\varepsilon_{\perp}\right)$ may then be deduced from the relative rotation $\left(\theta_{r}\right)$ of the planes via [8]

$$
\Delta \theta_{r}=\varepsilon_{\perp}(\sin 2 \theta) / 2 .
$$

From the measurement of the splitting of the $(28 \overline{6})$ and $(\overline{2} 10 \overline{4})$ lines, we deduced a value of $\varepsilon_{\perp}=2.4 \times 10^{-3}$, corresponding to a misfit $m=6 \times 10^{-3}$, and Ge concentration $x=0.14$, in good agreement with the nominal concentration of the layer investigated. It should be noted that the HOLZ line of the plane, perpendicular to the surface, is not split. This confirms the presence of a purely tetragonal distortion.

We would like to stress that similar morphology (flat surface, uniformity and free of dislocation) occurred also with (001) layers in this low range of strain and thus will not be shown here.

In order to determine the local distribution inside an undulating layer, the technique was next applied to nanometre scale areas at the crest of a $\mathrm{Si}_{0.7} \mathrm{Ge}_{0.3}(001)$ undulation: along a cross-section line and in plan-view geometry [6,7]. As an example, one set of experiments (cross-section view) recorded along the $\left[\begin{array}{ccc}15 & \overline{7} & 0\end{array}\right]$ axis are discussed hereafter. Other views along other axes lead to the same conclusions. The cross-sectional sample was tilted from the $\left[\begin{array}{lll}0 & 0 & 1\end{array}\right]$ axis along a $\langle 220\rangle$ Kikuchi band. A series of CBED patterns recorded along 

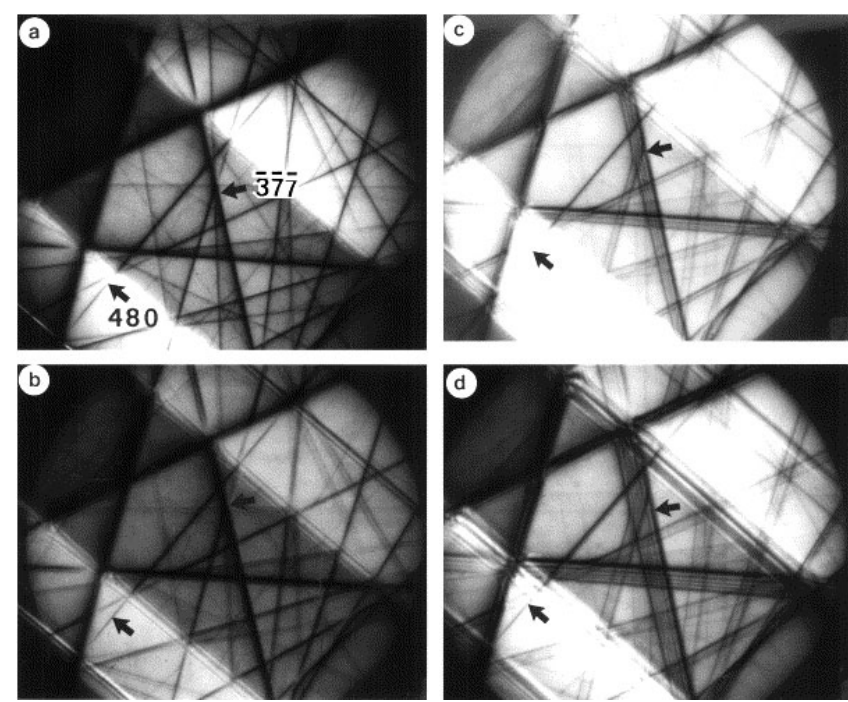

Figure 3. Evolution of the CBED patterns recorded along the $[15 \overline{7} 0]$ axis, in cross-section geometry, on an undulating (100) $\mathrm{Si}_{0.7} \mathrm{Ge}_{0.3}$ layer. The nanoscale electron beam was focused along a line starting from (a) the (100) Si substrate, (b)-(d) towards the topmost free surface of an undulation. The (480) HOLZ line, corresponding to a plane perpendicular to the (001) surface, does not display any noticeable splitting, leading to a fully strained in-plane lattice parameter. The $(\overline{3} \overline{7} \overline{7})$ HOLZ line, corresponding to a plane parallel to the surface, shows a gradual splitting, from the substrate towards the crest of the undulation, testifying to a gradual relaxation in the direction normal to the surface.

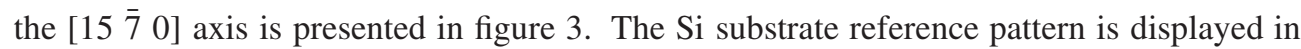
figure 3(a). Figures 3(b)-(d) show the gradual increase of the $(3 \overline{7} \overline{7})$ HOLZ lines splitting when the electron beam is displaced in the direction of the topmost $\mathrm{Si}_{0.7} \mathrm{Ge}_{0.3}$ surface. This is indicative of a gradual relaxation along the $z$-axis. It should be pointed out that the splitting of the (4 8 0) HOLZ line corresponding to a plane perpendicular to (001) is negligible. This is representative of a $\mathrm{Si}_{0.7} \mathrm{Ge}_{0.3}$ cell fully strained in the (001) plane. Regarding the plan-view

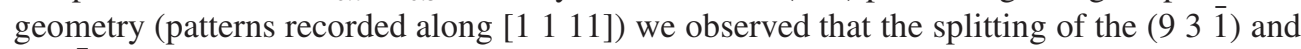
(3 $9 \overline{1}$ ) HOLZ lines, corresponding to planes symmetrical about the $\left[\begin{array}{lll}0 & 0 & 1\end{array}\right]$ axis were not equal. This was attributed to a triclinic deformation of the $\mathrm{Si}_{0.7} \mathrm{Ge}_{0.3}$ cell which was explained by the tetragonal distortion at the top of the undulation being larger than that at the bottom [7].

In order to obtain a more comprehensive analysis of the strain fields in the undulated $\mathrm{Si}_{0.7} \mathrm{Ge}_{0.3}(001)$ layer, we also performed GIXRD studies [7]. The scans parallel and perpendicular to the surface confirmed:

(i) the tetragonal distortion of the (004) planes parallel to the surface, in good agreement with the value of $\varepsilon_{\perp}$ predicted for $x=0.3$ [7]; and

(ii) the perfect fit between $\mathrm{Si}$ and $\mathrm{Si}_{0.7} \mathrm{Ge}_{0.3}(220)$ planes perpendicular to the surface proving the absence of elastic relaxation (figure 4(b)).

This confirms that contrary to what has been predicted theoretically in various elastic models, undulating layers are fully strained (i.e. not elastically nor plastically relaxed) and can be depicted by the schematic view given in figure 4(c). 

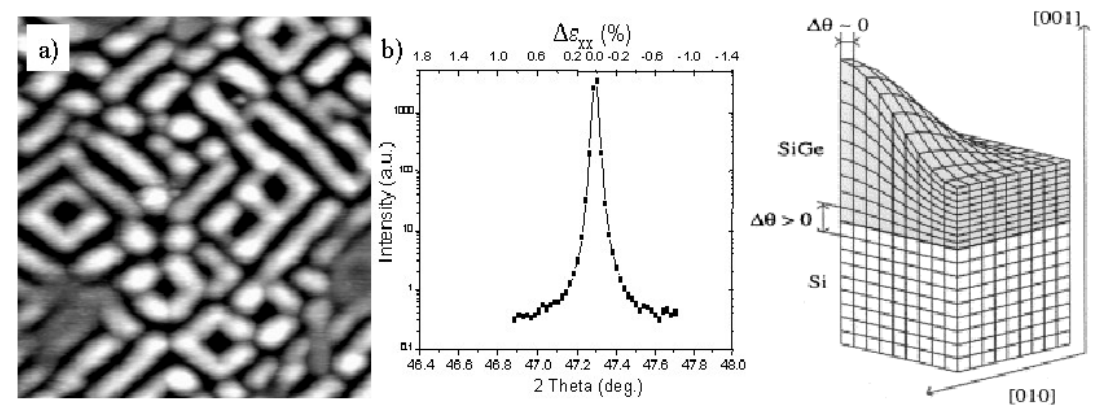

Figure 4. (a) An AFM image of the undulating $\mathrm{Si}_{0.7} \mathrm{Ge}_{0.3}$ (001) layer and (b) GIXRD $\theta-2 \theta$ scans around the (22) 0 ) reflection at $2 \theta=47^{\circ} 3^{\prime}$ and the $\Delta d / d$ average value in the layer. (c) A schematic representation of the strain distribution in an undulation extracted from CBED measurements.

\subsection{Plastic relaxation}

Plastic relaxation mechanisms have been the subject of extensive work [9-15] and are beyond the scope of this paper. However, in order to clarify the relaxation behaviour on $\mathrm{Si}(111)$ and (001), we will briefly recall the basic equation of the critical thickness $\left(h_{c r}\right)$. The latter is defined as the thickness at which it becomes energetically favourable to relax the stress by introducing MD in the heteroepitaxial thin film. The $h_{c r}$-calculation $[16,17]$ is based on an energetic balance between the elastic energy per unit area of a biaxially stressed coherent film and the dislocation energy per unit area of an incoherent film. It is commonly described by the Matthews and Blakeslee model [16]:

$$
h_{c r}=\left(\frac{b}{8 \pi}\right) \frac{\left(1-v \cos ^{2} \theta\right.}{(1+v) \epsilon \cos \lambda} \ln \left(\frac{\alpha h_{c r}}{b}\right)
$$

where $\theta$ is the angle between the dislocation line and its Burgers vector, $b, \lambda$ is the angle between the slip direction and the direction in the film plane which is perpendicular to the line of intersection of the slip plane and the interface, $\alpha$ is the core energy parameter. It should be remarked here that this model only describes the propagation of pre-existing threading dislocations, assumed to be present in the substrate, which is not a realistic case. However, up to now, this model provides a better fit of $h_{c r}$ than all the models based on the calculation of the energy of homogeneous dislocation nucleation.

Two different kinds of MD have been experimentally evidenced by high-resolution electron microscopy (HREM) analyses [10] on the two nominal orientations $\mathrm{Si}(111)$ and $\mathrm{Si}(001)$ : a $90^{\circ}$ Shockley partial $(a / 6)\langle 112\rangle$ dislocation and an undissociated $(a / 2)\langle 110\rangle$ dislocation respectively. Let us first compare the experimental $\left(h_{\text {exp }}\right)$ and theoretical $\left(h_{c r^{-}}\right)$values on the two orientations (001) and (111) in the case of $\mathrm{Si}_{0.7} \mathrm{Ge}_{0.3}(m=1.2 \%)$ grown at $600{ }^{\circ} \mathrm{C}$. The calculated values are $h_{c r} \sim 8 \mathrm{~nm}$ and $\sim 12 \mathrm{~nm}$ on (001) and (111) respectively while the experimental values are found to be much larger: $h_{\text {exp }} \geqslant 50 \mathrm{~nm}$ ) [8], and approximately the same on the two orientations. These discrepancies between theoretical predictions and experimental results are explained by the kinetic barrier to dislocation nucleation: in the MB model, MDs nucleate from the propagation of threading dislocations already present in the substrate while in the experiments they nucleate in the epitaxial film on point defects. The discrepancies tend to decrease at high misfit (stress-driven regime) and to increase at low misfit (kinetically driven regime). For instance, $\mathrm{Si}_{1-x} \mathrm{Ge}_{x}$ samples with $x=0.035(m=0.14 \%)$ and $x=0.042(m=0.17 \%)$ grown at 600 and $750^{\circ} \mathrm{C}$ were studied by means of $\mathrm{x}$-ray techniques. The samples are flat and fully strained (relaxation $<5 \%$ ). A reflection $\mathrm{x}$-ray topograph was used to image individual 
(a)

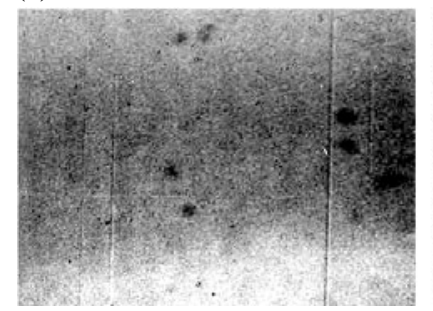

(b)

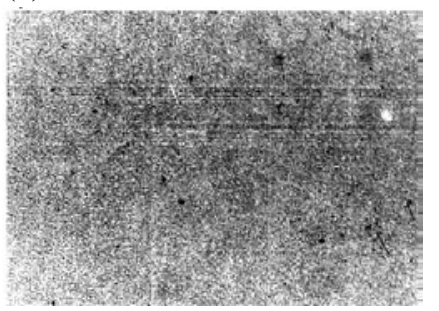

Figure 5. An MD array visualized by reflection $\mathrm{x}$-ray topography with $g=224$; (a) $x=0.035$, $h=800 \mathrm{~nm}, T_{g}=600^{\circ} \mathrm{C}$ and (b) $x=0.042, h=180 \mathrm{~nm}, T_{g}=750^{\circ} \mathrm{C}$

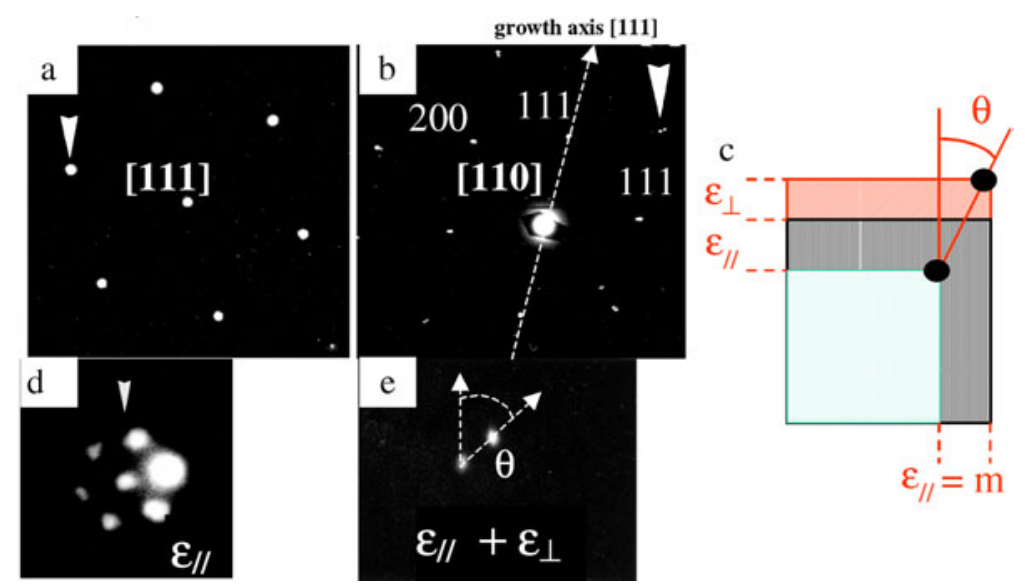

Figure 6. (a) Plan-view and (b) cross-section TED patterns of a $40 \mathrm{~nm}$ thick pure Ge layer deposited on $\mathrm{Si}(111)$. (c) is the schematic representation of the cell relaxation and (d) the TEM cross-section image of the $3 \mathrm{D}$ layer.

MDs and to determine the critical thickness [18] (figure 5). The results summarized in table 2 show that at $600^{\circ} \mathrm{C}$, for $x=0.035$ the onset of MD nucleation occurs at $h_{\text {exp }} \geqslant 800 \mathrm{~nm}(\sim 8$ times larger than $\left.h_{c r}\right)$ while at $750^{\circ} \mathrm{C}$ for $x=0.042$ it occurs at $\sim 180 \mathrm{~nm}(\sim 2$ times larger than $h_{c r}$ ). The dependency of $h_{c r}$ on the growth temperature is primarily explained by the kinetics of the relaxation inhibiting the formation of the MD arrays [19]. Moreover, it has been shown that the first source of MDs is the density of dislocations already present in the substrate. This means that when the substrate is free of dislocations the nucleation of MD is delayed.

In order to realize well-controlled two-dimensional electron and hole gas properties in $\mathrm{Si}-$ $\mathrm{Si}_{1-x} \mathrm{Ge}_{x}$ heterostructures with smooth surface morphology, the idea is to grow a fully relaxed buffer layer matching the lattice parameters of the substrate and of the active region. First, the simplest experiment is to grow thick $\mathrm{Si}_{1-x} \mathrm{Ge}_{x}$ layers. However, it does not permit one to fully relax the stress nor to obtain a smooth surface morphology (to pursue the processing of the layer). For instance the level of relaxation observed in the case of pure Ge/Si(111) (figure 6) has been estimated as $\sim 77 \%$ by measuring the parameters parallel and perpendicular to the growth direction $\left(\varepsilon_{\|} \sim 2.6 \%\right.$ and $\left.\varepsilon_{\perp} \sim 3 \%\right)$.

Another example of a $1 \mu \mathrm{m}$ thick layer (with Ge concentration $x \sim 0.25$ ) grown on $\mathrm{Si}(111)$ is presented in figure 7(a) [20]. After growth, the surface exhibited a triangular crosshatch along the three $\langle 110\rangle$ directions with a roughness of $2.2 \mathrm{~nm}$. The TEM cross-section image (figure 7(b)) evidences the bunching of the threading dislocations to form stacking faults 


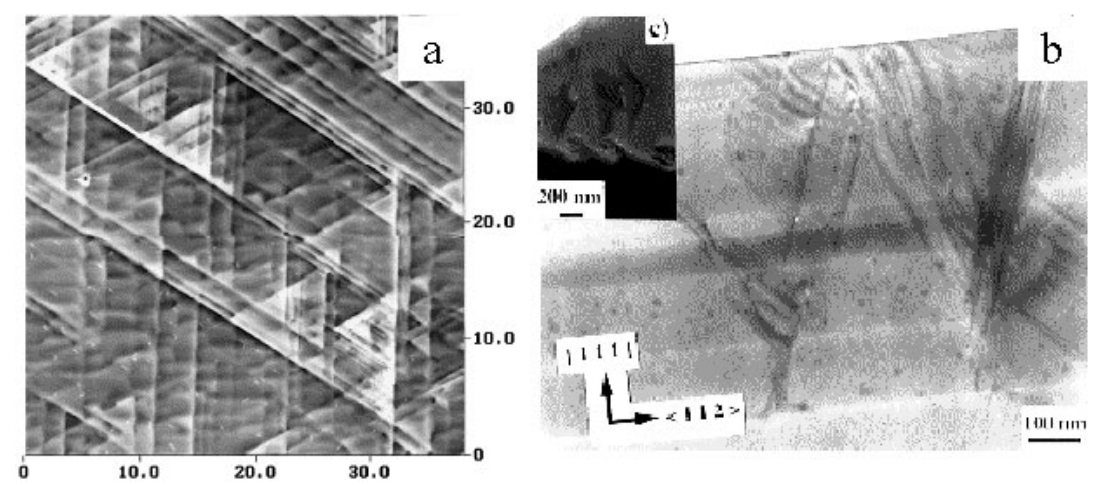

Figure 7. A relaxed $\mathrm{Si}_{1-x} \mathrm{Ge}_{x} 1 \mu \mathrm{m}$ thick buffer deposited on $\mathrm{Si}(111)$. (a) Surface morphology. (b), (c) TEM cross-sections of the threading dislocations bunched to form stacking faults appearing as bright and dark lines in plan view.

Table 2. Characteristics of $\mathrm{Si}_{1-x} \mathrm{Ge}_{x}$ layers with low Ge content.

\begin{tabular}{llllll}
\hline Ge concentration, $x$ & $T g\left({ }^{\circ} \mathrm{C}\right)$ & $h_{c r}(\mathrm{~nm})$ & $h_{\exp }(\mathrm{nm})$ & $\begin{array}{l}\text { MD density } \\
\left(\mathrm{cm}^{-1}\right)\end{array}$ & Relaxation rate $(\%)$ \\
\hline 0.35 & 600 & 105 & 170 & $<10^{-1}$ & $<5$ \\
0.35 & 600 & 105 & 800 & $<10$ & $<5$ \\
0.42 & 750 & 84 & 180 & $<10^{2}$ & $<5$ \\
\hline
\end{tabular}

$\left(\sim 7 \times 10^{8} \mathrm{~cm}^{-2}\right)$. This prevented the dislocations from gliding further to increase the misfit segment length. Moreover, these stacking faults induced step bunching on the surface.

A more promising approach is the so-called virtual substrate graded composition $\mathrm{Si}_{1-x} \mathrm{Ge}_{x}$ layer, which uses thick $\mathrm{Si}_{1-x} \mathrm{Ge}_{x}$ films $(\sim 1 \mu \mathrm{m})$ of increasing Ge concentration and greatly reduces the dislocation density in the top-layer region. The film studied was grown at $600^{\circ} \mathrm{C}$ and consisted of an initial $400 \mathrm{~nm}$ layer with $5 \%$ Ge followed by three $200 \mathrm{~nm}$ steps of increasing $\mathrm{Ge}$ content up to $20 \%$ and capped with a $200 \mathrm{~nm} \mathrm{18 \%} \mathrm{Ge} \mathrm{constant} \mathrm{composition} \mathrm{layer.} \mathrm{XRD} \mathrm{mea-}$ surements performed on this sample showed that the residual strain variation over the sample was negligible. Unfortunately this process also leaves a poor surface morphology (cross-hatch pattern) with an rms roughness of $4.7 \mathrm{~nm}$ which is generally believed to come from the dislocation gliding and the strain field of the dislocation in the virtual substrate region (figure 8(a)).

On another sample, Ge islands having a density of $3 \times 10^{9} \mathrm{~cm}^{-2}$ were pre-deposited to act as nucleation centres for dislocation loops and multiplication sources as well as pinning points for the threading dislocations $\left(2 \times 10^{8} \mathrm{~cm}^{-2}\right)$ or for the misfit segment at the interface with the substrate [20]. The cross-hatch was less ordered (figure 8(b)) and the number of threading dislocations had increased. However, no significant change was observed in the rms roughness $(4.7 \mathrm{~nm})$. For comparison, the morphology of a sample consisting of a $\sim 500 \mathrm{~nm}$ thick $\mathrm{Si}_{1-x} \mathrm{Ge}_{x}$ layer deposited on the top of a thin silicon layer pre-deposited at LT on the substrate is presented. It can be seen (figure 8(c)) that the latter process permits us to considerably reduce both the surface roughness ( $\mathrm{rms} \sim 1.1 \mathrm{~nm})$ and the density of dislocations $\left(\sim 5 \times 10^{4} \mathrm{~cm}^{-2}\right.$ as extracted from AFM images). This is explained by the presence of numerous point defects in the LT Si layer that act as nucleation centres for dislocations. Indeed, it is clearly shown in the cross-section TEM image that most of the dislocations nucleate at the Si substrate/LT Si layer interface (figure $8(\mathrm{~d})$ ). Moreover, the pinning of MDs is also evidenced by the absence of threading dislocations in the top layer of the $\mathrm{Si}_{1-x} \mathrm{Ge}_{x}$ layer. 

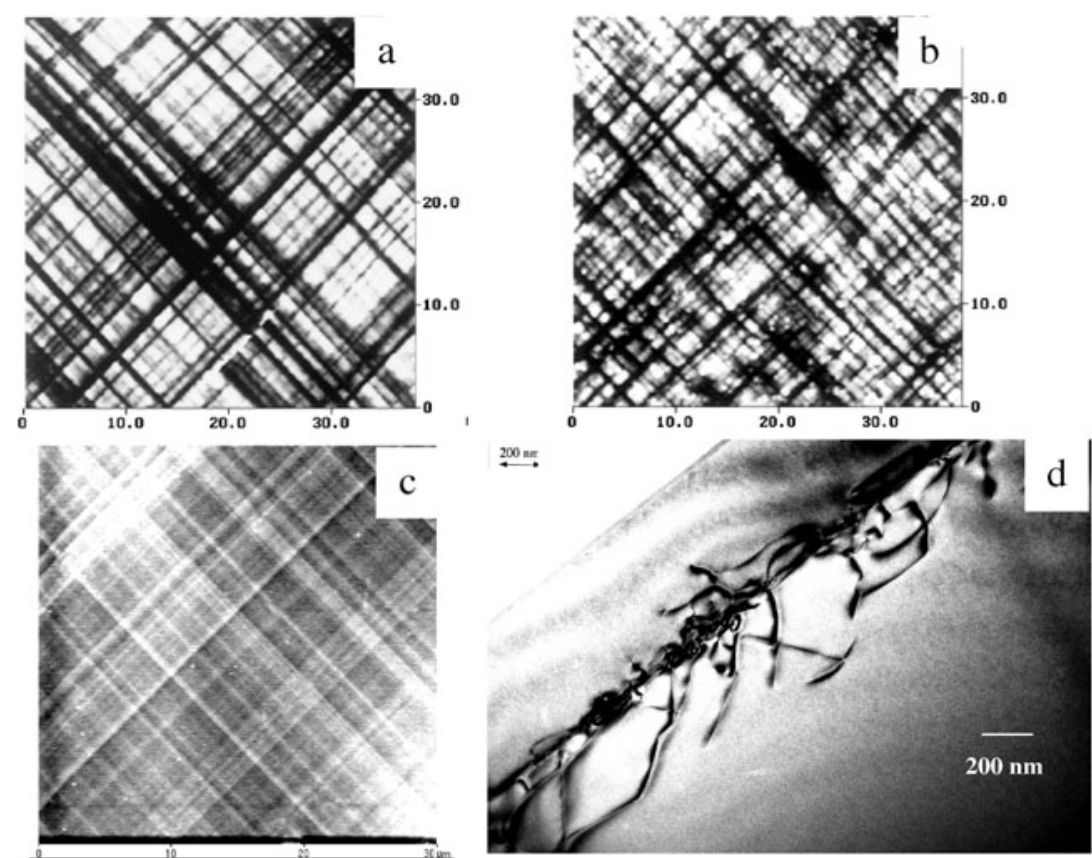

Figure 8. An AFM comparison of the surface morphology of relaxed buffer layers obtained in the following conditions: (a) a graded layer directly grown on the substrate; (b) a graded layer grown on pre-deposited Ge islands; and (c) an SiGe layer grown on a pre-deposited low-temperature (LT) Si layer. (d) The TEM cross-section image of (c), where pinning of MDs and propagation in the Si substrate are shown.

Various mechanisms have been proposed to explain the surface cross-hatch formation. Because of the lattice mismatch between the layer and the substrate, dislocations are introduced in the layer at the growth front $[21,22]$ and propagate to the epilayer/substrate interface where misfit segments are formed whose edge component relieves the strain accumulated in the layer. Due to the low strain inside the layer, it is favourable for the two threading dislocations associated with the misfit segment to glide in order to increase the misfit segment length rather than nucleate new dislocations. Whilst gliding, the misfit segments interact with each other to create low-energy sources for the introduction of new dislocations [23, 24]. During this movement, there is bunching of misfit segments which have the same Burgers vector [25].

Moreover we have shown that

(i) the threading dislocation density has no influence on the surface morphology and that

(ii) it is only the mean misfit segment length that is responsible for the cross-hatch morphology.

Surprisingly, a much lower roughness was observed on the (111) substrate compared to that on (001). We believe that the lower surface energy of the (111) surface is responsible for the low roughness, as already proposed for the action of hydrogen on the surface roughness in GSMBE or for growth on (118) surfaces [26].

We have shown unequivocally that the cross-hatch is not related to the threading dislocations, but only to the misfit dislocation length in the layer [20]. The surface free energy then determines the amplitude of the cross-hatch. In conclusion, the realization of new devices based on such relaxed buffer process will need further work before use. 

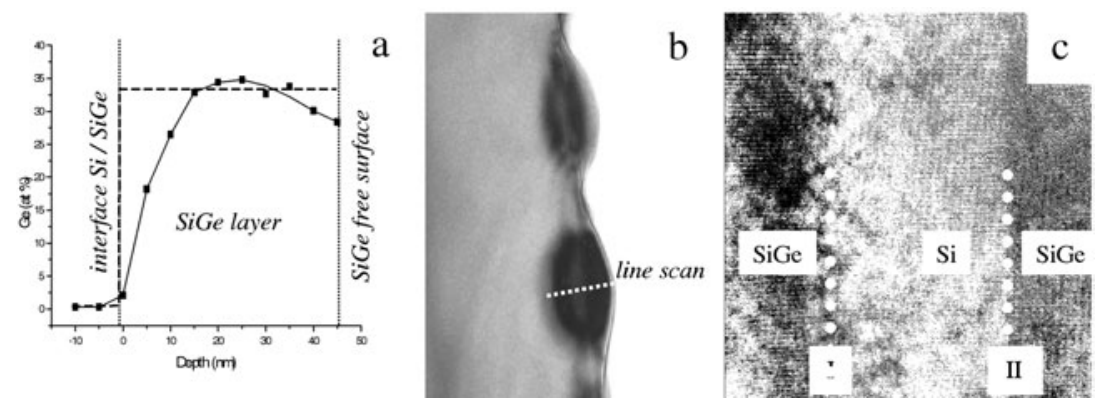

Figure 9. (a) Local Ge concentrations as obtained by EDS analyses performed along a cross-section line from the $\mathrm{Si} / \mathrm{SiGe}$ interface towards the topmost $\mathrm{SiGe}$ layer shown on the TEM cross-section in (b). (c) A TEM cross-section of the $\mathrm{Si} / \mathrm{SiGe}$ interfaces of a multi-layer sample. The diffraction contrast evidences the interdiffusion at the $\mathrm{SiGe} / \mathrm{Si}$ interface (I) being higher than that at the $\mathrm{Si} / \mathrm{SiGe}$ one (II).

\subsection{Elastic relaxation}

Two elastic relaxation events take place during $\mathrm{Si}_{1-x} \mathrm{Ge}_{x} / \mathrm{Si}$ growth when the elastic energy stored in the layer becomes high enough but just before the onset of plastic relaxation by nucleation of MDs: 'chemical relaxation' by strain-enhanced interdiffusion of Ge/Si and 'step edge relaxation' in 3D islands.

The first mechanism is well known but often difficult to accurately measure. Regarding the deposition of pure $\mathrm{Ge}$ on $\mathrm{Si}$ at $550^{\circ} \mathrm{C}$ (see figure 5) we were able to deduce a Ge concentration $\sim 0.79$ (from $\varepsilon_{\|}+\varepsilon_{\perp} \sim 3.35 \%$ ) far below the nominal one. This strain-enhanced interdiffusion mechanism is reduced for layers with lower Ge concentration. For instance, in undulated $\mathrm{Si}_{1-x} \mathrm{Ge}_{x}$ layers (with $x \sim 0.3$ ), the maximum Ge concentration (figure 9(a)) extracted from EDS line scan analyses (figure 9(b)) was found to be in agreement with the nominal one $(x \sim 0.33)$. However, the Ge concentration profile presents a maximum located at about the mid-depth of the layer and the $\mathrm{Si} / \mathrm{Si}_{1-x} \mathrm{Ge}_{x}$ interface extends over $\sim 15 \mathrm{~nm}$. This is very detrimental for the fabrication of many devices that need abrupt interfaces. Moreover, the lower Ge concentration at the top surface is explained by the native silicon dioxide. When the $\mathrm{Si}_{1-x} \mathrm{Ge}_{x}$ layer is buried by a $\mathrm{Si}$ cap layer, the resulting Ge concentration is commonly lower than the nominal one. This reduction is due to the strain-enhanced $\mathrm{Si} / \mathrm{Ge}$ interdiffusion in conjunction with the dynamic segregation of Ge during growth. We have shown that $\mathrm{Si} / \mathrm{Ge}$ interdiffusion can be almost completely suppressed in $3 \mathrm{D} \mathrm{Si}_{1-x} \mathrm{Ge}_{x}$ islands, when the interruption times between the growth of $\mathrm{Si}_{1-x} \mathrm{Ge}_{x}$ and $\mathrm{Si}$ cap layers are sufficiently long [27]. This was explained by the stabilization of low-energy facets that reduce the surface energy of the islands and maintain their shape/composition. Finally, because of the dynamic segregation of Ge during growth the interface $\mathrm{Si}_{1-x} \mathrm{Ge}_{x} / \mathrm{Si}$ layers are broader than the $\mathrm{Si} / \mathrm{Si}_{1-x} \mathrm{Ge}_{x}$ ones. This is evidenced by the diffraction contrast of TEM images (figure 9(c)) in which interface I appears broader than interface II.

The second mechanism is the elastic relaxation at the step edges of the $3 \mathrm{D}$ islands. This has been measured by means of XRD in the case of $\mathrm{Si}_{0.7} \mathrm{Ge}_{0.3}$ islands [28]. The results presented in figure 10 show that:

(i) no lateral elastic strain $\left(\varepsilon_{x x} \sim 0\right)$ is observed in 2D undulated layers at $h=5 \mathrm{~nm}$;

(ii) about $16 \%$ elastic relaxation $\left(\varepsilon_{x x} \sim 2 \times 10^{-3}\right)$ is reached in 'hut' islands with rectanglebased shape at $h=10 \mathrm{~nm}$; and

(iii) about $70 \%$ elastic relaxation $\left(\varepsilon_{x x} \sim 8 \times 10^{-3}\right)$ is reached in large 'dome' islands. 
$\varepsilon_{x x}(\%)$

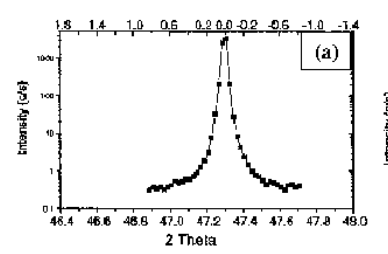

$\mathrm{E}_{\mathrm{xx}}(\%)$

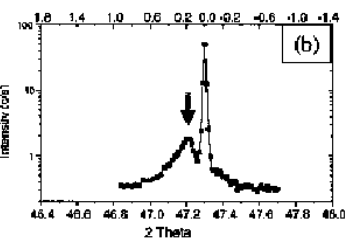

$\varepsilon_{x x}(\%)$

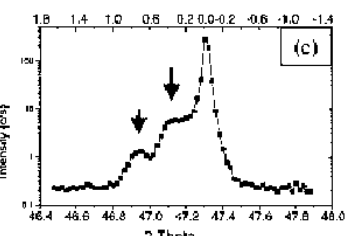

Figure 10. GIXRD $\theta-2 \theta$ scans around the $\operatorname{Si}(2 \overline{2} 0)$ reflection at average values of $2 \theta=47.3^{\circ}$ $(\lambda=0.15405 \mathrm{~nm})$ and $\varepsilon_{x x}$ for $\mathrm{Si}_{0.7} \mathrm{Ge}_{0.3}(001)$ (a) as-grown layers with $h \sim 5 \mathrm{~nm}$, (b) as-grown layers with $h \sim 10 \mathrm{~nm}$, and (c) annealed layers with $h \sim 5 \mathrm{~nm}$. The arrows indicate the peaks corresponding to (partially) relaxed structures.

In the detection limit of TEM observations, all the samples studied in this set of experiments were free of dislocations. The two levels of elastic relaxation observed in the two latter cases are attributed to different island shapes. This could explain the first-order shape transition between 'hut' and 'dome' islands (see section 4.2).

\section{Nucleation, growth, and self-assembly processes}

\subsection{Introduction}

It is commonly reported that self-assembling of QDs goes through the classical stages of nucleation and growth of islands followed by a last sequence of coarsening (Oswald ripening or other diffusive mechanism) [28]. This part of our review summarizes the current status of research in the field of nucleation, growth, and self-organization for $\mathrm{Si}_{1-x} \mathrm{Ge}_{x}$ QDs. Particular attention is paid to comparison of the $\mathrm{Si}_{1-x} \mathrm{Ge}_{x}$ surface evolution on $\mathrm{Si}(111)$ and that on $\mathrm{Si}(001)$. In particular, we report a systematic investigation of $\mathrm{Si}_{1-x} \mathrm{Ge}_{x}$ island morphologies that form in between the 2D-3D growth transition (with the exception of dislocated-induced morphologies).

The deposition of pure Ge on $\mathrm{Si}$ is commonly described as a classic Stranski-Krastanov (SK) process. It has been recently shown that the growth on (001) is considerably more complex than the simplified SK growth observed on (111). Briefly, Ge deposition on (001) can be summarized as follows [30-33]. In a first stage, growth proceeds in a layer-by-layer mode characterized by a fast increase of the ML step density and the formation of dimer vacancies that order in a $(2 \times n)$ reconstruction. $3 \mathrm{D}$ islands start to form just after this surface roughening, probably using the micro-roughness as nucleation centres [34]. As coverage continues to increase, different temperature-dependent metastable morphologies occur (hut clusters, domes, ...), that finally undergo a phase transition towards very large $(\phi \geqslant 1 \mu \mathrm{m})$ dislocated islands [35]. However, in this scheme of growth, the origin of the first stage of roughening is still under debate (kinetic or stress-driven instability). Also, the origin of the formation of hut islands and the transition from huts to domes are matters of controversy. Finally, usual models do not consider the role of the orientation and of the atomic configuration of substrates (surface diffusion anisotropy for instance) in the shape of the deposited layers.

Moreover, although there exist extensive theoretical and experimental studies on the strain relaxation mechanisms [30,36-45], the influence of the substrate orientation on these mechanisms has been poorly investigated [46-48].

In our experiments the $\mathrm{Si}_{1-x} \mathrm{Ge}_{x}$ deposited thickness was adjusted to maintain the structures in metastable states (see figure 11), just below the critical thickness of dislocation nucleation $\left(h_{c r}\right)$ but higher than the theoretical critical thickness for islanding $\left(H_{c r}\right)$. 


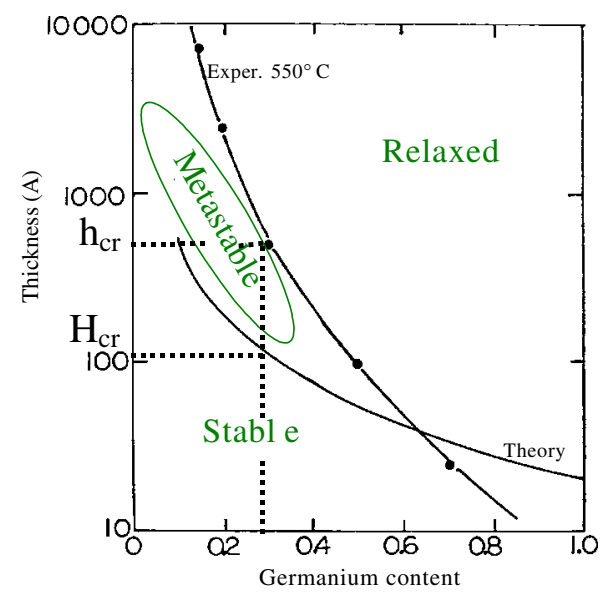

Figure 11. A schematic representation of the different regimes (strained, metastable, and relaxed) of $\mathrm{Si}_{l-x} \mathrm{Ge}_{x}$ growth as a function of the thickness and of the Ge concentration.

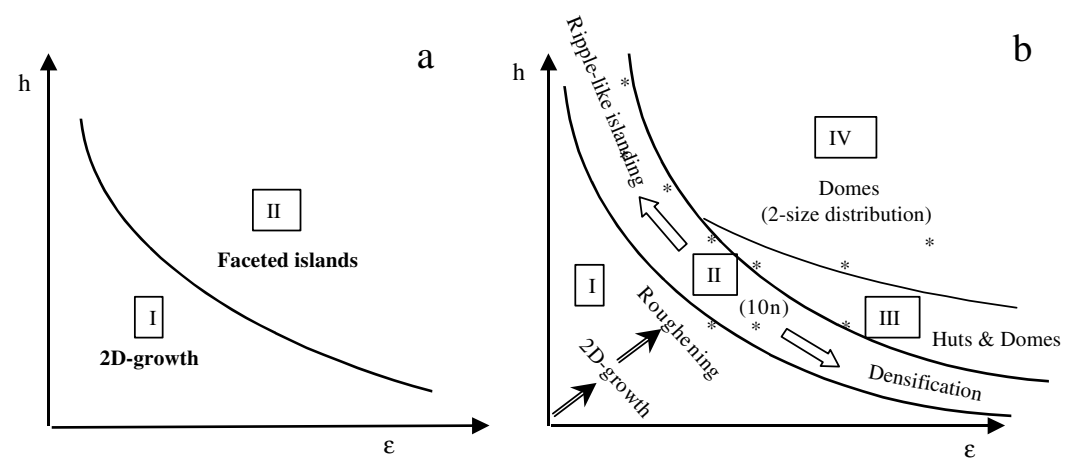

Figure 12. The kinetic phase diagram (at $T g \sim 550{ }^{\circ} \mathrm{C}$ ) representing the main growth regimes as a function of the deposited thickness $(h)$ and the misfit $(\varepsilon)$ : (a) on $\operatorname{Si}(111)$ and (b) on $\operatorname{Si}(001)$.

\subsection{Kinetic phase diagram}

In practice, even if the critical thickness of stress relaxation is the same on (001) and (111) surfaces [7, 49], huge differences are found in the kinetics of the 2D-3D growth transition. In particular, the island formation and evolution are very different on (001) and (111), (001) being unique in exhibiting the formation of metastable coherent (dislocation-free) islands. In fact, all the metastable states observed on (001) are completely inhibited on (111). This was reported by us in [50]. In order to summarize the behaviour on both orientations, kinetic phase diagrams of surface morphologies as a function of the two most relevant parameters (the deposited thickness $h$ and the misfit $\varepsilon$ ) are presented in figure 12 [51]. They have been extracted from systematic investigations of as-grown $\mathrm{Si}_{1-x} \mathrm{Ge}_{x}$ surfaces that occurred, in our growth conditions, by a competition between kinetic (step flow growth and very high supersaturation) and thermodynamic processes.

On $\mathrm{Si}(111)$ only two growth regimes can be distinguished: 2D layer-by-layer growth at low $(h, \varepsilon)$; and classical SK growth at high $(h, \varepsilon)$. In the latter case plastically relaxed islands that present large facets oriented along (113) and (111) have been obtained [7]. Undulations and dislocation-free islands were never observed on this substrate orientation. 


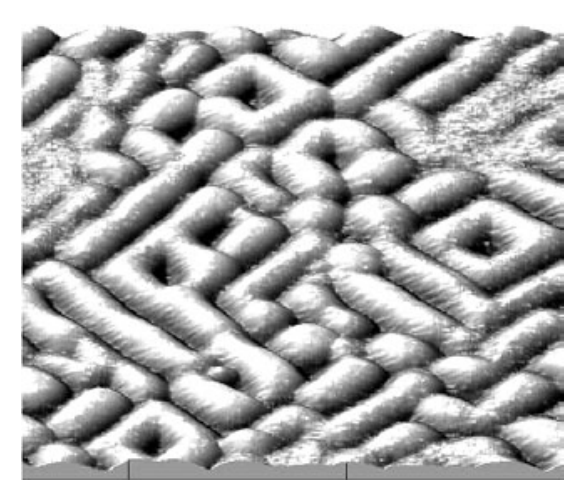

Figure 13. An AFM image of undulations elongated along $\langle 100\rangle$ and $\langle 010\rangle$ directions obtained in regime $\mathrm{I}$ for $\mathrm{Si}_{0.85} \mathrm{Ge}_{0.15}(h=100 \mathrm{~nm})$.

On (001) the evolution of $\mathrm{Si}_{1-x} \mathrm{Ge}_{x}$ surfaces is quite different and can be broken into four main regimes:

- Regime I is characterized by a layer-by-layer growth accompanied by a gradual increase of surface roughness which primarily consists of dimer vacancies [52], kinks, and additional steps [53, 54]. Vacancies are assumed to serve as a strain-relief mechanism [29, 33]. At sufficiently high density of vacancies they order to form the $(2 \times n)$ reconstruction which presumably further reduces the strain energy. Even if surface roughness increases very rapidly in this regime, the steady-state morphology is characterized by a succession of $S_{A}$ and $S_{B}$ steps oriented along the $\langle 110\rangle$ directions. A comprehensive review on quantitative scanning tunnelling microscopy (STM) analysis of surface roughening during submonolayer growth of $\mathrm{Ge}$ on $\mathrm{Si}(001)$ can be found in [33].

- In regime II, ripple-like islands (or undulations) that exhibit a broad distribution in size and in shape are observed at low $(h, \varepsilon)$. The striking feature of these ripple-like islands is their side orientation along $\langle 100\rangle$ directions. Furthermore, at increasing thickness they elongate in chains or in square patterns oriented along [100] and [010] (figure 13). They present very small aspect ratios $(h / L \sim 0.03)$ and side angles of about $\sim 5^{\circ}$ (instead of $11.3^{\circ}$ for (105) facets) without extended facets on their sides.

Such undulations are fully strained [7] ( $\Delta \varepsilon_{x x} \sim 0$ was found by both CBED and GIXRD). The kinetics of ripple-like island formation along the $\langle 100\rangle$ directions, i.e. at $45^{\circ}$ from the $(2 \times n)$ reconstruction rows, is still unclear. It turns out that such morphologies can be equilibrium structures of (001) surfaces subjected to biaxial compressive stress $[54,55]$ but it is evident that kinetic considerations [56-59] cannot be ignored since kinetic instabilities observed in Si homoepitaxy [60-63] give rise to similar morphological evolution of layers (see section 4.3).

At higher misfit $(\varepsilon=1.2 \%, x \sim 0.3$ ), square isotropic mounds (with lateral size $L \sim 100 \mathrm{~nm}$ ) nucleate, superimposed on the rough surface. These islands, usually called 'huts', adopt pyramidal shape with the four bases oriented along $\langle 100\rangle$ directions and the four facets approximately corresponding to (105) facets [30]. GIXRD analysis proves the absence of elastic relaxation in such 'hut' islands [28]. In this regime, their morphological evolution with the thickness differs from their evolution with the misfit (figure 14). Indeed, at increasing deposited thickness, there occurs a shape transition from square-based islands (figure 14(a)) to elongated rectangle-based islands (figure 14(b)), while an increasing 
misfit induces an increasing density of square-based islands. In fact the intersection point between regimes II, III, and IV represents an experimental compromise between density, size, and homogeneity of islands. Figure 14(c) gives an example of the $\mathrm{Si}_{1-x} \mathrm{Ge}_{x}$ islands obtained in these experimental conditions (density $\sim 2 \times 10^{10} \mathrm{~cm}^{-2}$ ).

In order to determine the stability of such 'hut' island shape, we have followed their morphological evolution during an annealing at $550^{\circ} \mathrm{C}$ [51]. Starting from a ripple-like asgrown surface, formation of fully strained 'hut' islands occurred after $1 \mathrm{~h} 30 \mathrm{~min}$ annealing (no elastic relaxation was detected at this stage). After $18 \mathrm{~h}$ annealing, islands evolved towards large isolated 'huts' that exhibited well-defined (105) facets (figure 14(d)). Elastic relaxation measured in these large hut islands $\left(\Delta \varepsilon_{x x} \sim 0.25 \%\right)$ is very low. They are consequently still highly strained (about $0.75 \%$ ).

No further evolution (of the morphology and of the elastic relaxation) occurred during the following $46 \mathrm{~h}$ annealing. This proves that large 'huts' represent an equilibrium steady state and we suggest that their morphology is stabilized by the compressive biaxial stress applied by the substrate to the islands. If this is the case, (105) facets would be expected to have lower surface energy than (100) facets under compressive stress. Thermal stability of hut islands (during long-term annealing) was also reported in [64]. However, this is in contradiction with the conclusions of $[32,65]$ which state that huts only provide a kinetically favourable path from $2 \mathrm{D}$ to stable macroscopic islands. In our scheme of growth, these results that seem contradictory are in fact compatible, as will be shown below (see the regime III description). Nevertheless, further experiments are needed to determine the exact origin of hut island formation (minimization of (105) surface energy under compressive stress).

- In regime III, coexistence of 'huts' and 'domes' is observed (figure 15(a)) [66, 67]. The two island groups are characterized by different aspect ratios $(\sim 0.15$ and $\sim 0.04$ for 'domes' and 'huts' respectively) and different shapes: pyramidal 'huts' that have been described previously (figure 15(b)) and round-shaped 'domes' (figure 15(c)) with the larger facets corresponding to $\{113\}$ and $\{111\}$ planes (figure $15(\mathrm{~d})$ ). Several other side orientations were found at the top of the domes, but they could not be accurately determined. For a detailed description of the dome shape, see [66]. The respective densities of 'huts' and 'domes' varies with the experimental conditions: 'domes' are favoured in the higher-stress regime, while 'huts' are favoured in the lower-stress regime. The most striking result here is that a much higher level of elastic relaxation was measured in 'domes'. For instance, $\Delta \varepsilon_{x x} \sim 0.78 \%$ was found in an as-grown $\mathrm{Si}_{0.5} \mathrm{Ge}_{0.5}$ layer with $h=5 \mathrm{~nm}(\varepsilon=2.1 \%)$.

In this growth regime, as-grown square islands also transform during annealing (longterm annealing at $550^{\circ} \mathrm{C}$ ) into larger round-shaped domes that constitute the steady-state morphology of this growth regime. This transition, based on a ripening process, is accompanied by a dramatic increase of the relaxation level $\left(\Delta \varepsilon_{x x} \sim 0.85 \%\right)$ [51]. This suggests that the 'hut'/'dome' transition is mainly driven by stress relaxation and that hut islands (and in particular (105) facets) are destabilized by the elastic stress relaxation. As a consequence, as the stress relaxation takes place, the (105) facets decrease in size at the expense of (113) and (111) facets that are the low-energy facets present in the equilibrium shape of bulk Si (without stress). In this scheme of growth each step accompanied by stress relaxation will induce the hut/dome transition. For instance, at an intermediate level of misfit (compressive stress), the islands are highly strained (low stress relaxation) and the (105) facets have low surface energy. Huts represent the steady-state morphology of this regime. At higher misfit, because stress relaxation is energetically favoured (elastic relaxation or dislocation nucleation) the islands are largely relaxed and the steady-state morphology then consists of domes. So, even if the formation of huts is possible during growth, they represent kinetic pathways in this stress regime and will rapidly transform into domes, during 

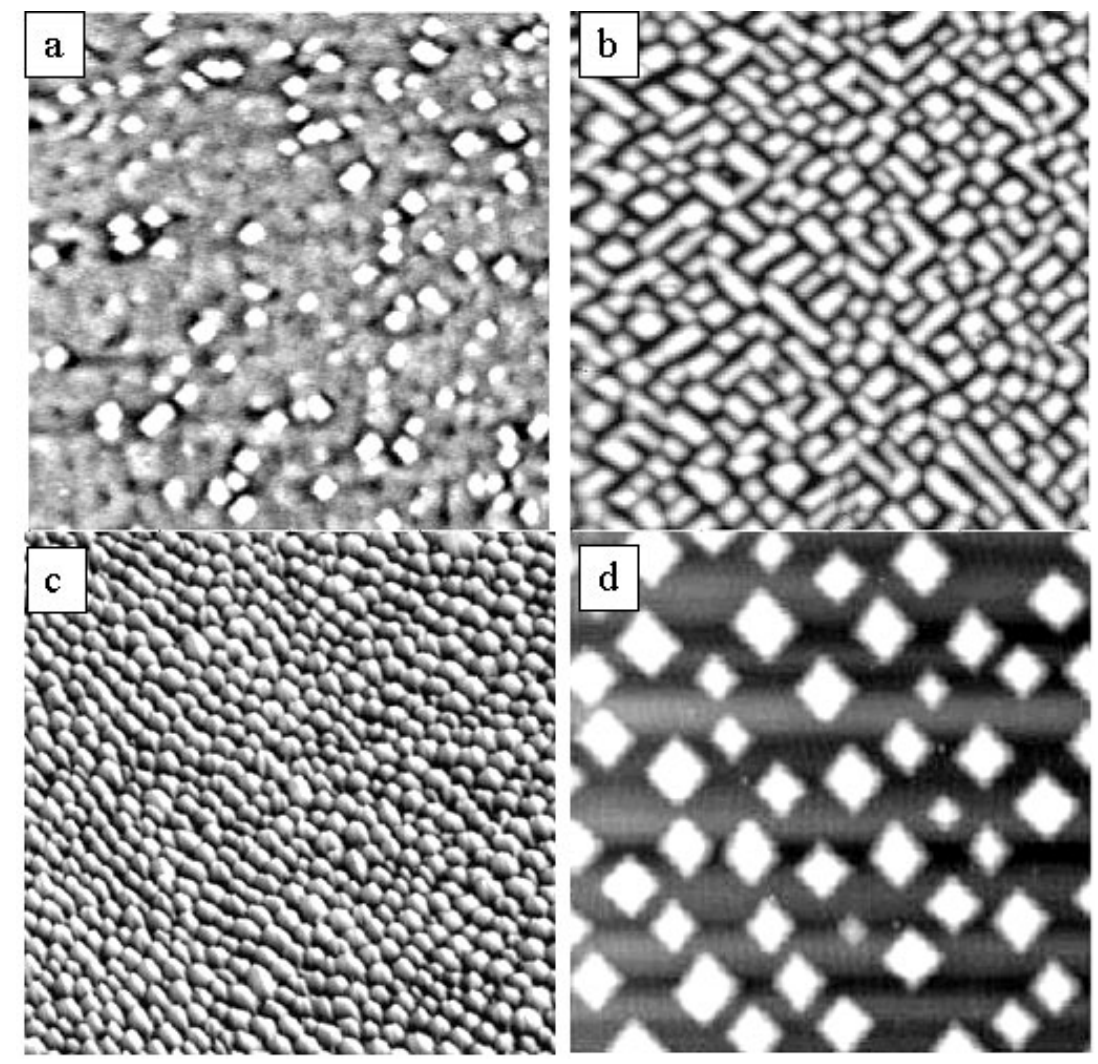

Figure 14. AFM images (scan size $2 \mu x 2 \mu$ ) of $\mathrm{Si}_{1-x} \mathrm{Ge}_{x}$ : (a) as grown 'hut' islands with $x=0.3$ and $h \sim 5 \mathrm{~nm}$; (b) as grown 'hut' islands with $x=0.3$ and $h \sim 10 \mathrm{~nm}$; (c) as grown 'hut' islands with $x=0.35$ and $h \sim 5 \mathrm{~nm}$; (d) 'hut' islands with $x=0.25$ and $h \sim 10 \mathrm{~nm}$ stabilised during $18 \mathrm{~h}$ annealing at $550^{\circ} \mathrm{C}$.

any annealing. We suggest that this could explain the contradictory results reported above.

- In regime $I V$, a bimodal size distribution of domes is observed. They correspond to dislocated and coherent structures. The latter ones are similar to those described in the previous section. Hut islands are never observed in this regime. The steady-state morphology consists of larger-sized relaxed islands. Such islands are not relevant for this paper. For a comprehensive review on the dislocation nucleation, see [13, 14].

\subsection{Growth instability}

We have seen in section 4.2 that on $\mathrm{Si}(001)$, regime II is characterized by the development of instabilities (undulations) that lead to a sinusoidal-like morphology. The evolution of such instabilities during epitaxial growth on Si surfaces has been of increasing interest over the past few years for two opposite reasons. First, because any corrugation of the SiGe surface is very detrimental in the fabrication of high-speed electronic devices that require abrupt interfaces and flat layers. Second, because in contrast, periodic sinusoidal morphology can be used as self-patterned templates for selective growth of self-assembled nanostructures (see section 4.4). 


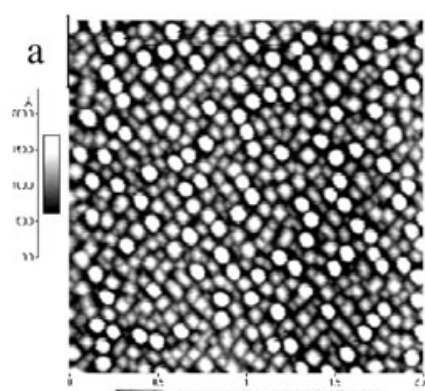

b
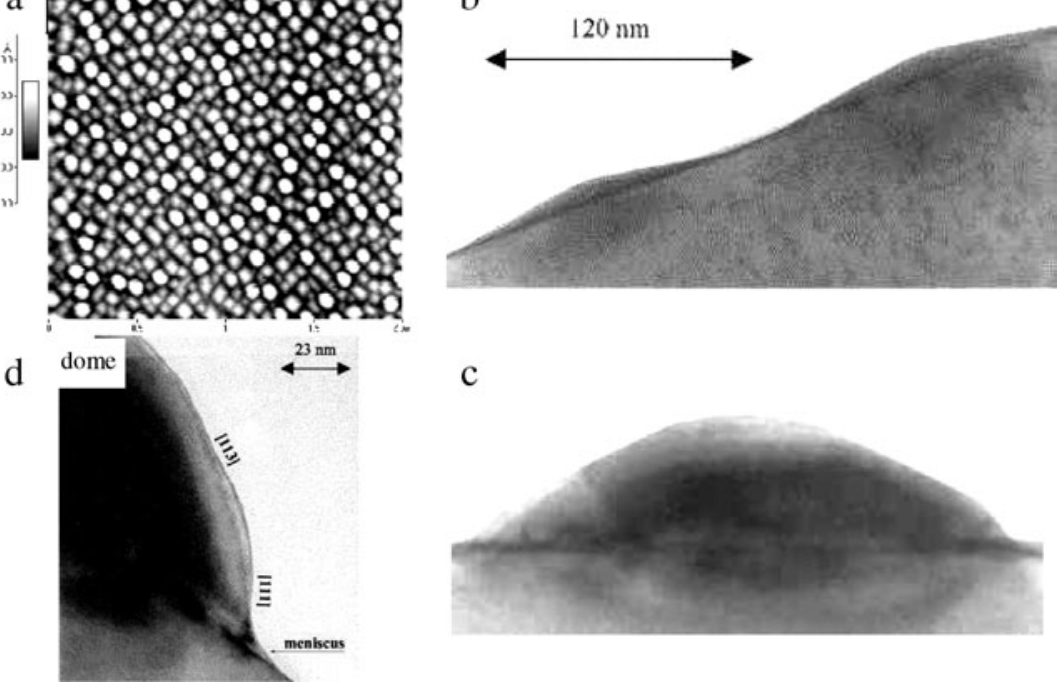

C

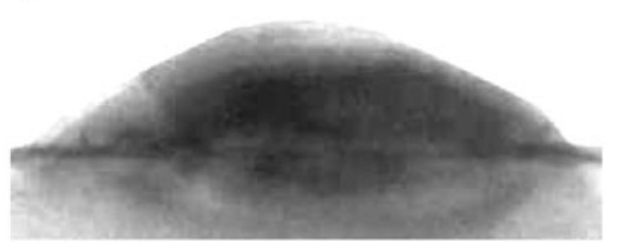

Figure 15. (a) An AFM image of the bimodal size distribution of islands due to the coexistence of square-based 'hut' and round-shaped 'dome' islands for $\mathrm{Si}_{0.6} \mathrm{Ge}_{0.4}(h=5 \mathrm{~nm}$ ). TEM crosssection images of (b) 'huts' and (c) 'domes'. The enlargement of (c) presented in (d) evidences the presence of (113) and (111) facets.

In the past, there has been considerable controversy regarding the influence of stress on growth instabilities. The main issue was whether surface undulation favours dislocation nucleation or not. In some cases, the lateral elastic relaxation of the layer on the top of the undulation was proven to lower the amount of accumulated elastic energy inside the heterolayer leading to larger critical thickness of strained pseudomorphic films [13, 38, 39]. In other cases, preferential dislocation nucleation was assumed to be initiated in highly strained local areas in the valley of the undulation $[15,36,68]$. In all cases, the main hypothesis was the existence of a critical wavelength and/or of a critical stress, beyond which the surface becomes unstable with respect to a sinusoidal corrugation $[44,45,69,70]$. This is the basic idea of the Asaro-TillerGrinfeld (ATG) modelling which considers the instability under the formulation of continuum elasticity. The layer becomes corrugated when the excess of surface free energy due to the corrugation and the elastic energy paid by the strain field distribution is compensated by the gain of elastic energy due to relaxation in 3D islands.

In the previous paragraph, we have reported that the growth instability which develops during $\mathrm{Si}_{1-x} \mathrm{Ge}_{x}$ growth on $\mathrm{Si}(001)$ does not develop on $\mathrm{Si}(111)$ in the same experimental conditions. Thanks to deeper analyses [7], this was attributed to the different atomic configurations of the $\mathrm{Si}(001)$ and $\mathrm{Si}(111)$ surfaces. This dramatic role of the atomic surface morphology and of the kinetics of step motion questions the validity of models based on the elastic relaxation in islands in order to explain the development of growth instabilities. In fact, in order to understand the mechanism, both kinetics (anisotropy of surface diffusion) and atomic arrangement of the surface (surface reconstruction and step edge configuration) should be considered. Hereafter, we investigate the role of step density and of stress on the onset/evolution of the growth instability. We concentrate our investigations on the morphology of $\mathrm{Si}$ and $\mathrm{Si}_{1-x} \mathrm{Ge}_{x}$ vicinal layers and on the influence of stress on this morphology. We show that different behaviours are observed depending on the nominal orientation of the substrate. 

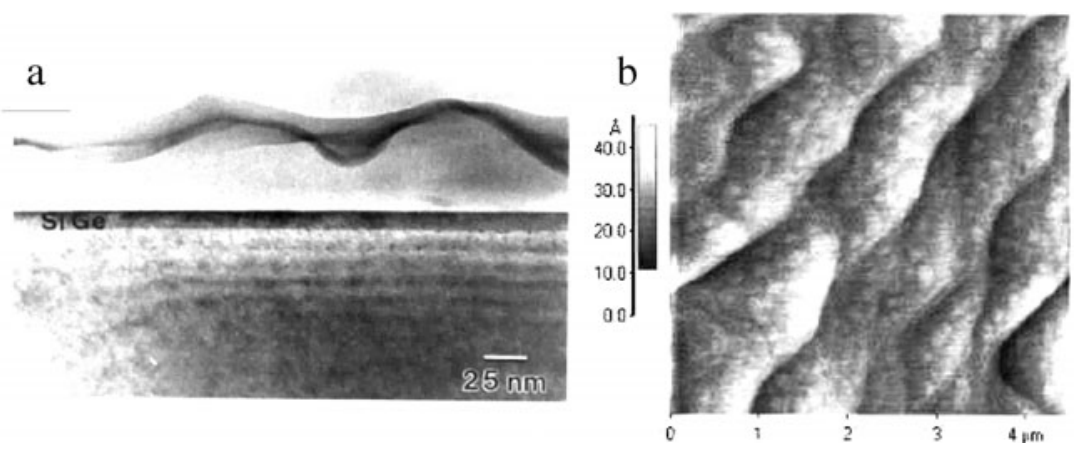

Figure 16. A $10 \mathrm{~nm}$ thick $\mathrm{Si}_{0.7} \mathrm{Ge}_{0.3}$ layer deposited on $\mathrm{Si}(111)$ : (a) a cross-sectional TEM observation and (b) an AFM image of the surface which exhibits large flat terraces $(\sim 0.2 \mu \mathrm{m})$ separated by trilayer steps $(\sim 1 \mathrm{~nm}$ height $)$.

\subsubsection{Growth on $\operatorname{Si(111).~}$}

4.3.1a. Singular Si(111). Instability was never observed during the homoepitaxy of Si on nominal $\mathrm{Si}(111)$ whatever the deposited thickness $(h)$ was (varying from 100 to $1000 \mathrm{~nm}$ ) [71]. The growing surface remained free of defects and perfectly flat throughout the growth. Even at $h \sim 1 \mu \mathrm{m}$ the layer exhibits a regular single-height (SH) array of steps and large $\sim 0.2 \mu \mathrm{m}$ terraces.

When a $\mathrm{Si}_{1-x} \mathrm{Ge}_{x}$ film is grown on $\mathrm{Si}(111)$, the film is biaxially compressed in the growing plane along the $\langle 110\rangle$ and $\langle 112\rangle$ crystalline directions. For small $h, \mathrm{Si}_{1-x} \mathrm{Ge}_{x}$ grows in a coherent layer-by-layer fashion and exhibits large terraces separated by trilayer steps $(\sim 1 \mathrm{~nm}$ height) [71]. Bi-dimensional nuclei are also visible on the terraces (figure 16).

As $h$ increases the elastic energy within the film quickly outruns the dislocation energy making it favourable for forming a partially incoherent structure when $h$ exceeds a critical value $h_{c r}$. The 2D-3D growth transition never occurs in this range of misfit and the dislocated layers do not have any periodic undulations [7]. However, 2D-3D transition occurs during the $\mathrm{Ge} / \mathrm{Si}$ growth, leading to dislocated relaxed Ge islands.

4.3.1b. Vicinal Si(111). Initially we studied the homoepitaxial growth of $\mathrm{Si} / \mathrm{Si}$ misoriented at $2^{\circ}, 6^{\circ}$, and $10^{\circ}$ (in the $\left[\begin{array}{lll}\overline{1} & \overline{1} & 2\end{array}\right]$ direction) [71]. Just after the in situ cleaning procedure preceding growth, the Si misoriented surfaces are composed of regular arrays of tri-atomic steps separated by flat (111) terraces $\left(5.5 \mathrm{~nm}\right.$ at $10^{\circ}$ off) that exhibit the $7 \times 7$ superstructure.

In all cases, for a deposited thickness $h$ lower than $150 \mathrm{~nm}$, we only observe a small kinetic roughness which can be regarded as a Gaussian roughness. For larger $h(\sim 500 \mathrm{~nm})$, a periodic undulated surface stabilizes during growth (figure 17(a)).

HREM observations have shown that one period of undulation (figure 17(b)) can be divided in two main areas: a climbing orientation (a) and a descending one (b). Higher-magnification images (figure 17(c)) show that both orientations (a) and (b) consist of combinations of lowenergy facets, (111) and (112). Most of the rising areas (a) comprise (111) facets, while most of the descending areas (b) consist of (112) ones. Consequently the surface profile can be schematically represented by the diagram presented in figure 17(d).

The variations of the amplitude $(A)$ and of the periodicity $(\lambda)$ are consistent with a kinetic step bunching mechanism: (1) $A$ and $\lambda$ evolve as $t^{\alpha}$ and $t^{\beta}$ respectively with the deposited thickness - the critical exponents extracted from experiments are $\alpha \sim 0.5$ and $\beta \sim 0.16$; 


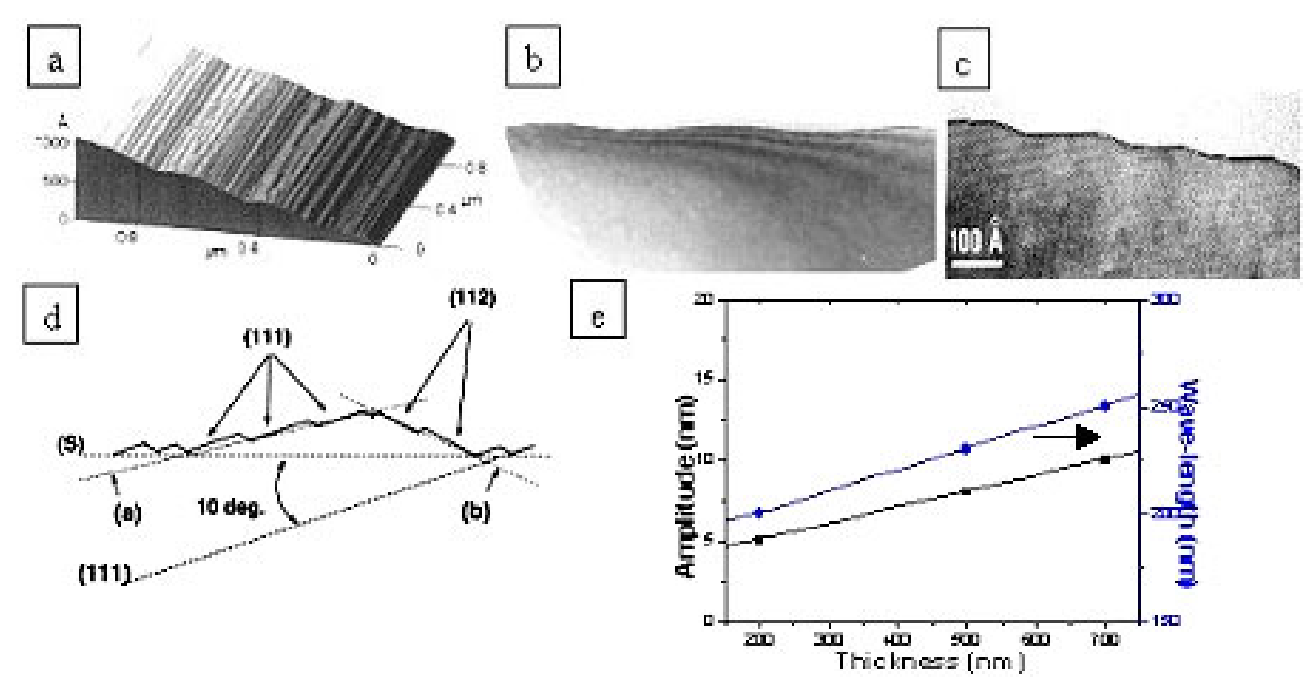

Figure 17. Homoepitaxy of $\mathrm{Si}(h \sim 500 \mathrm{~nm}) / \mathrm{Si}(111)$. (a) An AFM image of the anisotropic undulation. ((b), (c)) TEM cross-sectional images (b) of the periodic undulations and (c) of the local arrangement of the facets. (d) A schematic representation of one period of the undulation deduced from HREM measurements. (e) Morphological evolution of the amplitude $(A)$ and periodicity $(\lambda)$ of the instability with the deposited thickness.

(2) $\lambda$ increases with the temperature; and (3) the amplitude maximum of the instability is at $\sim 700^{\circ} \mathrm{C}$. The kinetic Monte Carlo simulation of the kinetic instability is in progress.

We then investigated the growth of $\mathrm{Si}_{0.7} \mathrm{Ge}_{0.3}$ layers when deposited at $2^{\circ}, 4^{\circ}, 6^{\circ}$, and $10^{\circ}$ off Si substrates $[28,71]$. We intentionally limited the study to fully strained $\mathrm{Si}_{0.7} \mathrm{Ge}_{0.3}$ layers (free of defects). The morphological evolution of the layers with the miscut angle (from $2^{\circ}$ to $10^{\circ}$ ) is shown in figure 18 . This evolution is consistent with a faceting instability (increase of $A$ and decrease of $\lambda$ with the miscut angle).

For $2^{\circ}$ miscut angle, the surface consists of high step bunching (from 3 to $10 \mathrm{ML}$ ) aligned along $\langle 113\rangle$ directions, leading to triangular shape. With increasing miscut angle, the triangular shape elongates along the direction of misorientation which is the direction of the step edges. At $10^{\circ}$ off, the surface exhibits large anisotropic periodic undulations with a typical asymmetric shape. $\lambda$ has been estimated from AFM analysis to be in the micrometre range and $A$ to be about $8 \mathrm{~nm}$. In a similar manner to that for Si layers, TEM cross-section analysis evidences the onset of (111) and (113) facet formation on the side parts of the undulation.

Regarding the effect of stress, we find that the biaxial compressive stress applied to the growing film during $\mathrm{Si}_{1-x} \mathrm{Ge}_{x}$ heteroepitaxy dramatically enhances the instability development. Indeed, for instance at $10^{\circ}$ off $\mathrm{Si}(111)$ the morphology of a $500 \mathrm{~nm}$ thick Si layer is comparable to those of $\mathrm{a} \mathrm{Si}_{1-x} \mathrm{Ge}_{x}(x=0.3)$ layer $10 \mathrm{~nm}$ thick obtained in the same experimental conditions. Moreover, faceting is more developed under biaxial compressive stress. We suggest that the onset of the instability could be attributed to a change of the interaction energy between steps and/or to a step edge energy, at a critical step density, due to local stresses at the step edges. The evolution of the phenomenon is then kinetically controlled by various kinetic factors (growth temperature, compositionally enhanced surface diffusion, step edge diffusion anisotropy, ...). In a second step, the periodic morphology, which is a metastable state, kinetically evolves towards a faceted equilibrium shape. 

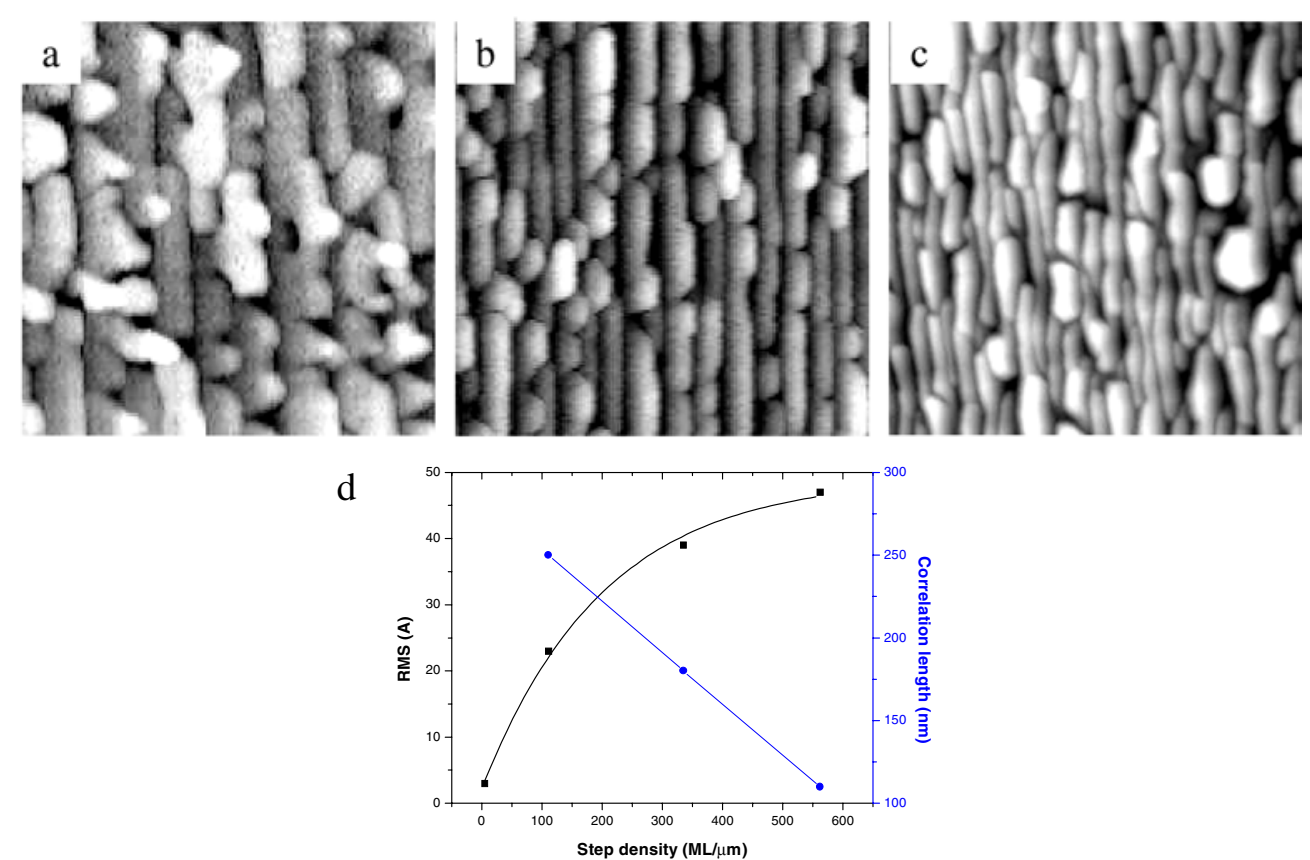

Figure 18. Morphological evolution of $10 \mathrm{~nm}$ thick $\mathrm{Si}_{0.7} \mathrm{Ge}_{0.3}$ layers with the misorientation of the substrate: from $2^{\circ}$ (a) to $6^{\circ}$ (b) and $10^{\circ}$ off (c). In all the images the monatomic steps are vertical. (d) Evolution of the corrugation amplitude $(A)$ and periodicity $(\lambda)$ with the step density (miscut angle).

\subsubsection{Growth on $\mathrm{Si}(001)$.}

4.3.2a. Singular $\mathrm{Si}(001)$. We have seen (section 4.2) that in regime II the $\mathrm{Si}_{1-x} \mathrm{Ge}_{x}(001)$ layers deposited on nominally flat substrates exhibit undulated surfaces with more or less isotropic mounds distributed at random on the surface. The origin of these undulations is commonly attributed as a stress-driven growth instability. However, we already observed similar morphologies during the growth of thick Si layers on nominal Si(001) (figure 19).

Moreover, we found in a previous work that the $\mathrm{Si}_{1-x} \mathrm{Ge}_{x}$ growth instability varies with

(1) an energetic term which depends on the ratio of surface energy and elastic energy; and

(2) a kinetic term which depends on the ratio of surface diffusion and arrival rate of the species.

In order to determine the influence of terms (1) and (2) on the nucleation and evolution of the surface corrugation we have performed a set of experiments for Ge concentrations varying between $x=0$ and 0.25 . The onset of the instability was related to a critical growth temperature of $\sim 600{ }^{\circ} \mathrm{C}$. At LT, the instability did not develop during growth. The $\mathrm{Si}_{1-x} \mathrm{Ge}_{x}$ layers were directly relaxed by MDs. This proves that the instability is kinetically driven. At HT, the instability develops for $\mathrm{Si}_{0.75} \mathrm{Ge}_{0.25} / \mathrm{Si}$ but not for $\mathrm{Si} / \mathrm{Si}$. Its amplitude evolves very abruptly with the deposited thickness (figure 20(d)). As an illustration, the morphology of Si and of $\mathrm{Si}_{0.75} \mathrm{Ge}_{0.25} \sim 500 \mathrm{~nm}$ thick layers deposited on $\mathrm{Si}(001)$ at $650^{\circ} \mathrm{C}$ are presented in figure 20 . It is obvious that the instability is stress dependent. A typical TEM image of an undulated layer evidences the absence of facets at the surface (figure 20(c)). 


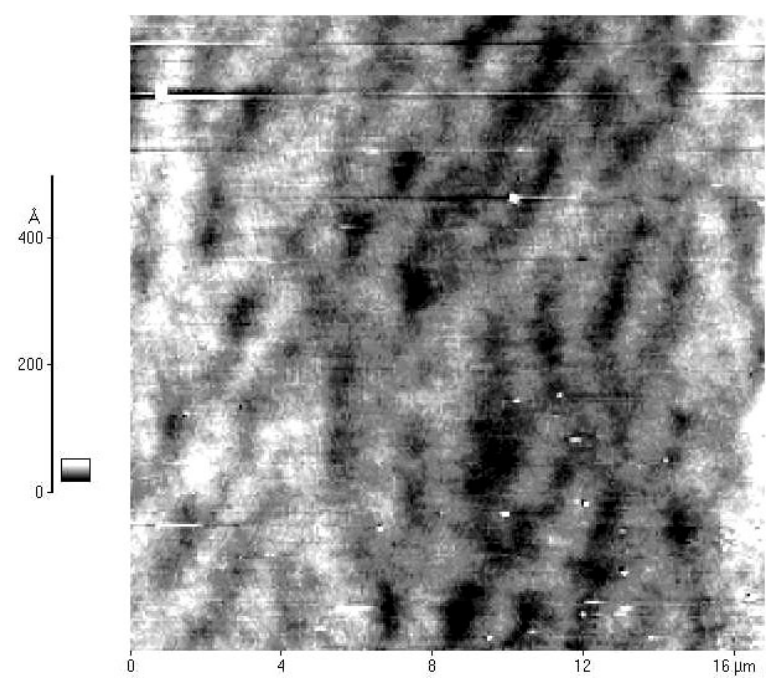

Figure 19. Surface undulation of a $\sim 500 \mathrm{~nm}$ thick Si layer when deposited on nominal $\mathrm{Si}(001)$ (with miscut $<0.5^{\circ}$ ).

4.3.2b. Vicinal $\mathrm{Si}(001)$. In contrast to what was observed on (111), there is no dramatic morphological change induced by the presence of steps on (001). The only difference induced by the misorientation of the substrate is an amplification of the corrugations observed during both homoepitaxy and heteroepitaxy.

In this set of experiments, the miscut angles have been varied between $1.5^{\circ}$ off and $10^{\circ}$ off in the [110] direction (parallel to the step edge). At LT, a kinetic growth instability develops on vicinal $\mathrm{Si}(001)$ during homoepitaxy of $\mathrm{Si}$ (in the absence of stress). The corrugation observed presents a maximum amplitude in the transient temperature regime between step flow and island nucleation (figure $21(\mathrm{~d}))$. At this temperature $\left(400^{\circ} \mathrm{C}\right.$ and $1.5^{\circ}$ off misoriented substrate) the undulation orientates along the pre-existing monatomic steps of the substrate and leads to a periodic ripple-like morphology (figure 21(b)). This instability tends to vanish at HT (figure 21(c)) and to become irregular (step meandering) at LT (figure 21(a)).

Independently of the amplitude, the correlation length of the corrugation continues to increase with the temperature (figure 21(d)) while the instability vanishes. Similar behaviour was observed for step bunching instability which develops during homoepitaxy on vicinal $\mathrm{Si}(111)$. Even if the exact physical driving force of the instability is still unknown (inverse Schwoebel barrier, step edge diffusion, ...), clear evidence of a kinetic growth regime is demonstrated here. Surprisingly, no obvious relation was found between the density of monatomic steps on the substrate (misorientation) and the amplitude/wavelength of the corrugation. Peculiar behaviour of the (118) facet $\left(10^{\circ}\right.$ off misoriented surface) could be invoked to explain this result.

Considering now the effect of compressive stress (Ge concentration) on the undulation, it is shown that the kinetic undulation which develops at LT during homoepitaxy is completely inhibited in the presence of stress during heteroepitaxy of $\mathrm{Si}_{1-x} \mathrm{Ge}_{x}$ layers, even for low $\mathrm{Ge}$ content $x \sim 0.05$ (figure 20). The influence of stress on the kinetic growth instability is not clear, but at least a change of the diffusion and sticking barriers is expected. Kinetic Monte Carlo simulation of growth instability is in progress to clarify this effect. At HT, opposite behaviour is observed: the onset of the corrugation is related to a critical level of stress and the corrugation amplifies with the level of stress. These opposite evolutions of the undulation with 

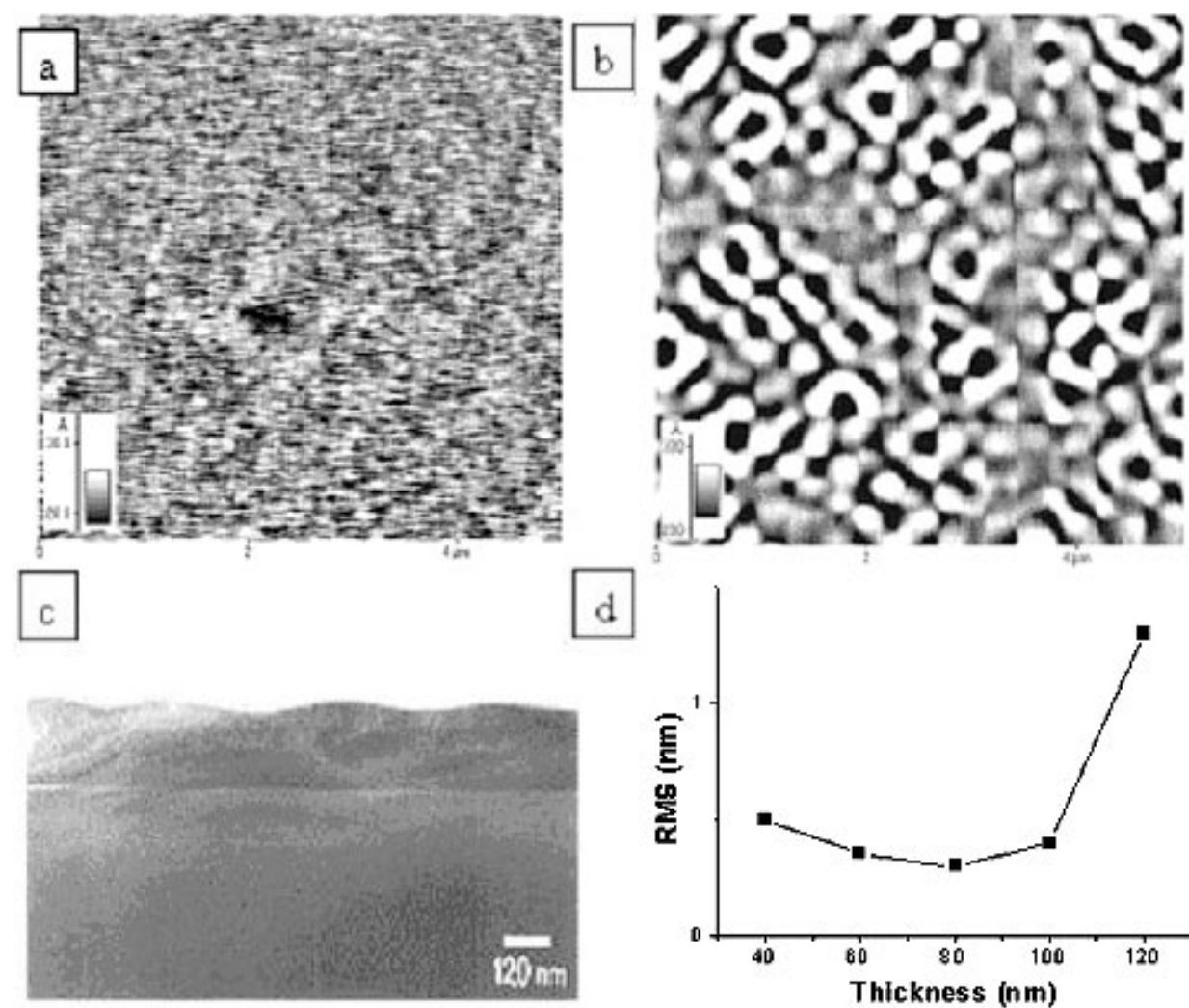

Figure 20. Surface morphology of a $\sim 500 \mathrm{~nm}$ thick (a) $\mathrm{Si}$ layer and (b) $\mathrm{Si}_{0.75} \mathrm{Ge}_{0.25}$ when deposited on nominal $\mathrm{Si}(001)$ (with miscut angle $<0.1^{\circ}$ ). [110] is vertical on the two images. (c) TEM crosssection image of the undulated layer of (b). (d) Evolution of the corrugation amplitude of the undulating layer of (b) with the deposited thickness.

stress at two different growth temperatures are reported in figures 22(c) and (d). The evolution on nominal $\mathrm{Si}(001)$ is reported as a reference. Similar behaviours are obtained on both $1.5^{\circ}$ and $10^{\circ}$ off misoriented substrates. These results have not been explained so far.

Let us focus lastly on the morphological evolution of $\mathrm{Si}_{0.7} \mathrm{Ge}_{0.3}(001)$ layers with the misorientation angle (figure 23). Different sets of samples were grown by both SSMBE and GSMBE and exhibited similar evolution [28,72]. The AFM images presented in figures 23(a)(c) correspond to the samples grown by GSMBE.

The mounds obtained at $0^{\circ}$ off remain isotropic up to $4^{\circ}$ off. At this value, they elongate perpendicularly to the steps and form triangle-shaped islands (figure 23(a)) that continue to elongate with the miscut angle (from $6^{\circ}$ to $10^{\circ}$ off). Perfect anisotropic undulations are finally obtained for a $10^{\circ}$ miscut angle (figure 23(c)). Surprisingly, this anisotropic undulation extends perpendicularly to the step direction, along [110] in contrast to what was observed on vicinal (111) and in contrast to the kinetic instability observed during homoepitaxy (on both (111) and (001) vicinal orientations). This means that the wire-shaped islands seem to 'ignore' the underlying atomic step distribution and cross over a large number of monolayer or bilayer steps. Consequently, on vicinal (001), the behaviour observed (elongation of the undulation perpendicularly to the pre-existing step edges) cannot be explained by a step bunching mechanism nor by any existing model. In addition, even if the effect of closely 

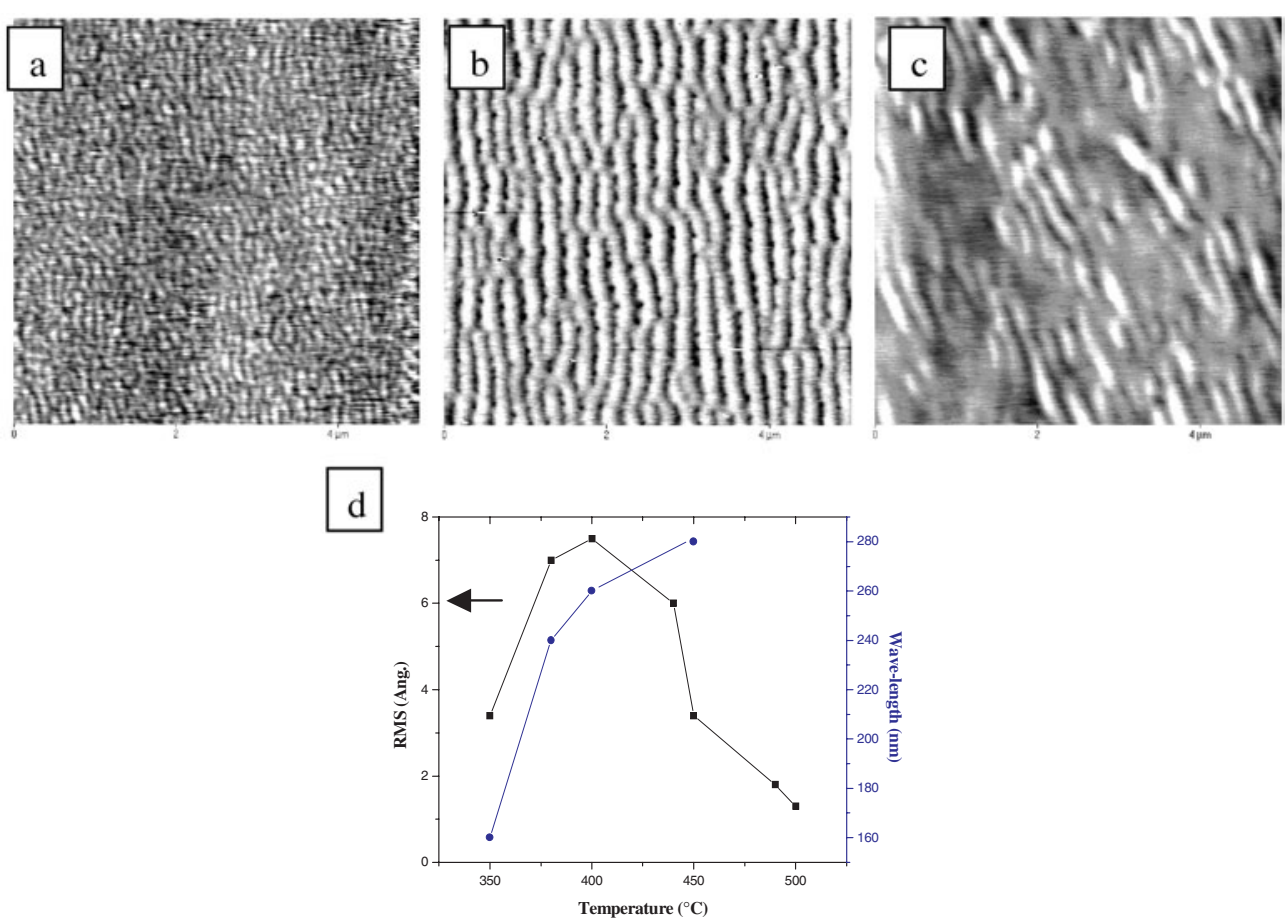

Figure 21. AFM images of $500 \mathrm{~nm}$ thick Si deposited on $\mathrm{Si}(001), 1.5^{\circ}$ off, at (a) $350{ }^{\circ} \mathrm{C}$, (b) $400^{\circ} \mathrm{C}$, and (c) $450^{\circ} \mathrm{C}$. In all the images monatomic steps are vertical. (d) Evolution of the corrugation parameters (RMS and wavelength) with the growth temperature.

packed steps $\left(10^{\circ}\right.$ off misoriented substrate) outwardly resembles those on both (001) and (111) orientations, the underlying mechanism should be entirely different since undulation orientations are either perpendicular or parallel to step edges. We must note that to check our results we systematically verified the substrate misorientation by Laue diffraction. Another intriguing result is that the wavelength of $\mathrm{Si}_{1-x} \mathrm{Ge}_{x}$ undulation remains constant whatever the density of steps (miscut angle) of the substrate. These results have been verified for two different Ge contents (figure 23(d)).

In the end, the problem to clarify is whether the $\mathrm{Si} / \mathrm{Si}$ and $\mathrm{Si}_{1-x} \mathrm{Ge}_{x} / \mathrm{Si}$ instabilities could be described by a unified model. This would permit one to predict the pattern parameters (amplitude, periodicity, and shape) in relation to the experimental conditions. We suggest that the faster amplification of the corrugation for $\mathrm{Si}_{1-x} \mathrm{Ge}_{x} / \mathrm{Si}$ is more driven by kinetics than by elastic relaxation. This leads to new capabilities for obtaining self-patterned substrates.

\subsection{Self-organization processes}

Several studies have been dedicated to the fabrication of nanostructures to confine carrier motion in reduced dimensions. The different processes developed to control the size and homogeneity of dots use either the SK growth mode [73-76] or patterning techniques (mainly lithography) [77-80]. In both cases difficulties have been encountered in controlling the aspect ratio $A / L$ (island height over lateral size) of dots and their location/density. Generally inhomogeneous size distributions of dots associated with broadened luminescence have been found. We have used mainly two different processes in order to produce self-organized nanostructures with better $A / L$ control. 

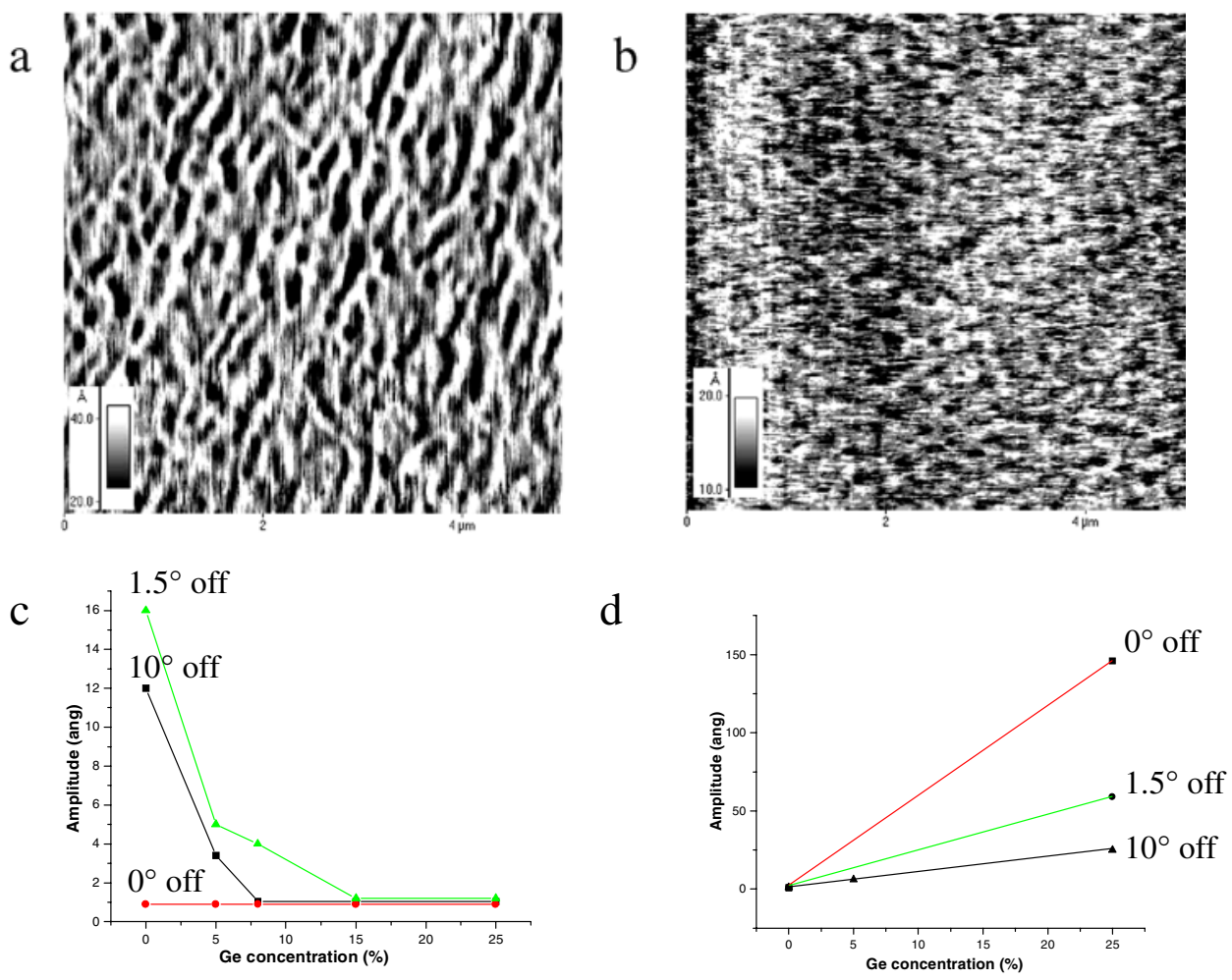

Figure 22. AFM images of $\sim 500 \mathrm{~nm}$ thick (a) $\mathrm{Si}$ and (b) $\mathrm{Si}_{0.95} \mathrm{Ge}_{0.05}$ layers deposited at $\sim 400^{\circ} \mathrm{C}$ on $\mathrm{Si}(001), 1.5^{\circ}$ off. (c) and (d) represent the evolution of the undulation amplitude with the Ge concentration at $T_{g} \sim 400$ and $T_{g} \sim 650^{\circ} \mathrm{C}$ respectively.

The first process consists of depositing Ge ML on a self-patterned $\mathrm{Si}_{1-x} \mathrm{Ge}_{x}$ template layer [27, 81]. Self-patterning results from the stress-driven instability detailed upper [7]. The crucial step of this process is selectively growing Ge dots on the top of the periodic prepatterned $\mathrm{Si}_{1-x} \mathrm{Ge}_{x}$ (or $\mathrm{Si}$ ) template layer without affecting the $\mathrm{Si}_{1-x} \mathrm{Ge}_{x}$ (or $\mathrm{Si}$ ) undulation wavelength (since undulations could vanish during the Ge post-deposition). Different effects are expected from the template layer: decrease of the $\mathrm{Si} / \mathrm{Ge}$ interdiffusion, transmission of stress into the Ge dots, creation of kink or step facets on the sides of the undulation, etc. The periodicity and amplitude of the instability were adjusted by varying the kinetics of growth (see section 4.3). The efficiency of the process has been evidenced for $7 \mathrm{ML}$ Ge deposited on the top of a $\sim 10 \mathrm{~nm}$ thick $\mathrm{Si}_{0.7} \mathrm{Ge}_{0.3}$ template layer on $\mathrm{Si}(001)$ and $\mathrm{Si}(001) 10^{\circ}$ off orientations [27]. We have shown in particular that $A / L$ could be increased by a factor of 2 by using this twostep process ( $7 \mathrm{ML}$ Ge deposited on top of a $\sim 10 \mathrm{~nm}$ thick $\mathrm{Si}_{0.7} \mathrm{Ge}_{0.3}$ template layer) and dot homogeneity could also be increased (see section 6 for PL evidence). The major role of the template layer is to control the Ge dot location, as can be seen in the AFM images of figure 24 .

The second process of self-organization uses Sb surfactant-mediated growth of Ge on $\operatorname{Si}(001)[82,83]$. This process has two major effects: it reduces the lateral size of Ge dots and increases their density. Figure 25 shows the evolution with the growth temperature of the Ge surface morphology (thickness $\sim 1.8 \mathrm{~nm}$ ) on $\mathrm{Si}(100)$ with $1 \mathrm{ML}$ of Sb pre-deposited. First, the different growth modes at 350,550 , and $750{ }^{\circ} \mathrm{C}$ are clearly seen. At $350{ }^{\circ} \mathrm{C}$ the surface is flat at the level of HREM observation (figure 26). However, the rms surface 

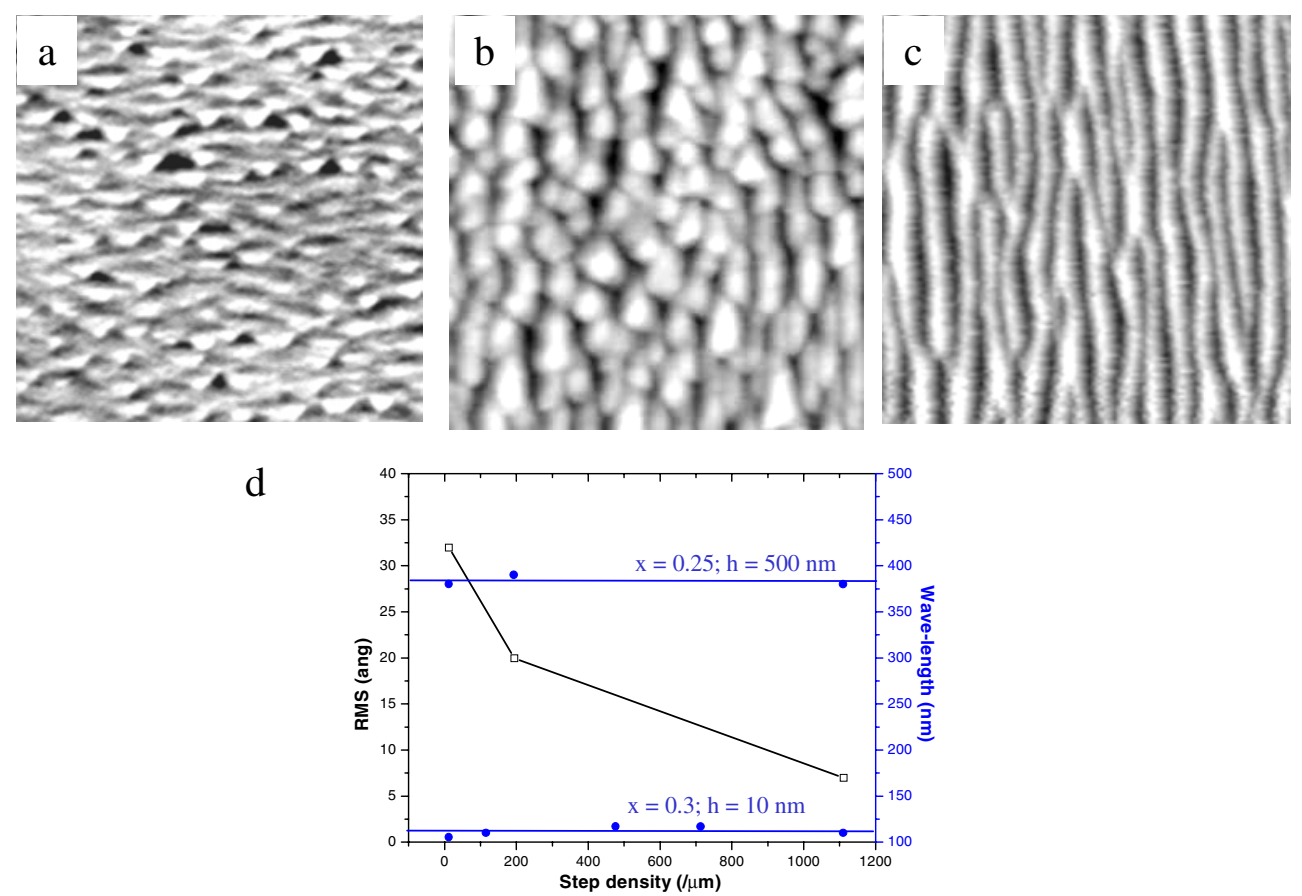

Figure 23. Morphological evolution of $10 \mathrm{~nm}$ thick $\mathrm{Si}_{1-x} \mathrm{Ge}_{x}$ layers $(x=0.3)$ grown on various Si substrates misoriented from the (001) nominal one: (a) $4^{\circ}$ off, (b) $6^{\circ}$ off, and (c) $10^{\circ}$ off. Monatomic steps are horizontal in all the images.

roughness measured on the AFM image $(\sim 0.5 \mathrm{~nm})$ (figure $25(\mathrm{a}))$ suggests the onset of $3 \mathrm{D}$ island nucleation $(L \sim 20-30 \mathrm{~nm})$. At $550{ }^{\circ} \mathrm{C}$ the formation of ultrasmall dense Ge islands is clearly evidenced (figure 25(b)). At higher temperature, Sb no longer has an influence due to its high rate of desorption from the Si surface. The large isolated islands (figure 25(c)) grown over the flat surface are very similar to those obtained during Ge growth without $\mathrm{Sb}$. This result confirms the total desorption of Sb observed in the literature at this temperature [84-87].

As regards the morphology of the Ge layer grown on a pre-deposited $1 \mathrm{ML} \mathrm{Sb}$, an almost flat layer is obtained at $350^{\circ} \mathrm{C}$ (figure 26(a)) while ultrasmall islands of only one type are obtained at $550^{\circ} \mathrm{C}$ (figure 26(b)). Due to the small extent of the facets (small lateral size of the islands), it is not possible to determine their exact orientations. However, these islands have a shape very different from those of the huts and domes. HREM images evidence the absence of dislocations in these small islands that are in consequence fully strained.

For comparison, in the same experimental conditions $\mathrm{Ge} / \mathrm{Si}$ growth without $\mathrm{Sb}$ at $T_{g}=550^{\circ} \mathrm{C}$ has been followed [82]. It results in the commonly observed bimodal 'huts' and 'domes' island distributions. As a consequence $\mathrm{Sb}$ modifies the growth of $\mathrm{Ge} / \mathrm{Si}$ in different ways. First it delays the 2D-3D transition at LT. This can be explained by the lower surface energy of $\mathrm{Sb}$ in comparison to those of both $\mathrm{Si}$ and $\mathrm{Ge}$. Another effect is the formation of smaller Ge dots with a higher density during Sb-mediated growth at higher temperature. This can be interpreted on the basis of the reduction of the surface diffusion of Ge adatoms on $1 \mathrm{ML}$ $\mathrm{Sb}$ that we have evidenced with RHEED experiments. But it can also be interpreted in terms of stress. Indeed, the level of stress is supposed to be higher for $\mathrm{Ge}: \mathrm{Sb} / \mathrm{Si}$ than for $\mathrm{Ge} / \mathrm{Si}$ due to the partial incorporation of the larger $\mathrm{Sb}$ atoms. Moreover, since SIMS experiments have 

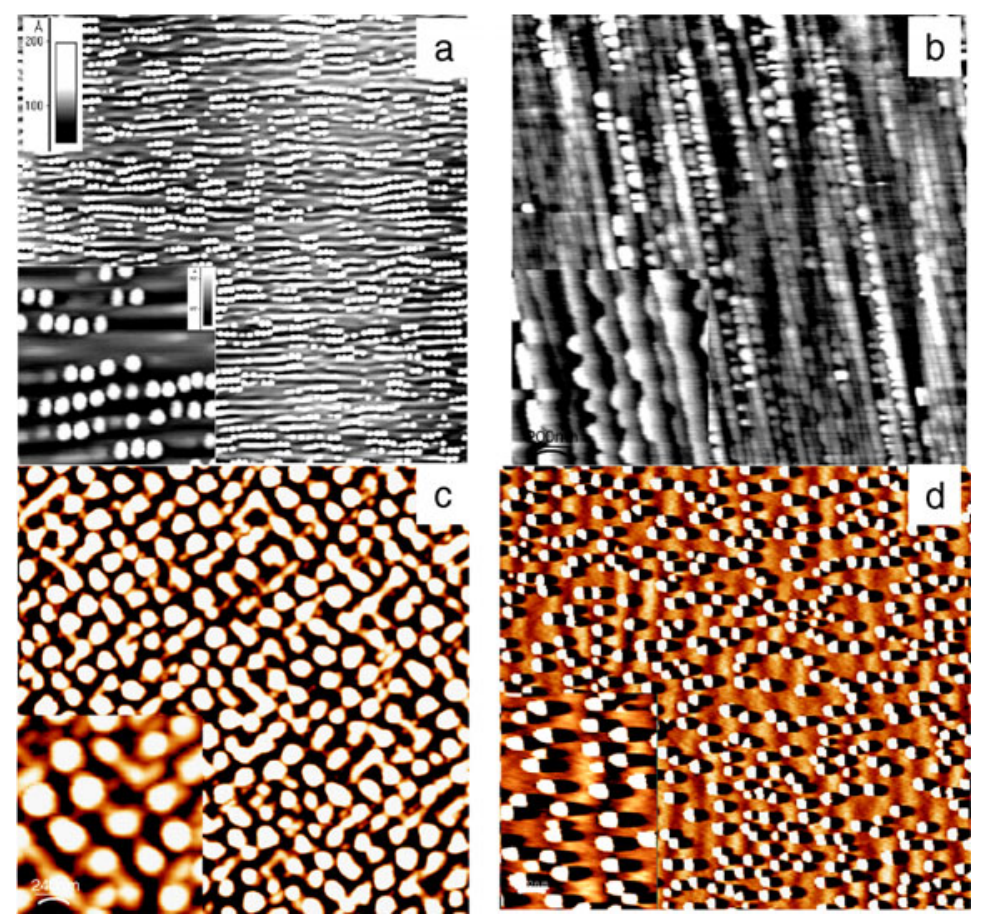

Figure 24. Self-organized Ge dots deposited on self-patterned substrates layers: (a) $\mathrm{Si}_{0.75} \mathrm{Ge}_{0.25}$ $10^{\circ}$ off (001), (b) $\mathrm{Si} 2^{\circ}$ off towards [11-2], (c) $\mathrm{Si}_{0.75} \mathrm{Ge}_{0.25}$ (001) and (d) $\mathrm{Si} 1.5^{\circ}$ off (001).
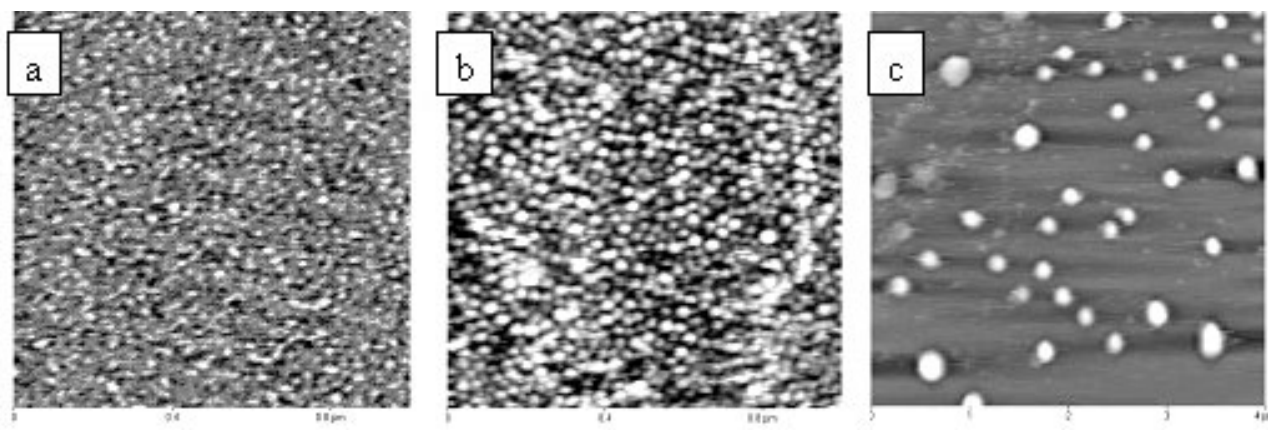

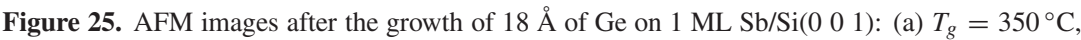
(b) $T_{g}=550^{\circ} \mathrm{C}$, and (c) $T_{g}=750^{\circ} \mathrm{C}$.

evidenced the partial desorption of $\mathrm{Sb}$ from the $\mathrm{Si}$ surface at $550^{\circ} \mathrm{C}$ and not at $350{ }^{\circ} \mathrm{C}$ [83], this could modify the density of nucleation sites and be a possible way to modify growth.

In conclusion, for $\mathrm{Sb}$-mediated growth of $\mathrm{Ge} / \mathrm{Si}(001)$, we have demonstrated that the first effect of $\mathrm{Sb}$ is to promote the $2 \mathrm{D}$ growth and to delay the 2D-3D growth transition, probably due to the reduction of the surface energy. A second effect is that of inducing the formation of ultrasmall islands $(\sim 30 \mathrm{~nm})$ with high surface density $\left(1.5 \times 10^{11} \mathrm{~cm}^{-2}\right)$ and homogeneous surface distribution at higher temperature $\left(550^{\circ} \mathrm{C}\right)$. Moreover, $\mathrm{Sb}$ was found to decrease the adatom surface diffusion, and to change the equilibrium shape of islands. Sb-mediated growth was then found to be an interesting tool for realizing both very small Ge islands and smooth Ge surfaces. 


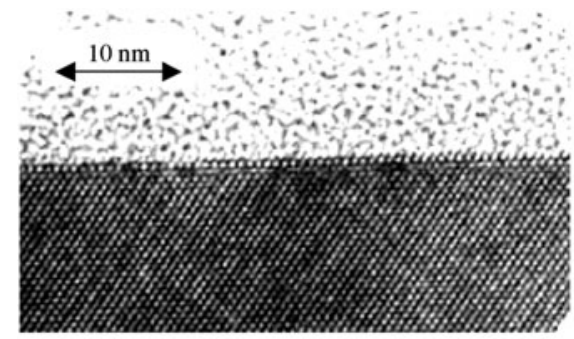

(a)

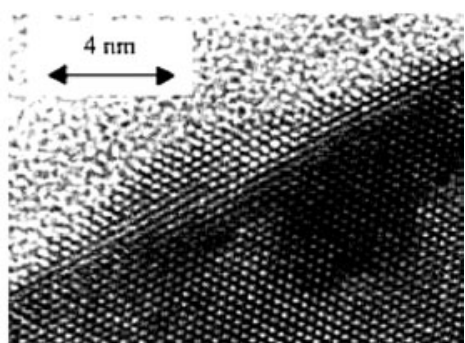

(b)

Figure 26. A cross-sectional TEM image of the $1 \mathrm{ML}$ Sb-mediated growth of $1.8 \mathrm{~nm}$ of Ge at (a) $T_{g}=350{ }^{\circ} \mathrm{C}$ and (b) $T_{g}=550^{\circ} \mathrm{C}$.

\section{Redistribution of dopants}

The fabrication of $\delta$-doped $\mathrm{Si} / \mathrm{SiGe}$ layers with controlled spatial distribution of the dopants normal to the growth plane is an important challenge because of the potential technological applications. The control of dopant distribution needs a complete understanding of diffusion, dynamic surface segregation, and desorption of the dopant atoms. We are concerned here with the incorporation/segregation of $\mathrm{Sb}$ and $\mathrm{B}$ during growth.

\subsection{Segregation coefficient}

SIMS profile analyses were performed to determine the segregation and incorporation coefficients for antimony ( $\mathrm{Sb}$ ) in $\mathrm{Si}$ or $\mathrm{Si}_{1-x} \mathrm{Ge}_{x}$ films as a function of temperature and Ge concentration in compressively stressed or relaxed samples [83]. The growth procedure producing $\mathrm{Sb}$-doped layers buried below an undoped $\mathrm{Si}_{1-x} \mathrm{Ge}_{x}$ layer (see for instance the $\mathrm{Sb}$ depth profile of figure 27, upper part) consisted of temperature-programmed sequences, schematically represented in figure 27. After deposition of $0.44 \mathrm{ML}$ of $\mathrm{Sb}$ at $400{ }^{\circ} \mathrm{C}, \mathrm{Si}_{1-x} \mathrm{Ge}_{x}$ layers (with $x$ varying between 0 and 0.2 ) were grown at constant temperature values $T g$ between 350 and $550^{\circ} \mathrm{C}$. At the end of this sequence, the sample was immediately cooled to ambient temperature (lower than $200^{\circ} \mathrm{C}$ ) and covered by an amorphous Si layer (approximately $20 \mathrm{~nm}$ thick), intended to trap the surface-segregated dopant atoms.

Figure 28(a) shows the evolution of the Sb (SIMS) profiles in a pure Si layer grown at different temperatures $(T g)$. At LT $\left(350^{\circ} \mathrm{C}\right)$ two peaks can be observed: one $\left(N_{\text {seg }}\right)$ relates to surface-segregated atoms and the other $\left(N_{i n c}\right)$ relates to incorporated atoms. As the growth temperature increases, $N_{\text {inc }}$ vanishes at the expense of $N_{\text {seg. }}$. The surface segregation coefficient $\left(r_{s e g}\right)$, which can be defined as the ratio of the integrated area of the surface peak $\left(N_{\text {seg }}\right)$ to the total of pre-deposited impurity atoms $\left(r_{\text {seg }}=N_{\text {seg }} / N_{\text {tot }}\right)$, varies exponentially versus the inverse growth temperature with $E_{\text {activation }}=0.36 \mathrm{eV}$ (figure $28(\mathrm{~b})$ ). At $550^{\circ} \mathrm{C}$, the $\mathrm{Sb}$ sheet concentration $\sim 0.4 \mathrm{ML}$ was determined by integrating the area of the peak. This value is in good agreement with the pre-deposited Sb coverage $(\sim 0.44 \mathrm{ML})$. It confirms the negligible $\mathrm{Sb}$ desorption from $\mathrm{Si}(001)$ at this temperature.

A similar set of experiments have been performed for the growth of biaxially strained $\mathrm{Si}_{1-x} \mathrm{Ge}_{x}$ films on $\mathrm{Sb} / \mathrm{Si}(001)$. A first interesting feature concerns the thermal desorption of $\mathrm{Sb}$ atoms from $\mathrm{Si}_{0.9} \mathrm{Ge}_{0.1}$ and $\mathrm{Si}_{0.8} \mathrm{Ge}_{0.2}$ surfaces, which occurs at $550{ }^{\circ} \mathrm{C}$, in contrast to the negligible desorption observed from the Si surface. Similar results have been found by Falkenberg et al [88]. This phenomenon can be attributed to the lower heat of sublimation of Ge leading to lower $\mathrm{Sb}-\mathrm{Ge}$ bond breaking energy in comparison to that for $\mathrm{Sb}-\mathrm{Si}$. In addition, 


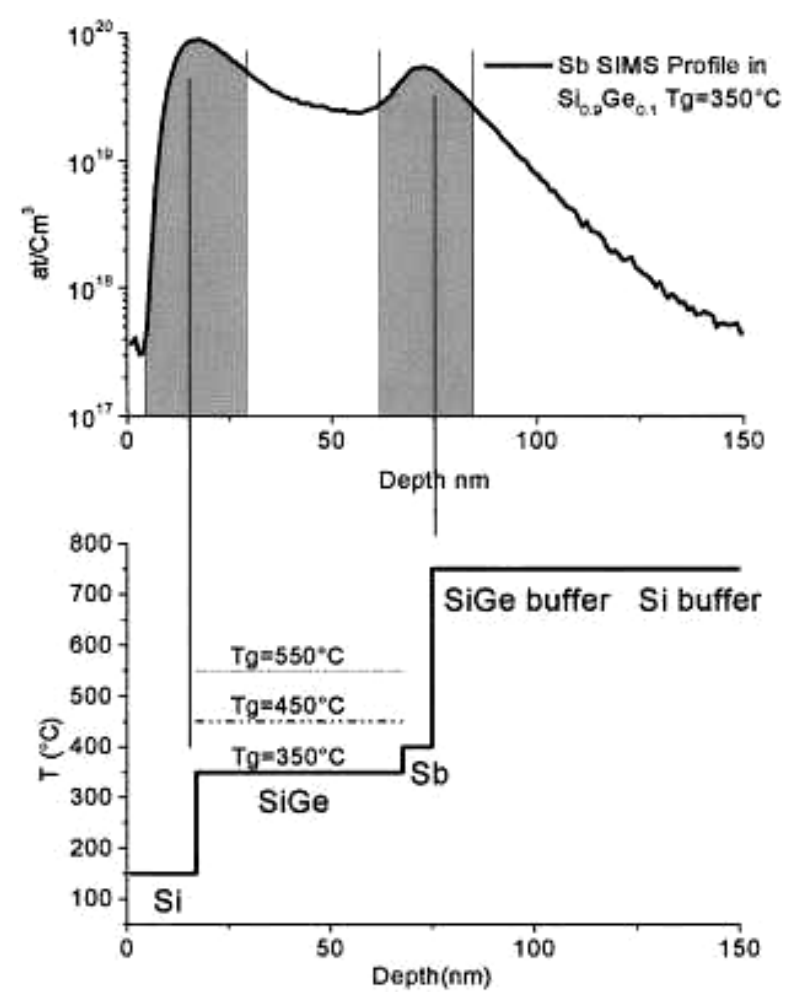

Figure 27. Temperature sequences during growth.
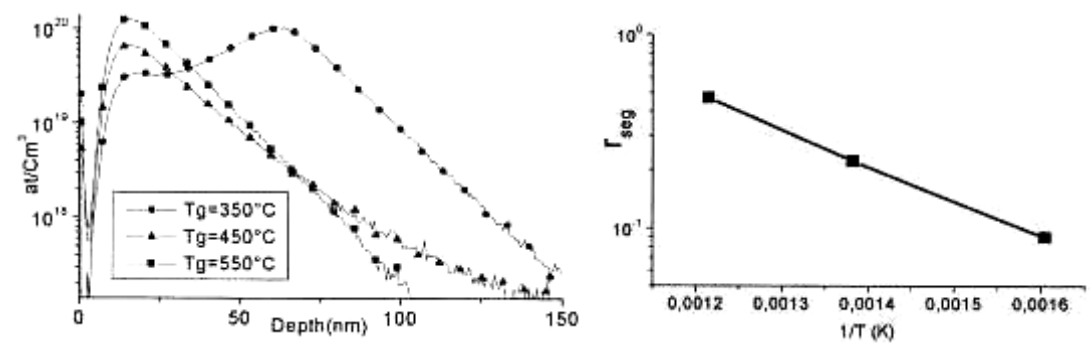

Figure 28. (a) SIMS profiles of Sb in $\mathrm{Si}: T g=350,450$ and $550^{\circ} \mathrm{C}$. (b) The $\mathrm{Sb}$ surface segregation coefficient $\left(r_{\text {seg }}\right)$ measured in $\mathrm{Si}$.

calculations [89] have shown that each $\mathrm{Sb}-\mathrm{Si}$ bond is approximately $0.1 \mathrm{eV}$ stronger than each $\mathrm{Sb}-\mathrm{Ge}$ bond. For details on Sb thermo-desorption phenomena, see [90].

From SIMS profiles, we also measured the incorporation coefficient $\left(r_{\text {inc }}\right)$, which is determined as the ratio of the integrated area of the peak $\left(N_{i n c}\right)$ to the total of pre-deposited impurity atoms. The Ge composition dependences of $r_{i n c}$ and $r_{\text {seg }}$ are presented in figure 29. A surprising feature is that $\mathrm{Sb}$-atom segregation increases with increasing Ge concentration in strained samples. Similar results have been reported by Fujita et al [91], in contrast to the results obtained for $\mathrm{B}$ atoms that are preferably incorporated in $\mathrm{Si}_{1-x} \mathrm{Ge}_{x}$ layers [92, 93].

The driving force for $\mathrm{Sb}$ segregation is still a matter of debate since contradictory results have been obtained (both experimentally and theoretically). Discrepancies between $\mathrm{Sb}$ and 


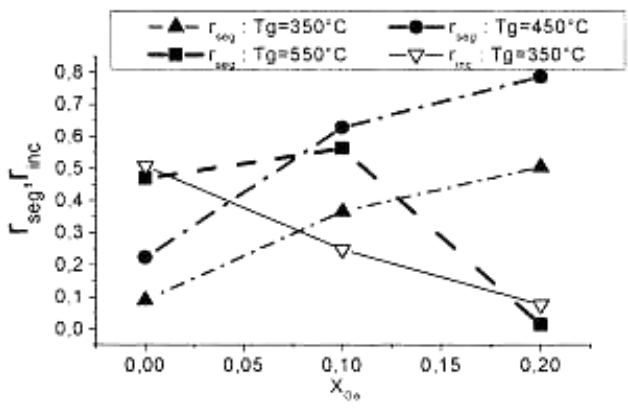

Figure 29. Coefficients of Sb surface segregation $\left(r_{\text {seg }}\right)$ and incorporation $\left(r_{\text {inc }}\right)$ in $\mathrm{Si}_{1-x} \mathrm{Ge}_{x}$.

B dopant-atom segregation/incorporation were mainly attributed to their different atomic sizes [93]. As regards the $\mathrm{B}$ behaviour, it was established that the reduced $\mathrm{B}$ surface segregation in $\mathrm{Si}_{1-x} \mathrm{Ge}_{x}$ films is due to the partial compensation by $\mathrm{Ge}$ atoms with larger atomic sizes of the tensile strain induced by the smaller size of B atoms. Another explanation based on differences between the bond breaking energies of $\mathrm{B}-\mathrm{Si}, \mathrm{Si}-\mathrm{Si}$, and $\mathrm{Sb}-\mathrm{Si}$ has been given by Ushio et al [94] from density functional calculations (without taking into account the strain). The lowering of the barrier energy at the numerous step edges induced by Sb during growth is also invoked [95-97].

In order to model $\mathrm{Sb}$ surface segregation during the growth of $\mathrm{Si}$ and $\mathrm{Si}_{1-x} \mathrm{Ge}_{x}$ layers during MBE experiments, calculations using a two-state atomic exchange model were performed and will be detailed elsewhere. Briefly, segregation is mainly driven by two contributions: an activation barrier for dopant-atom motion and an energetic term including chemical (alloying) and size effects and surface free energy. In such a model, the energetic contribution is not favourable at an increased surface segregation with increasing Ge ratios in $\mathrm{Si}_{1-x} \mathrm{Ge}_{x}$. In addition, by fitting the experimental results, we found that the kinetic activation barrier predominantly controls the evolution of Sb segregation in the overall range of temperature. We suggest that a lower kinetic barrier for $\mathrm{Sb}$-atom motion in $\mathrm{Si}_{1-x} \mathrm{Ge}_{x}$ can be invoked to explain this behaviour.

In order to separate the chemical (Ge concentration) and the strain (induced by the epitaxy) effects, five samples consisting of epitaxied $\mathrm{Si}_{1-x} \mathrm{Ge}_{x}$ structures were grown: three fully strained with Ge contents $x=0,0.09,0.18$ and two relaxed with $x=0.09,0.18$. The $\mathrm{Ge}$ composition of the layers was checked using Rutherford backscattering spectrometry (RBS). The structure of samples is a stacking of five layers (four for the relaxed sample) consisting of:

(a) $50 \mathrm{~nm}$ of $\mathrm{Si}_{1-x} \mathrm{Ge}_{x}$ deposited at $650{ }^{\circ} \mathrm{C}$;

(b) one monolayer of $\mathrm{Sb}\left(\sim 3 \times 10^{14} \mathrm{at} \mathrm{cm}^{-2}\right)$ deposited at $400^{\circ} \mathrm{C}$ (this Sb quantity will be referred to as $Q_{t}$ in the following);

(c) $6 \mathrm{~nm}$ of $\mathrm{Si}_{1-x} \mathrm{Ge}_{x}$ deposited at $200^{\circ} \mathrm{C}$;

(d) $45 \mathrm{~nm}$ of $\mathrm{Si}_{1-x} \mathrm{Ge}_{x}$ deposited at $550^{\circ} \mathrm{C}$;

(e) a $20 \mathrm{~nm}$ Si cap deposited at $T<200^{\circ} \mathrm{C}$ only on strained structures.

Layer (c) was grown at an unusually low temperature $\left(200^{\circ} \mathrm{C}\right)$ in order to bury as much as possible of the $\mathrm{Sb}$, to obtain $\delta$-doping, which can be used as a diffusion source. However, even at this very low growth temperature, part of $Q_{t}$ should segregate to the surface. In order to restore the crystallographic quality of this layer, a 5 min anneal was performed at $750^{\circ} \mathrm{C}$ before deposition of layer (d). This annealing temperature was decreased to $600{ }^{\circ} \mathrm{C}$ for the 


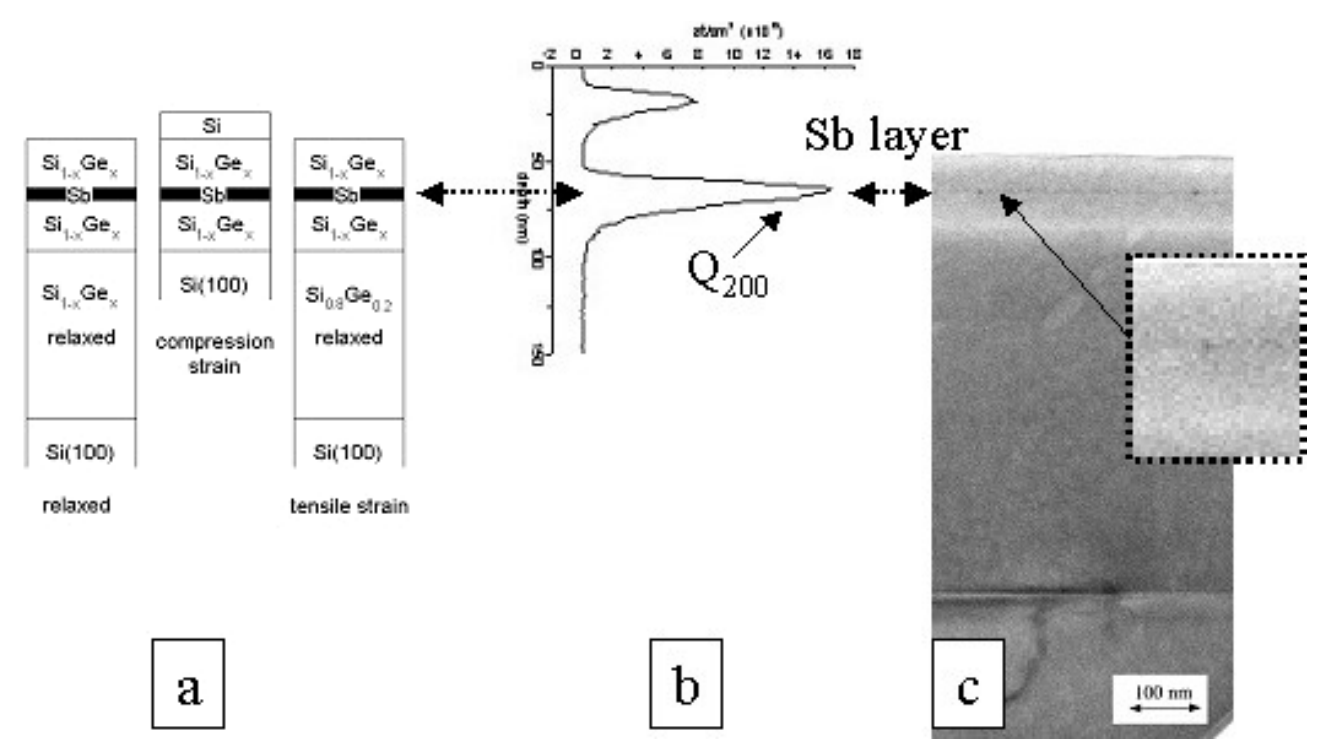

Figure 30. (a) samples structures, (b) Sb concentration profile obtained by SIMS for a $\mathrm{Si}_{0.82} \mathrm{Ge}_{0.18}$ layer epitaxially grown on $\mathrm{Si}(001)$ and (d) TEM cross section view of a $\mathrm{Sb} \delta$-doped $\mathrm{Si}_{0.91} \mathrm{Ge}_{0.09}$ layer tensely strained on a relaxed $\mathrm{Si}_{0.81} \mathrm{Ge}_{0.19}$ pseudo-substrate grown on $\mathrm{Si}(001)$.

relaxed sample to limit dislocation propagation in the topmost layer. Sb concentration versus depth profiles were measured by SIMS using a Cameca IMS4F operated at $8 \mathrm{keV}$ with $\mathrm{O}_{2}^{+}$ primary ions. Figure 30 shows a typical $\mathrm{Sb}$ concentration versus depth profile obtained for the $\mathrm{Si}_{0.82} \mathrm{Ge}_{0.18}$ biaxially compressed sample. Two spikes are observed, the surface spike resulting from the $\mathrm{Sb}$ segregation during growth at $550{ }^{\circ} \mathrm{C}$ (layer (d)), and a spike observed at about $50 \mathrm{~nm}\left(Q_{200}\right)$ corresponding to the Sb incorporated during the growth of layer (c) at $200^{\circ} \mathrm{C}$.

The $\mathrm{Sb}$ incorporation coefficient at $200^{\circ} \mathrm{C}$ is defined as the ratio between the integration of the peak $Q_{200}$ and the total amount of $\mathrm{Sb}$ deposited, $Q_{t}$. Figure 31 presents the evolution of this coefficient versus the Ge composition $(x)$ in the compressed and relaxed layers. Since the surface segregation shows the opposite behaviour to the incorporation (there is no $\mathrm{Sb}$ desorption at $200^{\circ} \mathrm{C}$ ), one can conclude that the $\mathrm{Sb}$ segregation during growth decreases in relaxed layers and increases in biaxially compressed layers when $x$ increases. One can note that the $\mathrm{Sb}$ incorporation in relaxed $\mathrm{Si}_{x} \mathrm{Ge}_{1-x}$ layers is close to 1 whatever the Ge concentration $(x=0.09$ and 0.18$)$.

These variations of Sb surface segregation with Ge concentration and strain may originate from a modification of:

(i) the equilibrium segregation energy $E$ (the driving force of the process);

(ii) the rate of exchange between the $\mathrm{Sb}$-segregated sublayer and its immediate neighbours (the kinetics of the process).

equilibrium segregation of $\mathrm{Sb}$ in $\mathrm{Si}$ has three main components which, in order of decreasing importance, are

(i) a lower Sb surface energy $(\gamma)$,

(ii) a larger $\mathrm{Sb}$ atomic size $(r)$,

(iii) a strong tendency to phase separation. 


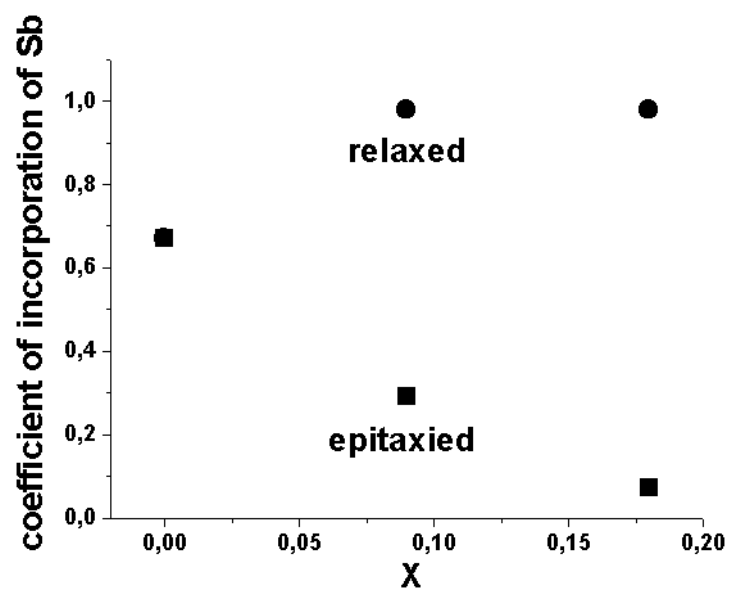

Figure 31. Sb incorporated during the growth at $200^{\circ} \mathrm{C}$ of relaxed $(\boldsymbol{)})$ and epitaxially grown $\mathrm{Si}_{1-x} \mathrm{Ge}_{x}$ layers versus the Ge composition $(x)$.

If $\mathrm{Ge}$ is added to $\mathrm{Si}$, one expects:

(i) a decrease of the surface energy of the $\mathrm{Si}(\mathrm{Ge})$ alloy (Ge has a lower surface energy than $\mathrm{Si}$ and segregates on $\mathrm{Si}$ ) and,

(ii) an increase in the alloy lattice parameter.

Both effects should induce a decrease in Sb equilibrium segregation. Moreover, since $\mathrm{Sb}-\mathrm{Ge}$ interactions are also repulsive, there should not be any synergetic influence between $\mathrm{Ge}$ and Sb surface segregation.

Considering compressive stress, since $\mathrm{Sb}$ has a larger size than $\mathrm{Si}$ (or $\mathrm{Ge}$ ), the segregation of $\mathrm{Sb}$ should be slightly larger in strained than in relaxed structures. However, if one considers that the main driving force for surface segregation is the minimization of surface energy, one can expect the equilibrium segregation of $\mathrm{Sb}$ to decrease both in relaxed and in epitaxially strained $\mathrm{Si}_{1-x} \mathrm{Ge}_{x}$ layers when $x$ increases (even if this decrease is less important in strained layers).

The opposite variations (increase for strained layers, decrease for relaxed layers) which are observed for $\mathrm{Sb}$ segregation during MBE growth are thus difficult to understand if one takes into account only equilibrium driving forces. The origin of this behaviour is more likely to be found in the kinetics of the process, as is the case for the variations with temperature.

In order to evaluate kinetic parameters, we measured in the same layers the Sb lattice diffusion coefficient as a function of strain and Ge composition. These measurements are based on the analysis of the modifications of the incorporated Sb distribution induced by an additional heat treatment. The variations of the $\mathrm{Sb}$ diffusion coefficients with Ge composition in relaxed and compressively strained layers are presented in figure 32 for a temperature of $800^{\circ} \mathrm{C}$. One can observe that $\mathrm{Sb}$ diffusion coefficients increase in relaxed and strained layers, the increase being larger in strained layers. This behaviour can be explained by the mechanism of diffusion of $\mathrm{Sb}$ in $\mathrm{Si}_{1-x} \mathrm{Ge}_{x}$ which is vacancy mediated. The activation barrier of diffusion decreases with Ge concentration (chemical effect) and, at constant Ge concentration, with biaxial compression (stress effect). In epitaxial layers, the increase of the Sb diffusion coefficient is thus linked to the addition of the two effects. Even if one cannot use directly the volume diffusion coefficients for the kinetics of the exchange between the free surface and its 


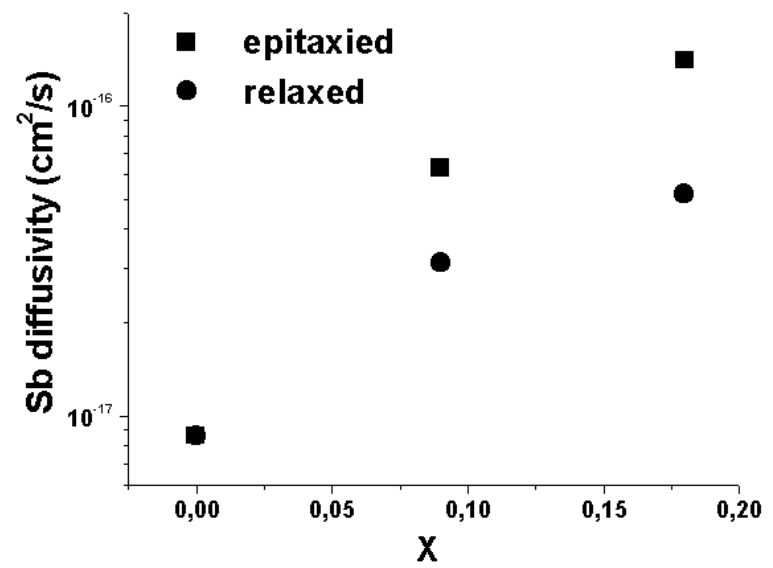

Figure 32. Variation of the coefficient of diffusion of $\mathrm{Sb}$ at $800^{\circ} \mathrm{C}$ in relaxed (-) and epitaxially grown ( $\square) \mathrm{Si}_{1-x} \mathrm{Ge}_{x}$ layers versus the Ge composition $(x)$.

immediate neighbours, one can expect the tendencies observed for lattice diffusion coefficients to be maintained, which would mean that the activation barrier for diffusion scales as

$$
Q_{\text {dif }}(\mathrm{Si})>Q_{\text {dif }}\left(\mathrm{Si}_{1-x} \mathrm{Ge}_{x}\right)_{\text {relax }}>Q_{\text {dif }}\left(\mathrm{Si}_{1-x} \mathrm{Ge}_{x}\right)_{\text {strained }} .
$$

while the former discussion on equilibrium segregation suggests that

$$
-E_{\text {seg }}(\mathrm{Si})>-E_{\text {seg }}\left(\mathrm{Si}_{1-x} \mathrm{Ge}_{x}\right)_{\text {strained }}>-E_{\text {seg }}\left(\mathrm{Si}_{1-x} \mathrm{Ge}_{x}\right)_{\text {relax }} .
$$

Using these modifications of $E_{\text {seg }}$ and $Q_{\text {dif }}$ in the framework of a two-state exchange model taking into account both the driving force for segregation $(E)$ and the kinetics of the process $(Q)$, it is possible to show that the Sb surface segregation during growth follows different kinetic regimes in relaxed and compressed layers. In the case of relaxed layers the evolution is more probably dominated by the modification of the segregation enthalpy, while in compressed layers the larger decrease of the $\mathrm{Sb}$ diffusion barrier promotes Sb segregation.

\subsection{Doping control}

We are concerned here with the incorporation of boron during GSMBE, for which two different approaches are feasible. In the first, which is the most used so far, B is supplied simultaneously with $\mathrm{Si}$ and $\mathrm{Ge}$ and is incorporated directly in the growing $\mathrm{Si}$ or $\mathrm{Si}_{1-x} \mathrm{Ge}_{x}$ film. It is generally shown that the dopant incorporation is a non-equilibrium process which is mainly dependent on the experimental kinetic parameters (temperature, flux ratios, growth rates and time, etc). The alternative procedure is to pre-deposit an ordered sub-monolayer quantity of B on which epitaxial layers of $\mathrm{Si}$ or $\mathrm{Si}_{1-x} \mathrm{Ge}_{x}$ are subsequently grown. Despite many comprehensive studies of the B doping of Si, very little is known about the application of this technique and its comparison with direct deposition. We briefly present here the results of a comparative study in which we are able to demonstrate an enhanced incorporation rate and a decrease in the concentration decay length with B pre-deposition. The technique has limitations however, which are related to the equilibrium steady-state coverage as a 2D film. Beyond this coverage, surface roughening due to 3D island growth occurs, which is detrimental to the Si or crystalline quality. In order to achieve sharp doping profiles we used different procedures and we showed that the combination of pre-deposition and co-deposition is the most efficient method for achieving highly doped layers (up to $7 \times 10^{19} \mathrm{~cm}^{-3}$ in $\mathrm{Si}$ and up to $2 \times 10^{19} \mathrm{~cm}^{-3}$ in $\mathrm{Si}_{1-x} \mathrm{Ge}_{x}$ ). For a detailed analysis of $\mathrm{B}$ incorporation in $\mathrm{Si}$ and $\mathrm{Si}_{1-x} \mathrm{Ge}_{x}$ films, see [92]. 
$\mathrm{B}_{2} \mathrm{H}_{6}$ is known to adsorb dissociatively on $\mathrm{Si}(001)$ over the typical range of temperatures used in $\mathrm{Si}$ growth from disilane $\left(500-1000^{\circ} \mathrm{C}\right)$. The saturation coverage is reduced by the presence of surface hydrogen, so higher B coverages are expected to occur at higher deposition temperatures $\left(\right.$ Great $\left.600^{\circ} \mathrm{C}\right)$, where hydrogen desorbs from the Si surface [98]. In ultrahighvacuum chemical vapour deposition (UHVCVD), for temperatures around $600{ }^{\circ} \mathrm{C}$, the sticking probability of $\mathrm{B}_{2} \mathrm{H}_{6}$ during adsorption was reported to be $<10^{-4}$ [99] while for co-deposition of $\mathrm{B}$ and $\mathrm{Si}$ (simultaneous supply of $\mathrm{B}_{2} \mathrm{H}_{6}$ and $\mathrm{Si}_{2} \mathrm{H}_{6}$ ) published values range from $6.4 \times 10^{-4}$ at $600{ }^{\circ} \mathrm{C}$ to $1.4 \times 10^{3}$ at $950^{\circ} \mathrm{C}$ [100], even though gas interaction considerations would predict a lower sticking probability in the latter case. The equilibrium solubility limit of electrically active $\mathrm{B}$ impurity in $\mathrm{Si}$ increases from $7 \times 10^{18}$ atoms cm ${ }^{-3}$ at $500^{\circ} \mathrm{C}$ to $3 \times 10^{19}$ atoms cm $\mathrm{cm}^{-3}$ at $700^{\circ} \mathrm{C}$ [101] but values one decade higher have been reported in films prepared by CVD and attributed to the non-equilibrium nature of the process [102]. B diffuses substitutionally in Si (by jumping from one vacant lattice site to the next), so to restrict diffusion and maintain sharp interfaces, low deposition temperatures (or high growth rates) are needed. Bulk diffusion of $\mathrm{B}$ in $\mathrm{Si}$ has been described [103] in the case of co-deposition of $\mathrm{B}_{2} \mathrm{H}_{6}$ and $\mathrm{Si}_{2} \mathrm{H}_{6}$ and in the case of a pre-deposited surface source. The calculated decay lengths for the two different processes are in the same range (see [92]). The deposition time was assumed to be $10 \mathrm{~min}$, which represents a minimum value for any relevant device structures. Experimentally, this implies that above $700^{\circ} \mathrm{C}$ we would not achieve realistic $\delta$-doping due to the large decay length $(\sim 4 \mathrm{~nm})$ of the doped layer and to the formation of disilicides [104]. Conversely, it has been reported that $\mathrm{B}$ diffusion is totally suppressed below $\sim 500^{\circ} \mathrm{C}[105,106]$. Bulk diffusion is not, however, the only process responsible for mass transport of B in Si. Motion in the growth direction (usually called 'segregation') is driven by other mechanisms which cannot be described as bulk diffusion. This results in both smearing of the dopant profiles and an enrichment of B at the surface with respect to the bulk concentration, as demonstrated in many experimental studies (e.g. [107-109]). The origins invoked for the segregation are principally the reduction of the strain at the surface (surface reconstruction, for example [110]) and the reduction of the surface free energy. Several atomistic models have been proposed to describe the process [111-114]. The results for As segregation during Si growth by GSMBE and also for Ge segregation in $\mathrm{Si}_{1-x} \mathrm{Ge}_{x}$ have been explained by the two-site exchange model [115118]. This considers that segregation occurs only by atomic interchange between a sub-surface layer and a growing (Si) surface layer. The process can occur either in a kinetically controlled regime (where segregation is slow relative to the growth rate) or in an equilibrium regime (where segregation is fast relative to the growth rate). Although the model is empirical, the rate equations involved allow the Gibbs energy of segregation and the segregation barrier to be determined from measurements of dopant profiles.

However, in the present case of B in Si we were unable to determine accurately the doping profile at various temperatures because of experimental difficulties:

(i) measurement of the low-B-coverage surface layer;

(ii) the mixing of diffusion and segregation mechanisms at temperatures in the range 650$700{ }^{\circ} \mathrm{C}$;

(iii) the realization of experiments with constant growth rates over a wide temperature range (from 500 to $700^{\circ} \mathrm{C}$ ).

In GSMBE experiments (low growth rates), optimal B doping conditions result from a compromise between temperature and growth rate, which are interdependent. Finally, creating an atomically flat surface is a matter of serious concern in devices with $\mathrm{Si} / \mathrm{Ge}$ doped heterostructures. Since these devices utilize the band discontinuity at $\mathrm{Si} / \mathrm{Ge}$ interfaces, the flatness of the layers is very important for obtaining high-quality device performances. 


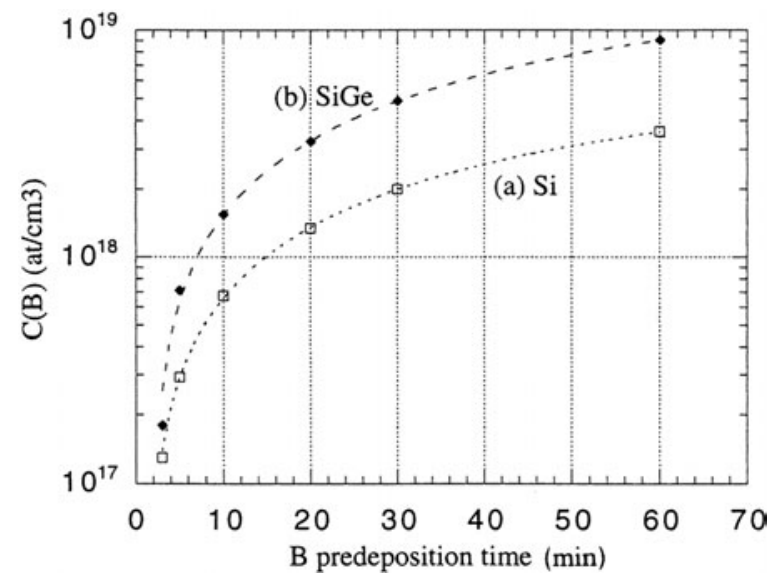

Figure 33. Evolution of $C(\mathrm{~B})$ with the pre-deposition time in (a) Si layers ( $\square$ ) and (b) SiGe layers $(\diamond)$.

However, even though one study reported flat (B-) doped layers with perfect crystallinity for B concentrations $\sim 10^{20} \mathrm{~cm}^{-3}$ [102], it is generally assumed that B-induced roughening occurs in the doping level range $10^{17}-10^{20} \mathrm{~cm}^{-3}$ and becomes disastrous above $\sim 10^{20} \mathrm{~cm}^{-3}$ [92, 119, 120]. In particular, high-resolution transmission electron microscopy (HRTEM) observations reveal microprecipitates and extended defects throughout the films in addition to enhanced surface roughening, caused by the appearance of $\{113\}$ facets [121]. Scanning tunnelling microscopy (STM) studies have explained the B-induced surface roughening by the pinning of the $\mathrm{Si}$ dimer rows leading to an enhanced roughness of the $\mathrm{S}_{B}$ step edges (perpendicular to the dimer rows [122]), at B coverage as low as 0.06-0.08 ML [105]. By contrast, $\mathrm{Si}_{1-x} \mathrm{Ge}_{x}$ layer morphology and crystallinity are expected to be improved in highly doped samples, since substitutional boron induces partial strain compensation because of its smaller atomic radius [123]. Increases of both the critical thickness [124] and of the B incorporation level [125] have been demonstrated for heavily boron-doped $\mathrm{Si}_{1-x} \mathrm{Ge}_{x}$ layers.

We are concerned here with the two competing processes of (i) incorporation and (ii) segregation occurring during B doping. The incorporation levels are investigated in the first part by measuring the SIMS and $e C(V)$ concentration profiles. We distinguish in this part the two-dimensional sheet concentration of $\mathrm{B}\left(N_{2 D}(\mathrm{~B})\right)$ determined by measuring the total integrated intensity under a B peak of the SIMS profiles and the highest B concentration spike $(C(B))$ directly extracted from the data (see [92]). Because of the well-known surfaceroughness-induced artefacts in the SIMS depth profiling technique [126], we decided to report only on those samples having perfect crystallinity and low surface roughness.

In this set of experiments, the quantity of $\mathrm{B}$ incorporated in the $\mathrm{Si}$ or $\mathrm{Si}_{1-x} \mathrm{Ge}_{x}$ overlayers only comes from the pre-deposition step. Since no desorption of B is expected to occur below $900^{\circ} \mathrm{C}, N_{2 D}$ (B) also represents the B surface coverage obtained during that pre-deposition step. $\mathrm{B}$ pre-deposition was performed between 450 and $600^{\circ} \mathrm{C}$. The sticking coefficient was found to be about $3 \times 10^{-3}$ and nearly independent of temperature. Figure 33 represents the evolution of $C(\mathrm{~B})$ with the pre-deposition time. After one hour of $\mathrm{B}$ deposition (which corresponds to $\sim 12$ L exposure, i.e. $12 \times 10^{-6}$ Torr s) both $N_{2 D}(\mathrm{~B})$ and $C(\mathrm{~B})$ slowly saturate. Under these conditions $\left(\mathrm{B}_{2} \mathrm{H}_{6}\right.$ partial pressure $\sim 7 \times 10^{-9}$ Torr $)$, maximum values of $N_{2 D}(\mathrm{~B}) \sim 2 \times 10^{13}$ atoms $\mathrm{cm}^{-2}$ and $C(\mathrm{~B}) \sim 4 \times 10^{18}$ atoms $\mathrm{cm}^{-3}$ were achieved. Figure 34 shows the evolution of $N_{2 D}$ (B) with the B flux, in the pressure limits of the GSMBE chamber (partial pressure 


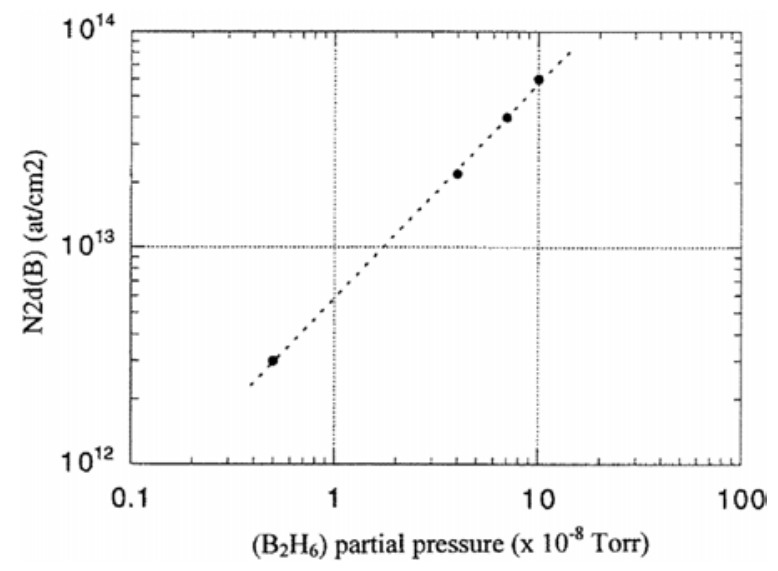

Figure 34. Evolution of the total sheet density in boron-doped $\mathrm{Si}$ with the partial pressure of $\mathrm{B}_{2} \mathrm{H}_{6}$ in the chamber during the pre-deposition.

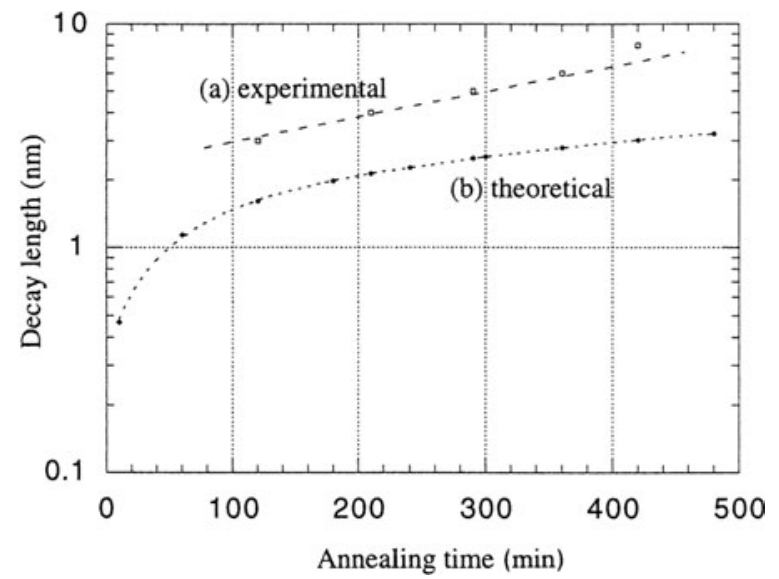

Figure 35. Theoretical decay length as a function of the annealing time compared to the experimental data.

between $\sim 7 \times 10^{-9}$ and $1.3 \times 10^{-7}$ Torr). In fact, 1/10 ML coverage is obtained for $\sim 30 \mathrm{~L}$ exposure and there is no further increase. B pre-deposition on $\mathrm{Si}_{1-x} \mathrm{Ge}_{x}(001)$ with $x=0: 1$ was performed under the same experimental conditions. The sticking coefficient extracted from these data $\left(\sim 10^{-3}\right)$ is lower than on $\mathrm{Si}$. This lower sticking coefficient has not been explained so far, but it could be related to a higher $\mathrm{Ge}-\mathrm{B}$ bond energy.

Furthermore, we observed a higher $C(\mathrm{~B})$ for $\mathrm{Si}_{1-x} \mathrm{Ge}_{x}$ alloys than for $\mathrm{Si}$ without degradation of the surface morphology. Even though accurate values are difficult to determine due to the broadening effect of the SIMS profiling technique, the diffusion length $\left(L_{\text {diff }}\right)$ is to a first approximation in good agreement with the calculated ones [108] (figure 35), confirming the substitutional diffusion of B into bulk $\mathrm{Si}$. A smaller $L_{\text {diff }}$ of $\mathrm{B}$ in $\mathrm{Si}_{1-x} \mathrm{Ge}_{x}$ than in $\mathrm{Si}$ is obtained, probably due to the larger size of $\mathrm{Ge}$ atoms reducing the mobility of $\mathrm{B}$ in the crystalline lattice. In all cases, below $600^{\circ} \mathrm{C}, L_{\text {diff }}$ is below the SIMS broadening limit and cannot be measured. Examples of sharp $\delta$-doped Si layer SIMS profiles are presented in figure 36 . They were obtained for a B exposure of $63 \mathrm{~L}\left(\mathrm{~B}_{2} \mathrm{H}_{6}\right.$ partial pressure $\left.\sim 1.3 \times 10^{-7} \mathrm{~T}\right)$ and an Si growth 


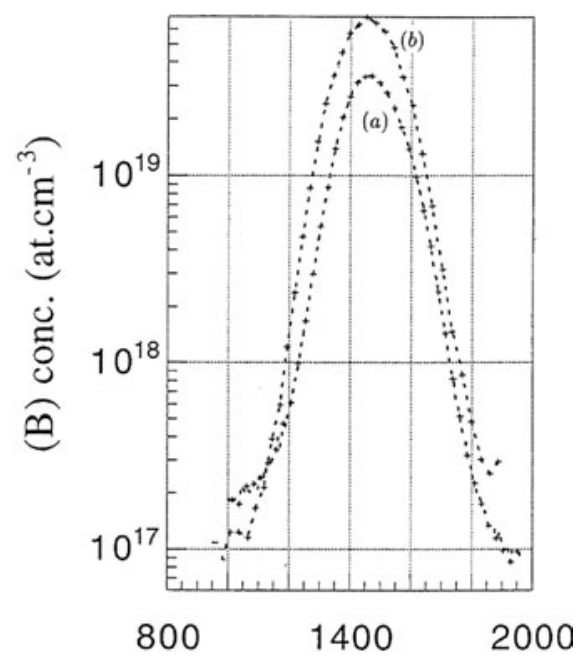

Figure 36. Comparison between the SIMS profiles of two Si boron $\delta$-doped layers. The predeposition was performed with $63 \mathrm{~L}$ of $\mathrm{B}_{2} \mathrm{H}_{6}$ and an Si overgrowth of $(a) 520^{\circ} \mathrm{C}$ and $(b) 600{ }^{\circ} \mathrm{C}$. A higher incorporation of boron is obtained at $600{ }^{\circ} \mathrm{C}$.

temperature of $(a) 520^{\circ} \mathrm{C}$ and $(b) 600^{\circ} \mathrm{C}$. For a similar decay length ( $\sim 8 \mathrm{~nm} /$ decade $)$, a slightly higher incorporation level is obtained for $\mathrm{Si}$ growth at $600^{\circ} \mathrm{C}$. In that case, confirmation of the sharp decay length is given by $e C(V)$ profiling (figure 37 ). Similar experiments were performed for $\mathrm{Si}_{0.8} \mathrm{Ge}_{0.2}$ layers and boron deposition at $(a) 550{ }^{\circ} \mathrm{C}$ and $(b) 600{ }^{\circ} \mathrm{C}$. The SIMS results are presented in figure 38 . We obtained narrower peaks than for $\mathrm{Si}$, with decay lengths inside the SIMS detection limit. Again, the higher the pre-deposition temperature, the higher the boron incorporation.

In order to achieve sharp $\delta$-doping layers with $C(\mathrm{~B})$ in the $10^{20}$ atoms $\mathrm{cm}^{-3}$ region (which corresponds to a B concentration of $\sim 0.2 \%$ in the Si layer) we used flux ratios $\left(J_{\mathrm{B}_{2} \mathrm{H}_{6}} / J_{\mathrm{Si}_{2} \mathrm{H}_{6}}\right)$ between $4 \times 10^{-4}$ and $8 \times 10^{-3}$. The variation of the incorporated $\mathrm{B}$ concentration $C(\mathrm{~B})$ as a function of $J_{\mathrm{B}_{2} \mathrm{H}_{6}}$ is determined from the $e C(V)$ profiles. Figure 39 shows that $C(\mathrm{~B})$ increases linearly with $J_{\mathrm{B}_{2} \mathrm{H}_{6}}$. In comparison with the previous experiments, similar decay lengths were obtained but the maximum $C(\mathrm{~B})$ which could be achieved $\left(C(\mathrm{~B}) \sim 10^{19}\right.$ atoms $\mathrm{cm}^{-3}$ ) was much lower. The $\delta$-doped layers with the sharpest profiles were in fact obtained (for both $\mathrm{Si}$ and $\mathrm{Si}_{1-x} \mathrm{Ge}_{x}$ ) by combining pre-deposition of $\mathrm{B}$ with a short $\mathrm{B}$ deposition during $\mathrm{Si}$ (figure 40) or $\mathrm{Si}_{1-x} \mathrm{Ge}_{x}$ (figure 41) growth.

We will now consider the segregation effect. The measured segregation length $\left(L_{\text {seg }}\right)$ is nearly independent of the pre-deposition time, i.e. of the boron surface coverage, which means that for our experimental conditions the growth rate is always lower than the segregation rate. Consequently, an equilibrium state, detailed in the next section, is reached before the end of the growth experiment. Qualitatively, $L_{\text {seg }}$ increases with the growth temperature, but the evolution is difficult to determine quantitatively. In all cases a smaller $L_{\text {seg }}$ is found in $\mathrm{Si}_{1-x} \mathrm{Ge}_{x}$ alloys than in Si (figures 36 and 38), which is attributed to the competitive segregation of Ge and of B. This effect has been employed to incorporate two types of dopant in Si in order to limit the segregation length of one of them. In order to quantify the B segregation and to control its influence on the $\mathrm{Si}$ or $\mathrm{Si}_{1-x} \mathrm{Ge}_{x}$ growth mechanisms, we have recorded and analysed the RHEED oscillations:

(i) before and after B pre-deposition and

(ii) during co-deposition of $\mathrm{B}$ and $\mathrm{Si}$ at various $\mathrm{B} / \mathrm{Si}$ flux ratios. 


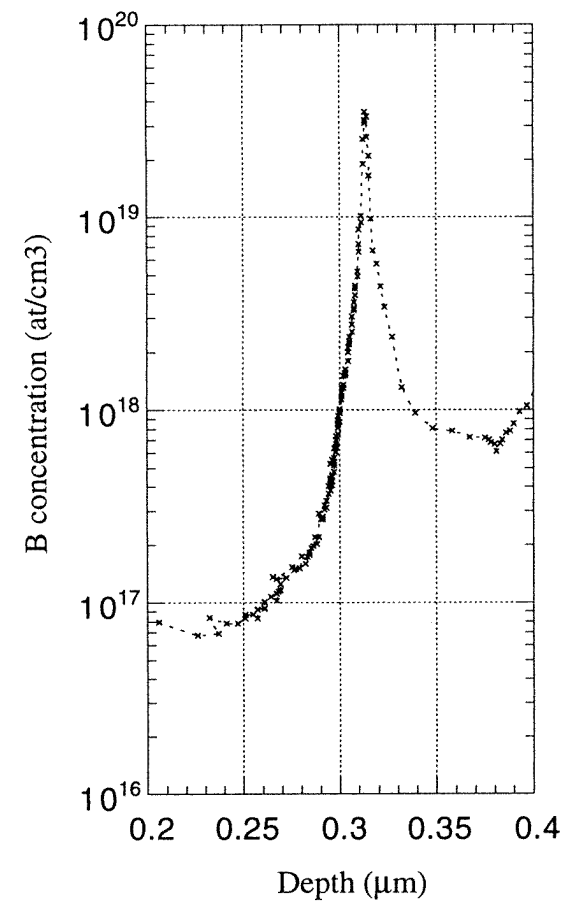

Figure 37. Hole density measured by $e C(V)$ profiling of the Si boron $\delta$-doped layer grown at $600{ }^{\circ} \mathrm{C}$ confirming the SIMS profile presented in figure $36(b)$.

Throughout the experiments, the RHEED reconstruction remains $(2 \times 1)+(1 \times 2)$ during the complete deposition of $\mathrm{B}$ and also during the growth of Si.

First, the growth rate of $\mathrm{Si}\left(R_{\mathrm{Si}}\right)$ was reduced by $20 \%$ whatever the quantity of B preadsorbed on the $\mathrm{Si}$ surface (figure 42 ). In addition, once $\mathrm{B}$ was adsorbed on the surface, $R_{\mathrm{Si}}$ never completely recovered its previous value (for pure $\mathrm{Si} / \mathrm{Si}$ ) and remained slightly lower even after $\mathrm{Si}$ deposition at $750^{\circ} \mathrm{C}$ for some hours. Experiments performed during co-deposition of $\mathrm{Si}$ and B produced identical decreases of $R_{\mathrm{si}}$ whatever the $J_{\mathrm{Si}_{2} \mathrm{H}_{6}} / J_{\mathrm{B}_{2} \mathrm{H}_{6}}$ ratio used (between $4 \times 10^{-4}$ and $8 \times 10^{-3}$ ). Moreover, the damping coefficient of the oscillations was not affected by the $\mathrm{B}$ pre-adsorption, even at the critical temperature of transition from $2 \mathrm{D}$ nucleation to step flow growth (figure 43). This result proves that the surface diffusion of Si adatoms is not modified by the presence of B and the preferential adsorption of B on step edges cannot therefore be invoked to explain the $\mathrm{B}$-induced decrease of $R_{\mathrm{Si}}$. Identical behaviour was also observed for the growth of SiGe alloys. Over the range of temperatures studied and for various $\mathrm{B}_{2} \mathrm{H}_{6}$ pre-deposition pressures, the growth rate of the SiGe overgrown layer is reduced by $\sim 15 \%$. However, the growth rate recovered more rapidly to its previous value (for pure $\mathrm{SiGe} / \mathrm{Si}$ ) after the growth of a thick buffer layer of Si. Very few previous studies have considered the influence of $\mathrm{B}$ doping on the $\mathrm{Si}$ growth rate, but it is commonly assumed that it is not affected by low concentrations of B. Glass et al [127] reported that B doping concentrations of $>6 \times 10^{19}$ atoms $\mathrm{cm}^{-3}$ increase $R_{\mathrm{Si}}$ by up to $50 \%$ at LT but reduce it by the same amount at HT.

At LT the $R_{\mathrm{Si}}$-increase was attributed to a weakening of the $\mathrm{Si}^{*}-\mathrm{H}$ bonds favouring $\mathrm{H}$ desorption, while at HT the $R_{\mathrm{Si}}$ decrease was attributed to the deactivation of a fraction of the Si dangling bonds. We have clearly shown that over a large range of $\mathrm{B}$ doping concentrations 


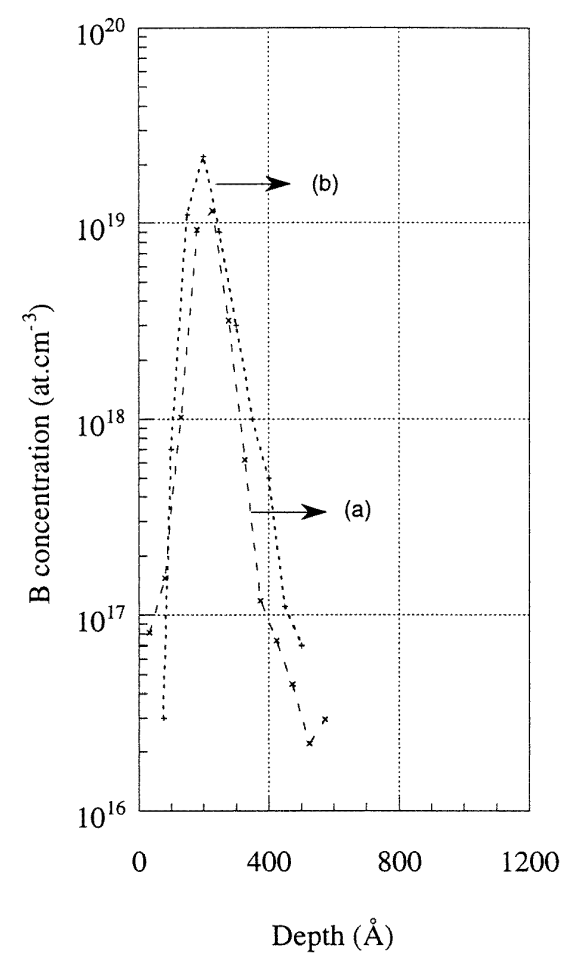

Figure 38. Experiments similar to those of figure 36, but on $\mathrm{Si}_{0.8} \mathrm{Ge}_{0.2}$ layers with overgrowth at (a) $550{ }^{\circ} \mathrm{C}$ and (b) $600^{\circ} \mathrm{C}$. Narrower peaks are obtained than for $\mathrm{Si}$ but the same trend is observed.

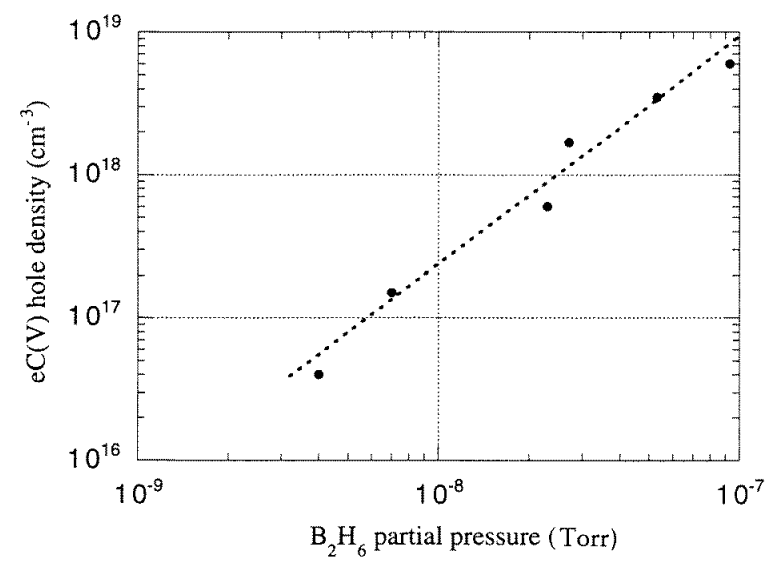

Figure 39. Hole density measured by $e C(V)$ profiling. The hole density increases linearly with the $\mathrm{B}_{2} \mathrm{H}_{6}$ pre-deposition time.

the small decrease of $R_{\mathrm{Si}}$ observed is not related to the quantity of $\mathrm{B}$ incorporated in the layer. Now if we consider (in agreement with the results reported above) that the $R_{\mathrm{Si}}$-decrease is related to deactivated dangling bonds, this means that in our experiments the quantity of $\mathrm{B}$ at the free surface is the same for very different quantities of B incorporated, which demonstrates conclusively that the quantity of B in the surface layer reaches saturation (equilibrium) coverage 

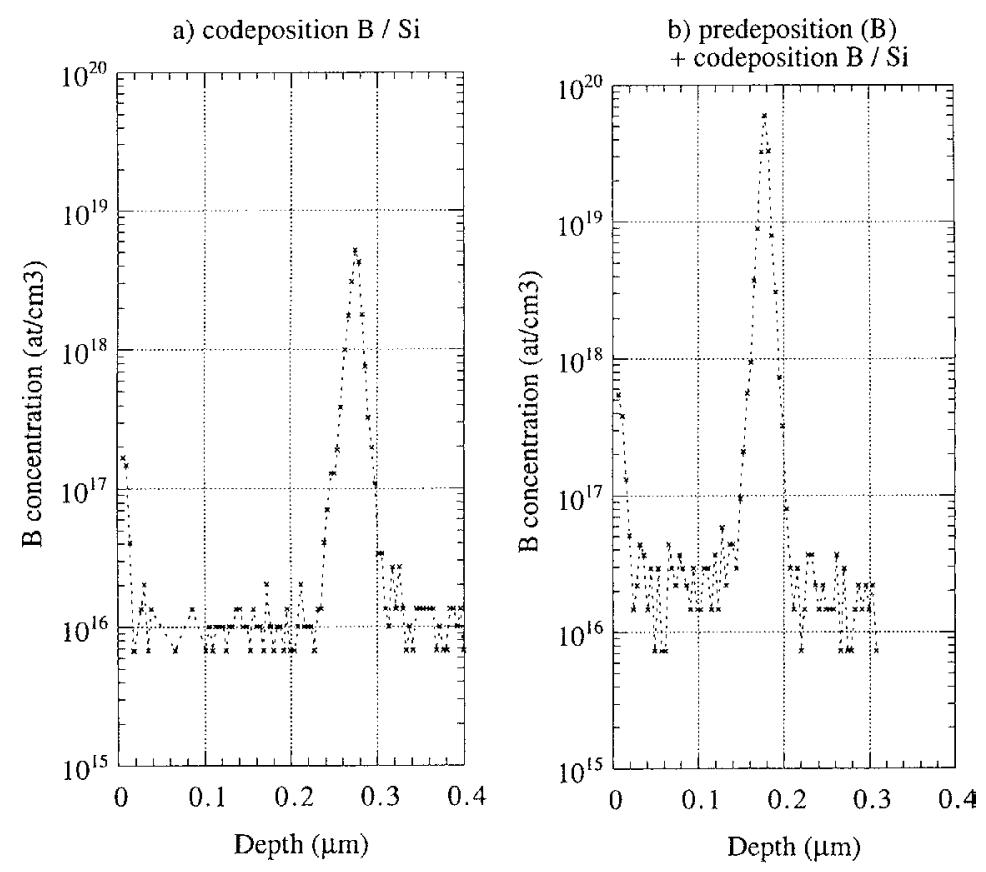

Figure 40. Comparison between the SIMS profiles of (a) a co-deposition of $\mathrm{B}_{2} \mathrm{H}_{6}$ and $\mathrm{Si}_{2} \mathrm{H}_{6}$ followed by $\mathrm{Si}$ deposition and (b) a pre-deposition of $\mathrm{B}_{2} \mathrm{H}_{6}$ followed by a short co-deposition of $\mathrm{B}_{2} \mathrm{H}_{6}$ and $\mathrm{Si}_{2} \mathrm{H}_{6}$. The decay lengths obtained are similar, but a higher doping is reached with the co-deposition step.

that minimizes the surface free energy, as occurs for many doping species ( $\mathrm{Sb}, \mathrm{As}$, and Ga for instance). We assume that in the experiments presented here, the critical equilibrium coverage is reached over the complete range of exposures tested. In accordance with the atomic model of Zhang et al [111], which indicates that high local stresses are induced by Si-B bonds, it can easily be assumed that for coverages higher than the equilibrium limit, B agglomerates into 3D islands in order to reduce the surface free energy (this is also the case for the doping species cited above). 3D islands would explain the different coverage levels obtained for the different exposures during B pre-adsorption. The coverage would then be limited by the shape of the B clusters, which become highly metastable for large heights and low lateral sizes.

Finally, a constant fraction of B continues to segregate at the growing surface during $\mathrm{Si}$ overgrowth. This 'floating' submonolayer of B maintains the critical equilibrium coverage and deactivates a fraction of the dangling bonds. This explains why in all our experimental conditions a constant reduction of $R_{\mathrm{Si}}$ is observed, even after the growth of thick Si buffer layers. Since the analyses reported in this work cannot give any information on the quantity of B floating at the surface (due to the abrasion process used), further analyses are needed to determine this quantity and to confirm the mechanism proposed.

In summary, it was shown that the combination of pre-deposition and co-deposition is the most efficient method for achieving highly doped layers (up to $7 \times 10^{19} \mathrm{~cm}^{-3}$ in $\mathrm{Si}$ ) with very abrupt interfaces and low surface roughness. The necessity of a brief co-deposition step was explained by there being a limit to the coverage of boron before islanding occurs during the pre-deposition step, which limits the maximum incorporation of boron and degrades the film morphology. The best results were obtained with boron doping at $600{ }^{\circ} \mathrm{C}$. Lower doping 


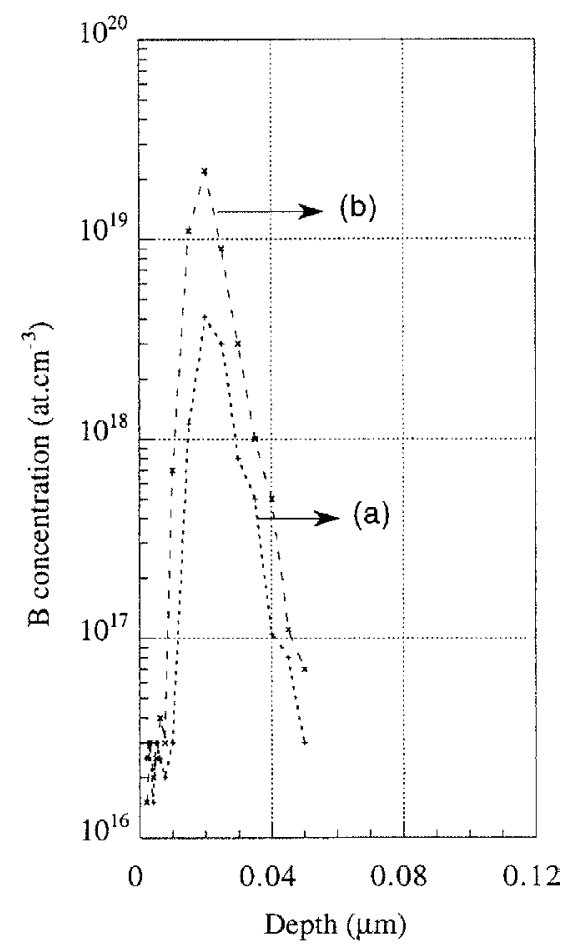

Figure 41. Experiments similar to those of figure 12 but on $\mathrm{Si}_{0.8} \mathrm{Ge}_{0.2}$ layers. The decay lengths are very small in both cases (below the SIMS resolution limit) but a higher doping is reached for the two-step deposition process.

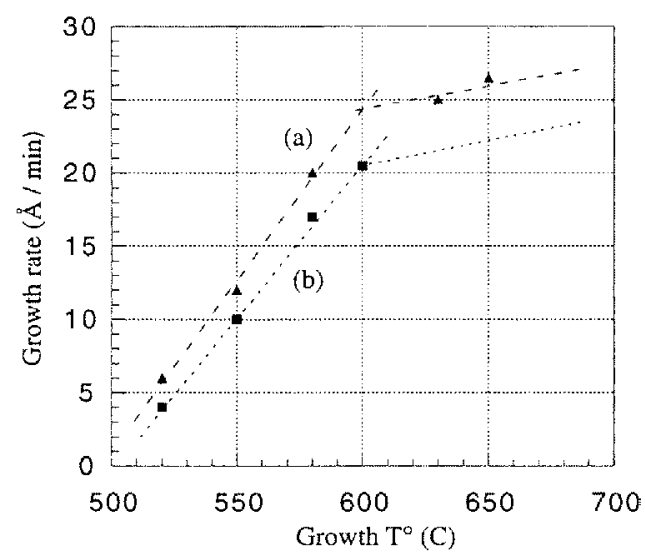

Figure 42. The growth rate of $\mathrm{Si}$ (a) compared to the growth rate of $\mathrm{Si}$ after a pre-deposition of boron (b). Over the range of temperatures studied and for various $\mathrm{B}_{2} \mathrm{H}_{6}$ pre-deposition pressures the growth rate of the $\mathrm{Si}$ overgrown layer is reduced by $20 \%$. Similar results are obtained during co-deposition of $\mathrm{B}_{2} \mathrm{H}_{6}$ and $\mathrm{Si}_{2} \mathrm{H}_{6}$ with various ratios of $J_{\mathrm{B}_{2} \mathrm{H}_{6}} / J_{\mathrm{Si}_{2} \mathrm{H}_{6}}$

levels were obtained in SiGe but with sharper interfaces than in Si. Supported by a RHEED oscillation study, we propose that there is a very stable surface coverage 'floating' during the subsequent overgrowth of both $\mathrm{Si}$ and $\mathrm{SiGe}$, to explain the observed decrease of the growth rate and the previous results. 


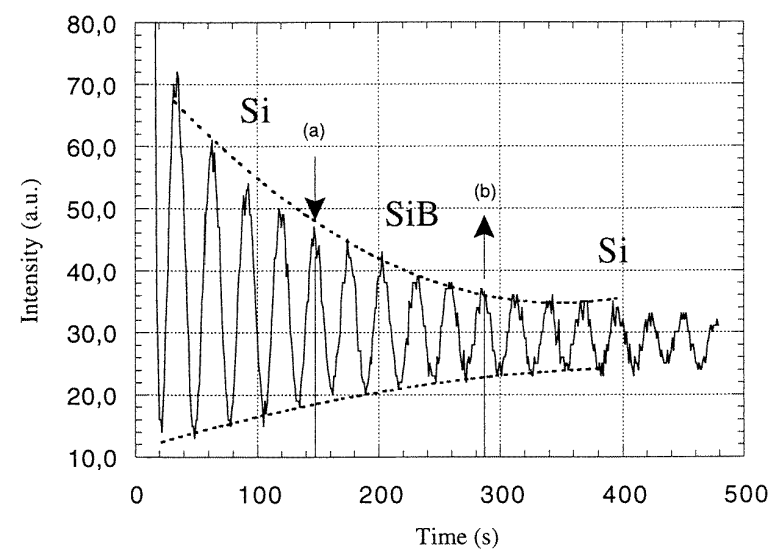

Figure 43. RHEED oscillations before, during, and after co-deposition of boron $\left(J_{\mathrm{B}_{2} \mathrm{H}_{6}} / J_{\mathrm{Si}_{2} \mathrm{H}_{6}}=\right.$ $\left.8 \times 10^{-3}\right)$ in $\mathrm{Si}$. No noticeable change in the damping of the oscillations with time is observed. Growth was performed at $\sim 600{ }^{\circ} \mathrm{C}$ which corresponds to the transition between $2 \mathrm{D}$ nucleation and step flow growth modes. This explains the high damping coefficient of the oscillations.

\section{Physical properties}

Beyond the understanding of growth mechanisms, the ultimate aim in building self-organized $\mathrm{Si}_{1-x} \mathrm{Ge}_{x}$-based nanostructures is to produce compounds showing good optoelectronic qualities. As a consequence, the testing of electronic properties of as-grown material is an appropriate way to assess $\mathrm{Si}_{1-x} \mathrm{Ge}_{x}$ structures. Electronic characteristics of heterostructures have been widely tested by luminescence techniques (PL, electroluminescence (EL), cathodoluminescence (CL)) and by electrical means mainly based on a capacitance-voltage $(C-V)$ methodology.

PL experiments have been carried out on various $\mathrm{Si}_{1-x} \mathrm{Ge}_{x}$ heterostructures showing a wide range of growth conditions (growth technique, growth temperature, Ge content, nominal $\mathrm{Si}_{1-x} \mathrm{Ge}_{x}$ layer thickness, substrate orientation, template heterostructures, ...).

Complete optical and electrical studies on fully strained [128] and relaxed [129] $\mathrm{Si}_{1-x} \mathrm{Ge}_{x}$ 2D wells grown by the chemical vapour deposition (CVD) technique have been reported.

Rapid thermal CVD-grown (RTCVD-grown) strained double heterostructures (DH) (with a Si cap covering the SiGe layer) and single heterostructures $(\mathrm{SH})$ (without any $\mathrm{Si}$ cap on the $\mathrm{Si}_{1-x} \mathrm{Ge}_{x}$ layer), grown at $800^{\circ} \mathrm{C}$ with $\mathrm{Ge}$ contents ranging from 7 to $19 \%$, were studied [99]. In this work free excitonic recombinations were clearly characterized in all capped structures (DH) whereas they were absent in uncapped layers $(\mathrm{SH})$. As free excitons are mainly localized in the $\mathrm{Si}_{1-x} \mathrm{Ge}_{x}$ layer due to the band line-up; this result clearly shows that the $\mathrm{Si}$ capping layer completely annihilates the high $\mathrm{Si}_{1-x} \mathrm{Ge}_{x}$ surface recombination velocity and consequently increases the radiative recombination rate.

It has also been shown that PL line characteristics can be used to extract structural properties of the $\mathrm{Si}_{1-x} \mathrm{Ge}_{x}$ alloy. For instance the ratio $I_{N P} / I_{T O}$ (intensity of the non-phonon (NP) line over the intensity of the phonon-assisted transverse optical (TO) replica) has been used to study alloy disorder in the $\mathrm{Si}_{1-x} \mathrm{Ge}_{x}$ layer. This ratio showed a good matching with the probability of finding a $\mathrm{Si}-\mathrm{Ge}$ pair, i.e. followed a $x_{\mathrm{Ge}}\left(1-x_{\mathrm{Ge}}\right)$ curve [129]. In addition the NP line FWHM has be used to control layer relaxation and interface roughness.

As we discussed in the previous sections, the $\mathrm{Si}_{1-x} \mathrm{Ge}_{x}$ growth mode can lead to the formation of dislocation-free 3D islands showing a large distribution of size and morphology depending on growth conditions, level of stress, etc. In order to assess the capabilities of those 


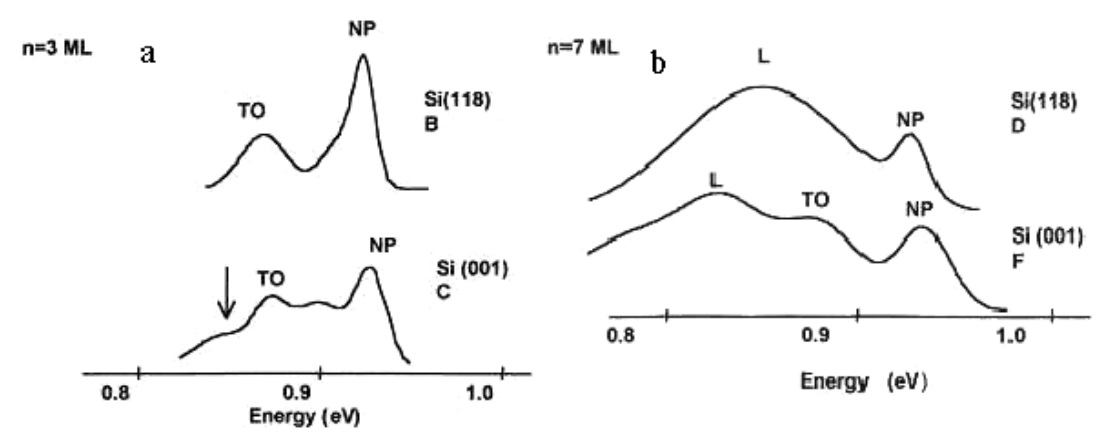

Figure 44. $\mathrm{PL}$ spectra of $\mathrm{Si} / n \mathrm{Ge} / \mathrm{Si}_{0.7} \mathrm{Ge}_{0.3} / \mathrm{Si}$ structures obtained at $6 \mathrm{~K}$ on (001) and (118): (a) $n=3 \mathrm{ML}$, (b) $n=7 \mathrm{ML}$.

Ge-rich crystalline clusters as trapping dots for excitons, several PL studies on encapsulated $\mathrm{Si}_{1-x} \mathrm{Ge}_{x}$ nanostructures have been carried out $[130,131]$.

In [5] a strong relation between morphology and luminescence of islands grown on template layers $\left(n \mathrm{Ge} / \mathrm{Si}_{1-x} \mathrm{Ge}_{x} / \mathrm{Si}\right.$ structures) has been established by PL and AFM experiments. PL related to the two-dimensional (2D) buffer layer was always characterized by a NP line and its TO replica at $58 \mathrm{meV}$ in the lower-energy side.

In this section, three main features are discussed: the influence of surface misorientation, the influence of growth temperature (when the substrate is misoriented), and the influence of a two-step process using a self-patterned $\mathrm{Si}_{0.7} \mathrm{Ge}_{0.3}$ template layer to organize the $\mathrm{Ge}$ dots $[132,133]$.

\subsection{Influence of substrate misorientation}

The results reported in the literature for quantum dots grown on $\mathrm{Si}(100)$ substrates show a 2D/3D changeover corresponding to a Ge coverage between 3 and 4 ML [132]. In order to investigate the influence of the substrate orientation on the 2D/3D SK growth mode changeover, we compare PL measurements performed on $\mathrm{Si} / \mathrm{Ge} / \mathrm{Si}_{0.7} \mathrm{Ge}_{0.3} / \mathrm{Si}(100)$ and $\mathrm{Si} / \mathrm{Ge} / \mathrm{Si}_{0.7} \mathrm{Ge}_{0.3} / \mathrm{Si}(118)$ structures (figure 44 ). For a Ge coverage of $3 \mathrm{ML}$ (samples B and $\mathrm{C}$ in figure 44(a)), we observe the NP and the transverse optical (TO) lines related to the 2D $\mathrm{Si}_{0.7} \mathrm{Ge}_{0.3}$ template layer. The observed energies agree with the Ge content and thickness. If we look at the $\mathrm{C}$ sample spectrum, we can observe a new structure. Compared to sample $\mathrm{B}$, although sample $C$ still exhibits the NP/TO pair, its PL spectrum presents a new emission at low energy. This new emission could correspond to the 2D/3D SK growth mode changeover in accordance with the literature results [134]. For a Ge coverage of $7 \mathrm{ML}$ (samples D and F in figure 44(b)), a broad luminescence around $850 \mathrm{meV}$ correlated with the 3D island formation is observed for both orientations. Consequently, we can conclude that the 2D/3D transition starts close to $3 \mathrm{ML}$ for the (100) substrate orientation and later (around $7 \mathrm{ML}$ ) for the (118) substrate orientation. Therefore, the substrate orientation strongly influences the nanostructure morphology. AFM characterizations have shown that hut islands are formed on $\mathrm{Si}(100)$ surface when wire-shaped islands with reduced lateral size are formed on $\mathrm{Si}(118)$ vicinal surfaces. This result is also very promising as regards island size reduction and uniformity.

\subsection{Influence of growth temperature}

In this section, we want to show that the growth temperature of the Ge monolayers is a determinant parameter for the island growth mechanism. Figure 45 shows the PL signal related 
a)

A

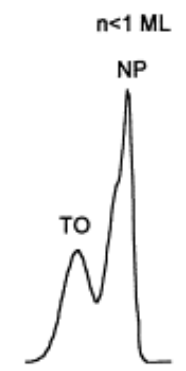

B

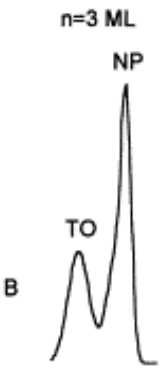

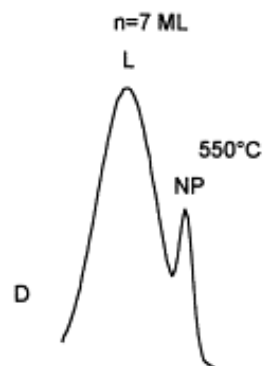

b)
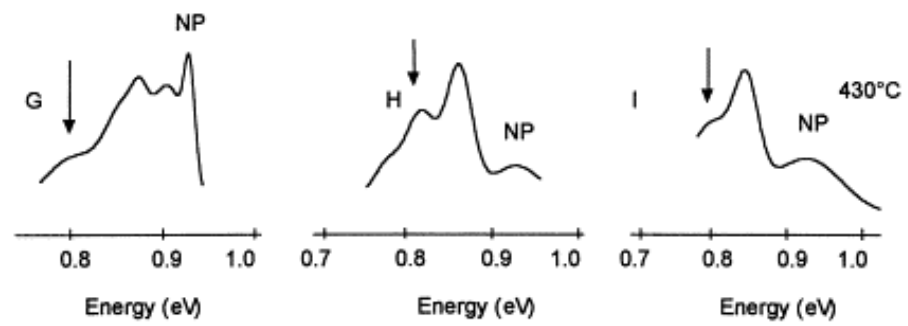

Figure 45. $\mathrm{PL}$ spectra of $\mathrm{Si} / n \mathrm{Ge} / \mathrm{Si}_{0.7} \mathrm{Ge}_{0.3} / \mathrm{Si}(118)$ structures for $n=1,3$, and $7 \mathrm{ML}$ obtained at $6 \mathrm{~K}$ for two growth temperatures of the Ge coverage: (a) $550{ }^{\circ} \mathrm{C}$, (b) $430{ }^{\circ} \mathrm{C}$.

to samples $\mathrm{G}, \mathrm{H}$, and I with a Ge coverage of 1,3 , and $7 \mathrm{ML}$, deposited at $430^{\circ} \mathrm{C}$. The spectra are quite different compared with figure 45 (a), where Ge monolayers were grown at $550^{\circ} \mathrm{C}$. First, at LT, we observe a strong intensity decrease of the luminescence and a new emission which systematically appears at low energy (around $820 \mathrm{meV}$ ). In contrast, the intensity of the NP line related to the SiGe wetting layer seems to vanish for Ge coverages of 3 and $7 \mathrm{ML}$, in comparison with the TO line. Finally, we did not observe the broad band at $n=7$ ML. We know that, at $430{ }^{\circ} \mathrm{C}$, the growth regime is governed by the hydrogen desorption while at $550^{\circ} \mathrm{C}$ the reaction is supply limited. At $430^{\circ} \mathrm{C}$, the $\mathrm{SiGe}$ surface is more hydrogen rich than at $550^{\circ} \mathrm{C}$. It is well known that hydrogen can act as a surfactant and may prevent the $2 \mathrm{D} / 3 \mathrm{D}$ growth mode changeover. Consequently, at $430^{\circ} \mathrm{C}, 2 \mathrm{D}$ growth is prevailing. This explains the absence of the broad band which indicates that no island was formed. Therefore, the new emission at LT may be correlated with defects due to $\mathrm{H}$ adsorption. In conclusion, the growth temperature seems to be a determinant for the island formation.

\subsection{Nature of the recombinations}

In order to study the influence of light on structures grown on $\mathrm{Si}(118)$ vicinal surfaces, and to determine the fundamental mechanism of carrier recombination, we have performed PL measurements at $6 \mathrm{~K}$ with variable excitation densities. Figure 46 presents the behaviour of sample $\mathrm{B}(n=3 \mathrm{ML})$ and sample $\mathrm{D}(n=7 \mathrm{ML})$ when the excitation power increases from 0.6 to $20 \mathrm{~W} \mathrm{~cm}^{-2}$. The peak intensities are normalized to the higher-intensity peak. We observe an important shift $(20 \mathrm{meV})$ of the signal toward the higher energies. This indicates a strong dependence on the excitation power. This behaviour is not conventional in SiGe/Si type-I systems, but it can be explained by a type-II band line-up. In a type-II interface, a two-dimensional electron gas (2DEG) is formed in the conduction band and when the excitation power increases, the 2DEG fills with the photogenerated carriers. This filling induces an energy increase of the transition and hence we observe a blue-shift. Therefore, we have reported in figure 47 the 

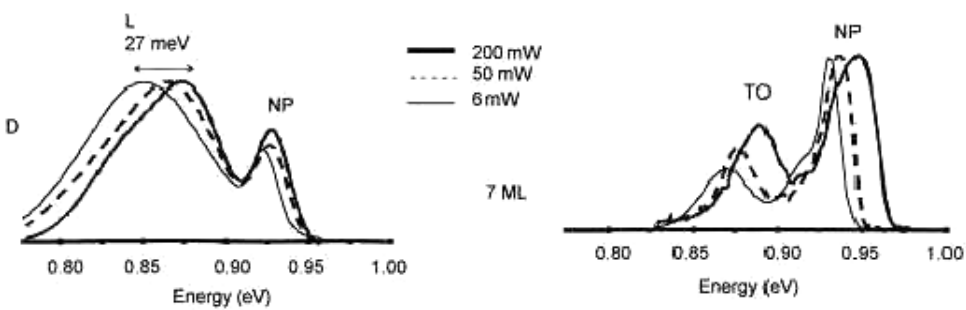

$3 \mathrm{ML}$

Figure 46. PL spectra of $\mathrm{Si} / n \mathrm{Ge} / \mathrm{Si}_{0.7} \mathrm{Ge}_{0.3} / \mathrm{Si}$ structures obtained at $6 \mathrm{~K}$ for various excitation power densities: $n=3 \mathrm{ML}$ (right), $n=7 \mathrm{ML}$ (left).

$6 \mathrm{~K}$

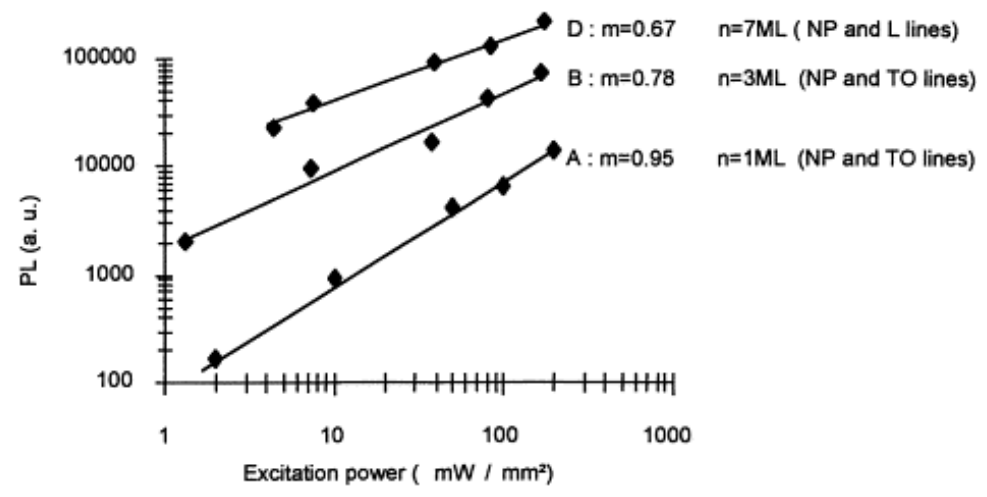

Figure 47. Excitation power dependence of the PL intensity for Ge coverages of $n=1,3$, and 7 ML.

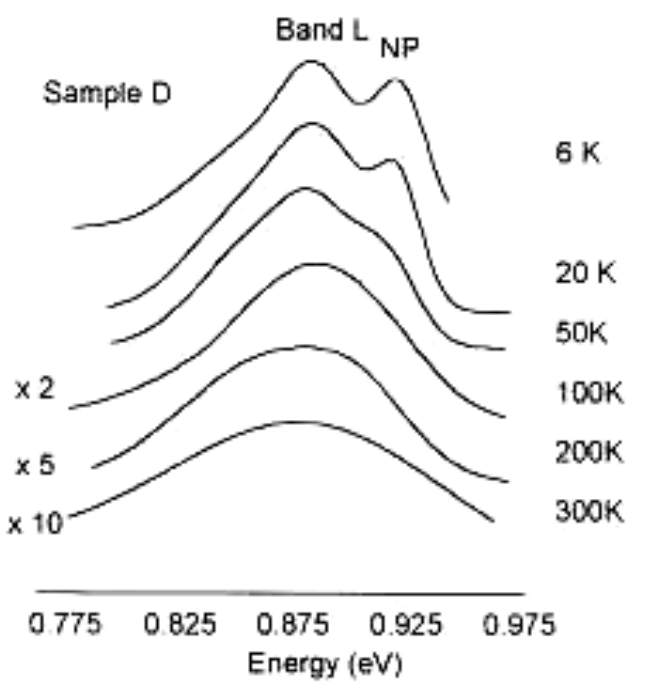

Figure 48. $\mathrm{PL}$ spectra of $\mathrm{Si} / 7 \mathrm{ML} \mathrm{Ge} / \mathrm{SiGe} / \mathrm{Si}(118)$ structures obtained at temperatures varying between $6 \mathrm{~K}$ and ambient. 
coefficient $m\left(I=P^{m}\right)$, where $I$ represents the PL intensity and $P$ the power density. For $n=1$ and $3 \mathrm{ML}, m$ was obtained for the NP/TO pair and for 7 ML $m$ was obtained for the L and NP lines. The coefficient $m<1$ decreases when the Ge coverage increases. In a type-II interface, the indirect excitons are firstly localized in the interface roughness, then they recombine. But the interface states are limited; hence saturation quickly occurs and $m<1$. Therefore, when few nanostructures are formed at $n=7 \mathrm{ML}$, they rapidly saturate, particularly for high excitation power. This explains the strong decrease of the coefficient $m$ for the D sample.

\subsection{Luminescence temperature}

Finally, PL spectra of sample D ( $n=7 \mathrm{ML}$ ) are reported in figure 48 for various temperatures. The PL signal related to the Ge islands persists up to room temperature and the intensity is only reduced by a factor of 10 as compared to LT spectra. In contrast, the 2D luminescence arising from quantum wells disappears around $50 \mathrm{~K}$. This result demonstrates the effect of the spatial confinement of the carriers in the Ge islands up to room temperature. This important property is very promising for optoelectronic device applications.

We have proved that it is possible to engineer PL spectra by making relevant changes in growth conditions. For instance, an increase by a factor of three of the radiative recombination of $2 \mathrm{D}$ corrugated systems (consisting of $3 \mathrm{ML}$ of $\mathrm{Ge}$ deposited on a $\mathrm{Si}_{0.7} \mathrm{Ge}_{0.3}$ template layer) when using highly misoriented substrates has been obtained. While the reason for the enhanced intensity is not clear, the influence of the wire-shaped morphology could be invoked. The detrimental effect of decreasing the growth temperature on the optical properties of the samples has been confirmed. Furthermore, some room temperature luminescence experiments have produced results that hold out considerable promise for future applications.

\section{Conclusions}

In this paper, growth, self-assembly, and properties of $\mathrm{Si}_{1-x} \mathrm{Ge}_{x}$ nanostructures have been reviewed. In a general way, kinetic growth parameters and substrate orientation (by way of surface reconstruction, step structure, and step density) were reported to have a peculiar influence on growth modes and relaxation mechanisms.

Both plastic and elastic relaxations were studied as stress-relief processes. As regards the first mechanism, larger experimental critical thicknesses for MD nucleation as compared to the ones derived from standard elastic theories were reported. This was attributed to the influence of kinetics on MD introduction and propagation. In the related framework of SiGe virtual substrate realization, an efficient process using LT pre-deposition of Si was shown. As regards elastic relaxation mechanisms, both chemical and step edge relaxation processes have been addressed. In the first process, the influence of growth conditions (Ge concentration and growth interruption time) on strain-induced $\mathrm{Si} / \mathrm{Ge}$ interdiffusion has been studied. In the second process, elastic relaxation levels in the layers were found to be associated with the morphology of the layers. In particular, a negligible lateral elastic relaxation in undulating $\mathrm{SiGe} / \mathrm{Si}(001)$ layers was reported, in contrast to what was expected from various theoretical models. Discrepancies with such models were further observed, when studying SiGe morphological evolution with main growth parameters on (111) and (001) surfaces. For both orientations, experimental kinetic phase diagrams of surface morphologies were extracted. In the (111) case, two growth regimes were observed, according to the SK process. In contrast, in the (001) case, four regimes could be determined and several metastable island morphologies were observed.

The origin of development of SiGe growth instabilities on (001) has also been addressed by comparing the morphological evolution of $\mathrm{Si}$ and $\mathrm{SiGe}$ layers grown either on nominal 
or vicinal (111) and (001) surfaces. Various growth instability regimes (pure kinetic regime, pure and kinetically activated strain-induced regime) were observed. Their dependence on surface orientation/misorientation clearly evidenced the significant role of both kinetics and atomic arrangement of the surface in the origin and evolution of SiGe growth. The potential use of these growth instabilities as templates for growth of assembled Ge nanostructures was finally illustrated. Improvement of SiGe self-organization using an Sb surfactant-mediated $\mathrm{Ge}$ growth process was also reported. In this case, very small Ge islands with high density were obtained. This mainly results from the Sb-induced reduction of Ge surface diffusion.

The control of doping of SiGe layers has been studied by addressing $\mathrm{Sb}$ and $\mathrm{B}$ incorporation/segregation during growth.

Finally, SiGe nanostructure optical properties have been studied by means of PL. Relations between layer growth conditions (and then layer morphologies) and PL spectra have been reported. In particular, in the case of Ge growth on a template substrate, PL intensity was found to be enhanced and to persist up to room temperature.

\section{Acknowledgments}

We wish to thank B Gallas, B Joyce, G Bremond, A Souifi and P Gas for their collaborations. We are also grateful for financial support from the EC projects SiGeNet (No HPRN-CT-199900123) and FORUM FIB (No IST-2000-29573).

\section{References}

[1] Paul D J 1999 Adv. Mater. 11191

[2] Chevrier J, Cruz A, Pinto N, Berbezier I and Derrien J 1994 J. Physique I 41309

[3] Liu W K, Mokler S M, Ohtani N, Roberts C and Joyce B A 1992 Surf. Sci. 264301

[4] Gay J M, Stocker P and Réthoré F 1993 J. Appl. Phys. 738169

[5] Bremond G, Serpentini M, Souifi A, Guillot G, Jacquier B, Abdallah M, Berbezier I and Joyce B A 1999 Microelectron. J. 3035

[6] Berbezier I, Gallas B and Derrien J 1998 Surf. Rev. Lett. 5133

[7] Berbezier I, Gallas B, Ronda A and Derrien J 1998 Surf. Sci. 412-3 415

[8] Armigliato A, Baldoni R, Corticelli F and Frabboni S 1995 Microsc. Microanal. Microstruct. 6449

[9] Matthews J W 1975 J. Vac. Sci. Technol. 12126

[10] Hull R and Bean J C 1992 Crit. Rev. Solid State Mater. Sci. 17507

[11] Kamat S V and Hirth J P 1990 J. Appl. Phys. 676844

[12] LeGoues F K, Copel M and Tromp R M 1989 Phys. Rev. Lett. 631826

[13] LeGoues F K 1996 MRS Bull. XXI 38

[14] Eaglesham D J, Kvam E P, Maher D M, Humphreys C J and Bean J C 1992 Phil. Mag. A 592802

[15] Albrecht M, Christiansen S, Strunk H P, Hansson P O and Bauser E 1993 Solid State Phenom. 32-3 433

[16] Matthews J W, Jackson D C and Chambers A 1975 Thin Solid Films 26129

[17] Van der Merve J H 1963 J. Appl. Phys. 34117

[18] Putero M 1999 PhD Dissertation University Aix-Marseille III, Marseille

[19] Pichaud B, Putero M and Burle N 1998 J. Physique IV 8227

[20] Gallas B, Hartmann J M, Berbezier I, Abdallah M, Zhang J, Harris J J and Joyce B A 1999 J. Cryst. Growth 201-2 547

[21] Kvam E P et al 1987 MRS Bull. 104

[22] Fukuda Y, Kohama Y, Seki M and Ochmachi Y 1989 Japan. J. Appl. Phys. 28 L19

[23] Fukuda Y, Kohama Y, Seki M and Ochmachi Y 1988 Japan. J. Appl. Phys. 271593

[24] LeGoues F K, Ott J A, Eberl K and Iyer S S 1992 Appl. Phys. Lett. 61174

[25] Beanland R, Aindow M, Joyce T B, Kidd P, Lourenço M and Goodhew P J 1995 J. Cryst. Growth 1491

[26] Fernandez J M, Matsumura A, Zhang X M, Lie M H, Hart L and Thornton T J 1995 J. Mater. Sci. 6330

[27] Berbezier I, Abdallah M, Ronda A and Bremond G 2000 Mater. Sci. Eng. B 69-70 367

[28] Ronda A, Abdallah M, Gay J M, Stettner J and Berbezier I 2000 Appl. Surf. Sci. 162-3 576 
[29] Pchelyakov O P, Bolkhovityanov Y B, Dvurechenskii A V, Nikiforov A I, Yakimov A I and Voigtländer B 2000 Thin Solid Films $\mathbf{3 6 7} 75$

[30] Mo Y-W, Savage D E, Swartzentruber B S and Lagally M G 1990 Phys. Rev. Lett. 651020

[31] Hammar M, LeGoues F K, Tersoff J, Reuter M C and Tromp R M 1996 Surf. Sci. 349129

[32] Kamins T I, Carr E C, Williams R S and Rosner S J 1997 J. Appl. Phys. 81211

[33] Liu F, Wu F and Lagally M G 1997 Chem. Rev. 971045

[34] Sutter P and Lagally M G 2000 Phys. Rev. Lett. 844637

[35] LeGoues F K, Reuter M C, Tersoff J, Hammar M and Tromp R M 1994 Phys. Rev. Lett. 73300

[36] Gao H 1994 J. Mech. Phys. Solids 42741

[37] Jesson D E, Chen K M and Pennycook S J 1996 MRS Bull. XXI 31

[38] Springholz G and Bauer G 1993 Phys. Rev. B 4810998

[39] Cullis A G 1996 MRS Bull. XXI 21

[40] Grilhé J 1993 Acta Metall. Mater. 41909

[41] Tersoff J and LeGoues F K 1994 Phys. Rev. Lett. 723570

[42] Müller P and Kern R 1996 Appl. Surf. Sci. 1026

[43] Ratsch C, Zangwill A, Smilauer P and Vvedensky D D 1994 Phys. Rev. Lett. 723194

[44] Srolovitz D J 1989 Acta Metall. 37621

[45] Pidduck A, Robbins D, Cullis A, Leong W and Pitt A 1992 Thin Solid Films 22278

[46] Eaglesham D J, Gossmann H J and Cerullo M 1990 Mater. Res. Soc. Symp. Proc. 19851

[47] Hull R, Bean J C, Peticolas L J, Bahnck D, Weir B E and Feldman L C 1992 Appl. Phys. Lett. 612802

[48] Pchelyakov O P, Markov V A, Nikiforov A I and Sokolov L V 1997 Thin Solid Films 306299

[49] Deelman P W, Thundat T and Schowalter L J 1996 Appl. Surf. Sci. 104-5 510

[50] Gallas B, Berbezier I, Ronda A and Derrien J 1997 Thin Solid Films 29422

[51] Volpi F, Portavoce A, Ronda A, Shi Y, Gay J M and Berbezier I 2000 Thin Solid Films 38046

[52] Wu F, Chen X, Zhang Z Y and Lagally M G 1995 Phys. Rev. Lett. 74574

[53] Alerhand O L, Vanderbilt D, Meade R D and Joannopoulos J D 1988 Phys. Rev. Lett. 611973

[54] Zong L, Hojo A, Matsushita Y, Aiba Y, Hayashi K, Takeda R, Shirai H, Saito H, Matsushita J and Yoshikawa J 1996 Phys. Rev. B 54 R2304

[55] Mukherjee S, Pehlke E and Tersoff J 1994 Phys. Rev. B 491919

[56] Smilauer P and Vvedensky D D 1995 Phys. Rev. B 5214263

[57] Ratsch C, Smilauer P, Vvedensky D D and Zangwill A 1996 J. Physique I 6575

[58] Siegert M and Plischke M 1994 Phys. Rev. E 50917

[59] Snyder C W, Mansfield J F and Orr B G 1992 Phys. Rev. B 469551

[60] Pierre-Louis P and Misbah C 1996 Phys. Rev. Lett. 764761

[61] Rost M, Smilauer P and Krugg J 1996 Surf. Sci. 369393

[62] Lee N E, Cahill D G and Greene J E 1996 Phys. Rev. B 537876

[63] Schelling C, Springholz G and Schäffler F 1999 Phys. Rev. Lett. 83995

[64] Floro J A, Chason E, Freund L B, Twesten R D, Hwang R Q and Lucadamo G A 1999 Phys. Rev. B 591990

[65] Ross F M, Tromp R M and Reuter M C 1999 Science 2861931

[66] Medeiros-Ribeiro G, Bratkovski A M, Kamins T I, Ohlberg D A A and Williams R S 1998 Science 279353

[67] Goryll M, Vescan L, Schmidt K, Mesters S, Lüth H and Szot K 1997 Appl. Phys. Lett. 71410

[68] Jesson D E, Pennycook S J, Baribeau J M and Houghton D C 1993 Phys. Rev. Lett. 711744

[69] Asaro R J and Tiller W A 1972 Metall. Trans. 31789

[70] Grinfeld M A 1993 J. Intell. Mater. Syst. Struct. 4

[71] Lapena L, Berbezier I, Gallas B and Joyce B 1998 Thin Solid Films 336124

[72] Berbezier I, Gallas B, Lapena L, Fernandez J, Derrien J and Joyce B 1998 J. Vac. Sci. Technol. B 161582

[73] Apetz R, Vescan L, Hartmann A, Dieker C and Lüth H 1995 Appl. Phys. Lett. 66445

[74] Fukatsu S, Yoshida H, Fujiwara A, Takahashi Y and Shiraki Y 1992 Appl. Phys. Lett. 61804

[75] Schittenhelm P, Gail M, Brunner J, Nützel J F and Abstreiter G 1995 Appl. Phys. Lett. 671292

[76] Noël J P, Rowell N L, Houghton D C and Perovic D D 1990 Appl. Phys. Lett. 571037

[77] Kim E S, Usami N and Shiraki Y 1998 Appl. Phys. Lett. 721617

[78] Vescan L, Dieker C, Souifi A and Stoica T 1997 J. Appl. Phys. 816709

[79] Higgs V, Lightowlers E C, Usami N, Shiraki Y, Mine T and Fukatsu S 1995 J. Cryst. Growth 1501070

[80] Brunner J, Rupp T S, Gossner H, Ritter R, Eisele I and Abstreiter G 1994 Appl. Phys. Lett. 64994

[81] Abdallah M, Berbezier I, Dawson P, Serpentini M, Bremond G and Joyce B 1998 Thin Solid Films 336256

[82] Portavoce A, Ronda A and Berbezier I 2002 Mater. Sci. Eng. B 89205

[83] Portavoce A, Volpi F, Ronda A, Gas P and Berbezier I 2000 Thin Solid Films 380164

[84] Metzger R A and Allen F G 1984 Surf. Sci. 137397 
[85] Ladevèze M, Tréglia G, Müller P and Arnaud d'Avitaya F 1998 Surf. Sci. 395317

[86] Andrieu S and Arnaud d'Avitaya F 1989 Surf. Sci. 219277

[87] Metzger R A and Allen F G 1984 J. Appl. Phys. 55931

[88] Falkenberg G, Seehofer L and Johnson R L 1997 Surf. Sci. 377-9 75

[89] Jenkins S J and Srivastava G P 1998 Surf. Sci. 398 L308

[90] Portavoce A, Bassani F, Ronda A and Berbezier I 2002 Surf. Sci. submitted

[91] Fujita K, Fukatsu S, Usami N, Shiraki Y, Yaguchi H, Ito R and Nakagawa K 1993 Surf. Sci. 295335

[92] Berbezier I, Gallas B, Fernandez J and Joyce B 1999 Semicond. Sci. Technol. 14198

[93] Ni W-X, Hansson G V, Cardenas J and Svensson B G 1998 Thin Solid Films 321131

[94] Ushio J, Nakagawa K, Miyao M and Maruizumi T 1998 Phys. Rev. B 583932

[95] Markov I 1994 Phys. Rev. B 5011271

[96] Oppo S, Fiorentini V and Scheffler M 1993 Phys. Rev. B 712437

[97] Kandel D and Kaxiras E 1995 Phys. Rev. B 752742

[98] Jang S M, Liao K and Reif R 1995 J. Electrochem. Soc. 1423513

[99] Lu M L, Vitkavage J and Meyerson B S 1986 J. Appl. Phys. 594032

[100] Lu Q, Bramlett T R, Lee N E, Hasan M A, Karasawa T and Greene J E 1995 J. Appl. Phys. 773067

[101] Vick G L and Whittle K M 1969 J. Electrochem. Soc. 1161142

[102] Meyerson B S, LeGoues F K, Nguyen T N and Harame D L 1987 Appl. Phys. Lett. 50113

[103] Schubert E F 1993 Doping in III-V Semiconductors (Cambridge: Cambridge University Press)

[104] Saitoh N, Akamine T, Aoki K and Kojima Y 1993 Japan. J. Appl. Phys. 324404

[105] Gates S M and Koleske D D 1993 Thin Solid Films 225160

[106] Zhang Z, Kulakov M A, Bullemer B, Eisele I and Zotov A V 1996 Appl. Phys. Lett. 69494

[107] Larsson M I and Hansson G V 1993 J. Cryst. Growth 134203

[108] Kim H, Glass G, Park S Y, Spila T, Taylor N, Abelson J R and Greene J E 1996 Appl. Phys. Lett. 693869

[109] De Frésart E, Wang K L and Rhee S S 1988 Appl. Phys. Lett. 5348

[110] Kaxiras E 1993 Europhys. Lett. 21685

[111] van der Vegt H A, Breeman M, Ferrer S, Etgens V H, Torrelles X, Fajarrdo P and Vlieg E 1995 Phys. Rev. B 5114806

[112] Tromp R M and Reuter M C 1992 Phys. Rev. Lett. 68954

[113] Ohno T 1994 Phys. Rev. Lett. 73460

[114] Yu B D and Oshiyama A 1994 Phys. Rev. Lett. 723190

[115] Fukatsu S, Fujita K, Yaguchi H, Shiraki Y and Ito R 1992 Surf. Sci. 26779205

[116] Jorke H 1988 Surf. Sci. 193569

[117] Ohtani N, Mokler S M, Xie M H, Zhang J and Joyce B A 1993 Surf. Sci. 284305

[118] Xie M H, Zhang J, Lees A, Fernandez J M and Joyce B A 1996 Surf. Sci. 367231

[119] Lu X, Jiang Z, Zhu H, Zhang X and Wang X 1996 Appl. Phys. Lett. 683278

[120] Wang Y and Hamers R J 1995 Appl. Phys. Lett. 662057

[121] Lin H C, Lin H-Y, Chang C-Y, Jung T G, Wang P J, Deng R-C and Lin J 1994 Am. J. Phys. 761884

[122] Radamson H H, Joelsson K B, Ni W X, Hultman L and Hansson G V 1995 J. Cryst. Growth 15780

[123] Chadi D J 1987 Phys. Rev. Lett. 591691

[124] Tillack B, Zaumseil P, Morgenstern G, Krüger D and Ritter G 1995 Appl. Phys. Lett. 671143

[125] Rodriguez A, Rodriguez T, Sanz-Hervas A, Kling A, Soares J C, da Silva M F, Ballestros C and Gwilliam R M 1997 J. Mater. Res. 121698

[126] Sardela M R, Ni J W X, Radpisheh H and Hansson G V 1992 Thin Solid Films 22242

[127] Glass G, Kim H, Sardela M R, Lu Q, Carlsson J R A, Abelson J R and Greene J E 1997 Surf. Sci. 392 L63

[128] Souifi A, Bremond G, Benyattou T, Guillot G, Dutartre D and Berbezier I 1992 J. Vac. Sci. Technol. B 102002

[129] Grillot P N, Ringel S A, Michel J and Fitzgerald E A 1996 J. Appl. Phys. 802823

[130] Chen H, Cheng W Q, Xie X G, Huang Q and Zhou J M 1997 Appl. Phys. Lett. 70446

[131] Vescan L, Goryll M, Stoica T, Gartner P, Chretien O, Mateeva E, Dieker C and Hollander B 2000 Appl. Phys. A 71423

[132] Serpentini M, Souifi A, Abdallah M, Berbezier I and Bremond G 1999 J. Lumin. 80 515-18

[133] Bremond G, Serpentini M, Souifi A, Guillot G and Joyce B 1999 Microelectron. J. 30357

[134] Sunamura H, Usami N, Shiraki Y and Fukatsu S 1995 Appl. Phys. Lett. 663024 